\title{
Modeling and Simulation of an Autonomous Hybrid Power System
}

Stamatia Gkiala Fikari 


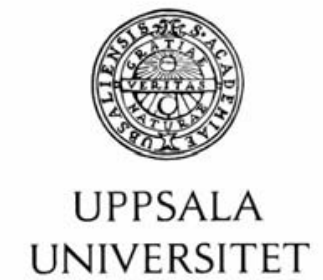

Teknisk- naturvetenskaplig fakultet UTH-enheten

Besöksadress:

Ångströmlaboratoriet

Lägerhyddsvägen 1

Hus 4, Plan 0

Postadress:

Box 536

75121 Uppsala

Telefon:

$018-4713003$

Telefax:

$018-4713000$

Hemsida:

http://www.teknat.uu.se/student

\section{Abstract \\ MODELING AND SIMULATION OF AN \\ AUTONOMOUS HYBRID POWER SYSTEM}

Stamatia Gkiala Fikari

In this report, the modeling process and operation of an autonomous hybrid power system is studied. It is built based on a hypothetical case study of electrification of a remote village of 100 inhabitants in Kenya. The power demand is estimated and the costs of equipment components are specified after extensive research, so that the techno-economical design of the system can be carried out. The microgrid consists of photovoltaics, wind turbine, batteries, diesel genset, basic loads and water pumping and purification load. The system is modeled and simulated in terms of power management and its operation as well as the performance of the dispatch strategy is assessed. Problems like the management of extra power or tackling the deficit of power in the system are addressed. The model represents reliably the behavior of the microgrid and several improving actions are suggested.
Handledare: Sara Ghaem Sigarchian

Ämnesgranskare: Joakim Widén

Examinator: Roland Mathieu MSc ET 15004 


\section{Acknowledgements}

I would like to thank Sara Ghaem Sigarchian, PhD candidate of KTH, at the Polygeneration Research Group of the Energy Department for the chance she gave me to work on such an interesting topic, for supervising my work and guiding me through it.

I am also thankful to Roland Mathieu of the Department of Engineering Sciences of Uppsala University and responsible for my MSc program there, for his cooperation and vigorous and kind help through the last year of my studies there.

I wish to thank Joakim Widén, senior lecturer at the Department of Engineering Physics of Uppsala University and subject reader of my thesis, for his valuable comments improving my work.

I want also to express my satisfaction for meeting Harold Rene Chamorro Vera PhD Candidate of Electrical Energy Systems Research Group of the Department of Electrical Engineering in KTH for his consult and inputs at a crucial point of my work, for his cooperation and the interesting idea of a different approach to microgrids.

I would also like to express my happiness for cooperating with Foivos Palaiogiannis student of National Technical University of Athens while trying to model in detail the photovoltaics with their power electronics. It is really luck to find someone who offers so selflessly and generously his help.

I want to express my happiness for cooperating with Kostas Latoufis the previous years, because he introduced me to the concept of microgrids and how they can be used to offer social services and give power to the people. This is an inspiration for my whole thinking as an electrical engineer.

Last but not least, I would like to express my gratitude and love to my family and my closest friends for their support, patience and encouragement through all this time. Without them, I don't know if I could have made it. 


\section{Contents}

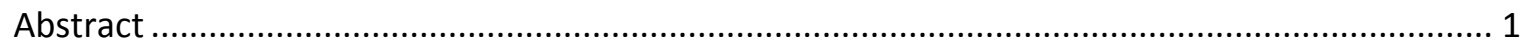

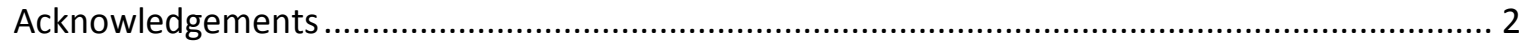

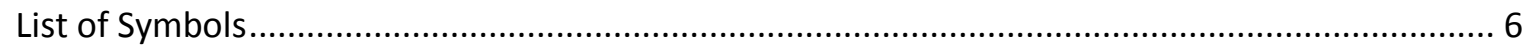

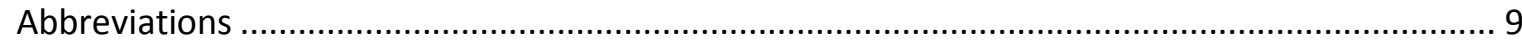

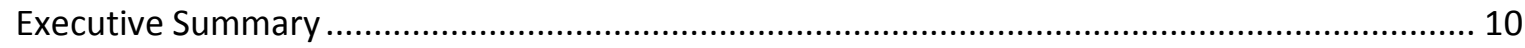

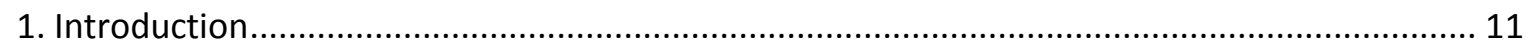

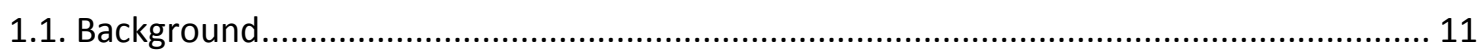

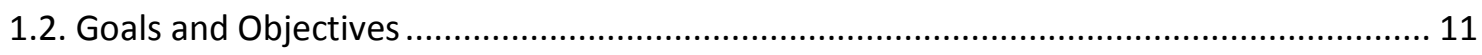

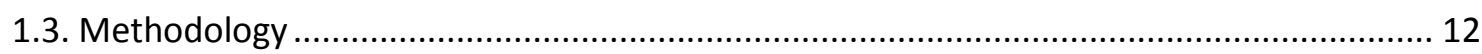

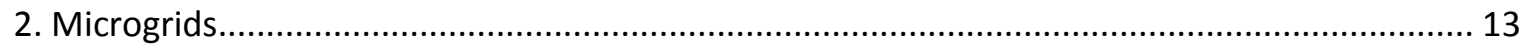

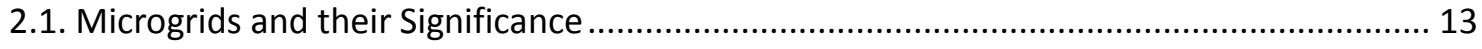

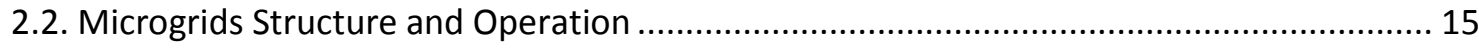

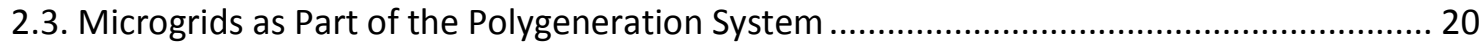

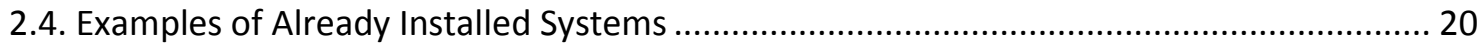

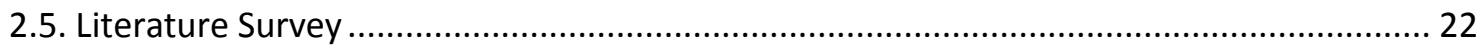

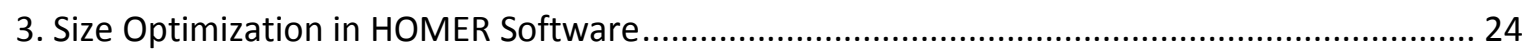

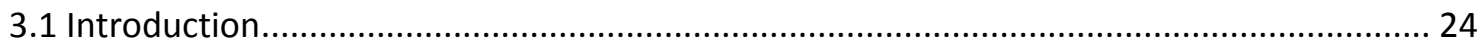

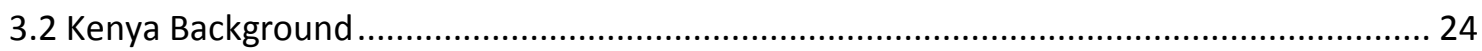

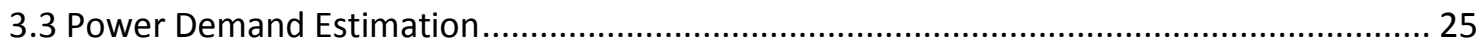

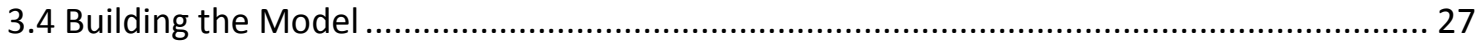

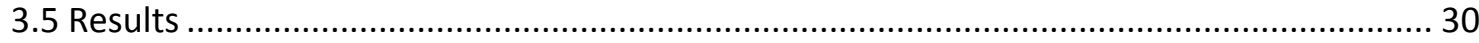

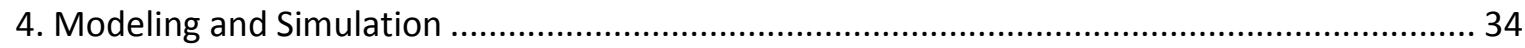

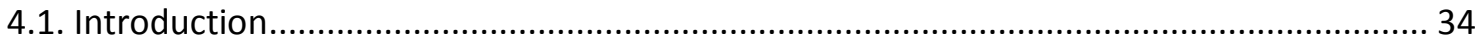

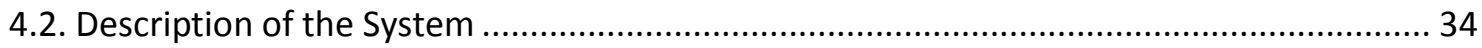

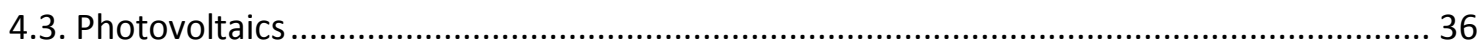

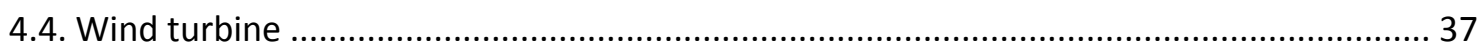

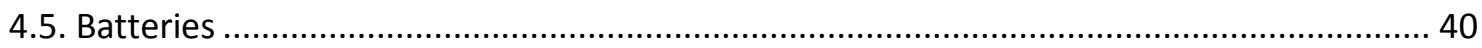

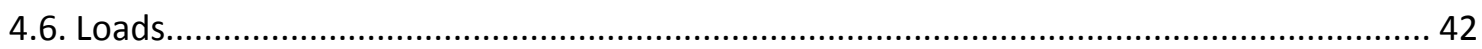

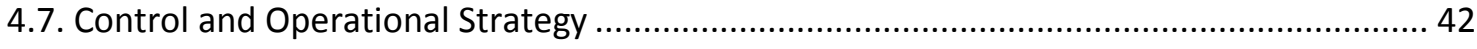

4.8. Description of the Different Cases for the Simulation ....................................................... 46

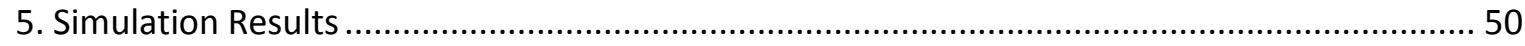

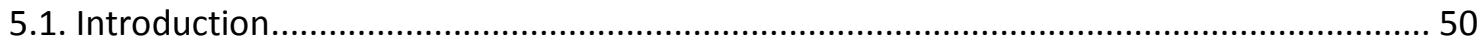

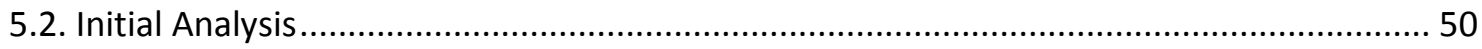

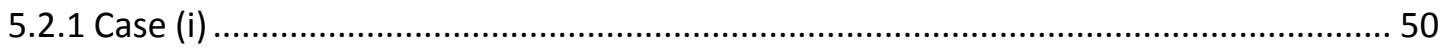




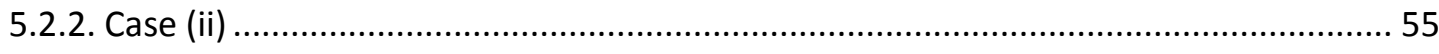

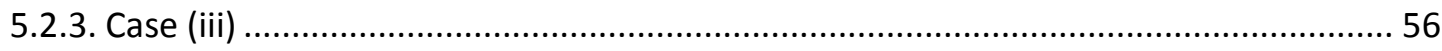

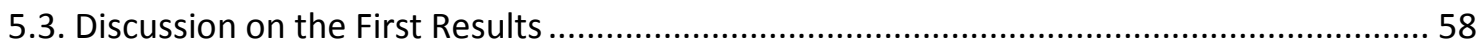

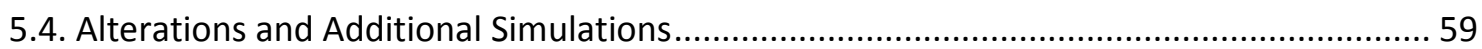

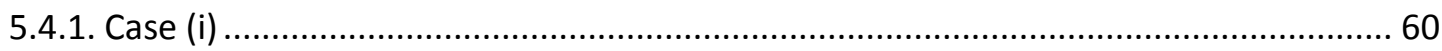

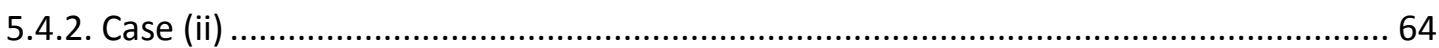

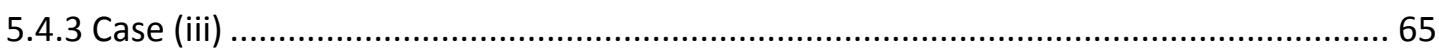

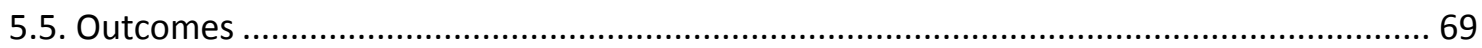

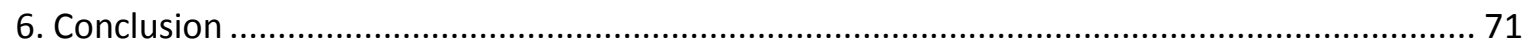

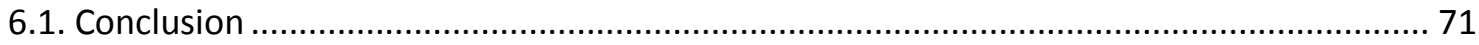

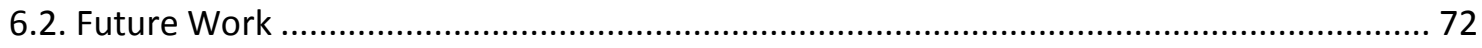

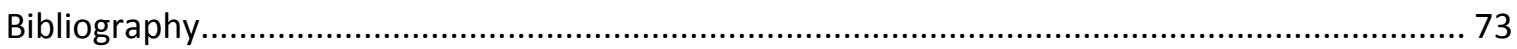

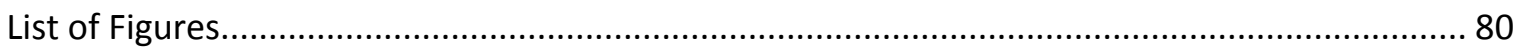

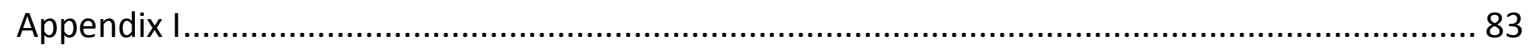

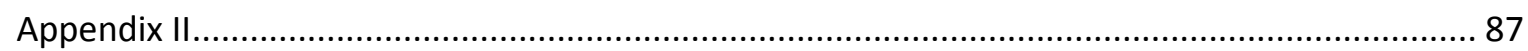

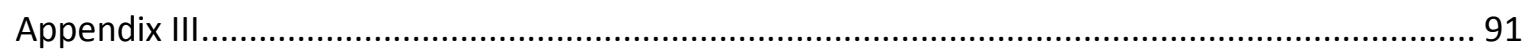

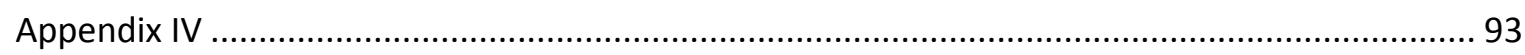

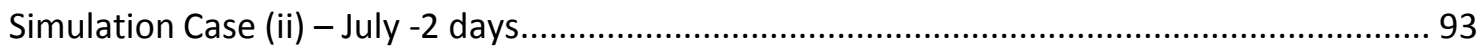

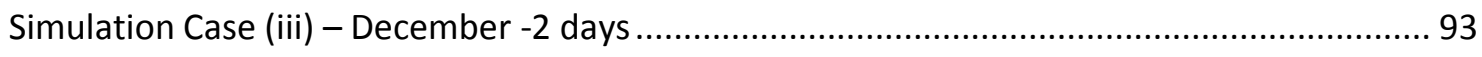

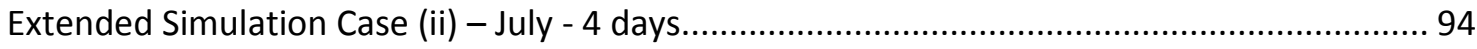

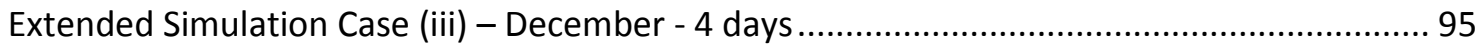

Extended Simulation Case (iii) - December - 4 days - with lower pv production on $2-3^{\text {rd }}$ day 


\section{List of Symbols}

A

BAT_CH

BAT_DISCH

$c_{p}$

$E_{\text {del_daily }}$

$\mathrm{E}_{\mathrm{D} \_ \text {min }}$

$E_{\text {wp_daily }}$

$E_{\text {wtr_daily }}$

$f_{v}$

G

g

$\mathrm{G}_{\mathrm{STC}}$

$I_{\text {dc_bat }}$

$I_{\text {max_char }}$

$I_{\text {max_disch }}$

$k_{p}$

$N_{p}$

$\mathrm{n}_{\text {rotor }}$

Pac_bat

$P_{\text {del }}$

$P_{d g}$

$P_{d g \_n}$

$P_{\text {dif }}$

$\mathrm{P}_{\mathrm{D}_{-} \text {total }}$
Surface Swept by the Wind Turbine Rotor $\left[\mathrm{m}^{2}\right]$

Signal Activating Battery Charging

Signal Activating Battery Discharging

Aerodynamic Power Coefficient

Daily Energy Demand of the Deferrable Load [Wh]

Minimum Energy towards the Deferrable Load Every Day [Wh]

Daily Energy Demand of the Water Pumping [Wh]

Daily Energy Demand of the Water Purification [Wh]

Derating factor for the photovoltaics performance

Solar Irradiance $\left[\mathrm{W} / \mathrm{m}^{2}\right]$

Gravitational constant $\left[\mathrm{m} / \mathrm{sec}^{2}\right]$

Solar Irradiance for Standard Test Conditions $\left[\mathrm{W} / \mathrm{m}^{2}\right]$

DC Current at Battery Output $[A]$

Maximum Charging Current of the Batteries corresponding to the Maximum Charge Rate $[\mathrm{A}]$

Maximum Discharging Current of the Batteries corresponding to the Maximum Charge Rate $[\mathrm{A}]$

Temperature coefficient of the Photovoltaic Panel related to Power $\left[\% /{ }^{\circ} \mathrm{C}\right]$

Total number of photovoltaic panels

Rotational speed of the rotor [rpm]

The power output of the battery converter on the ac bus [W]

Power to Deferrable Load [W]

Power Output of the Diesel Genset [W]

Rated Power of the Diesel Genset [W]

Power Difference Signal (the difference between the produced power and the primary load) [W]

Maximum Power towards the Deferrable load [W] 


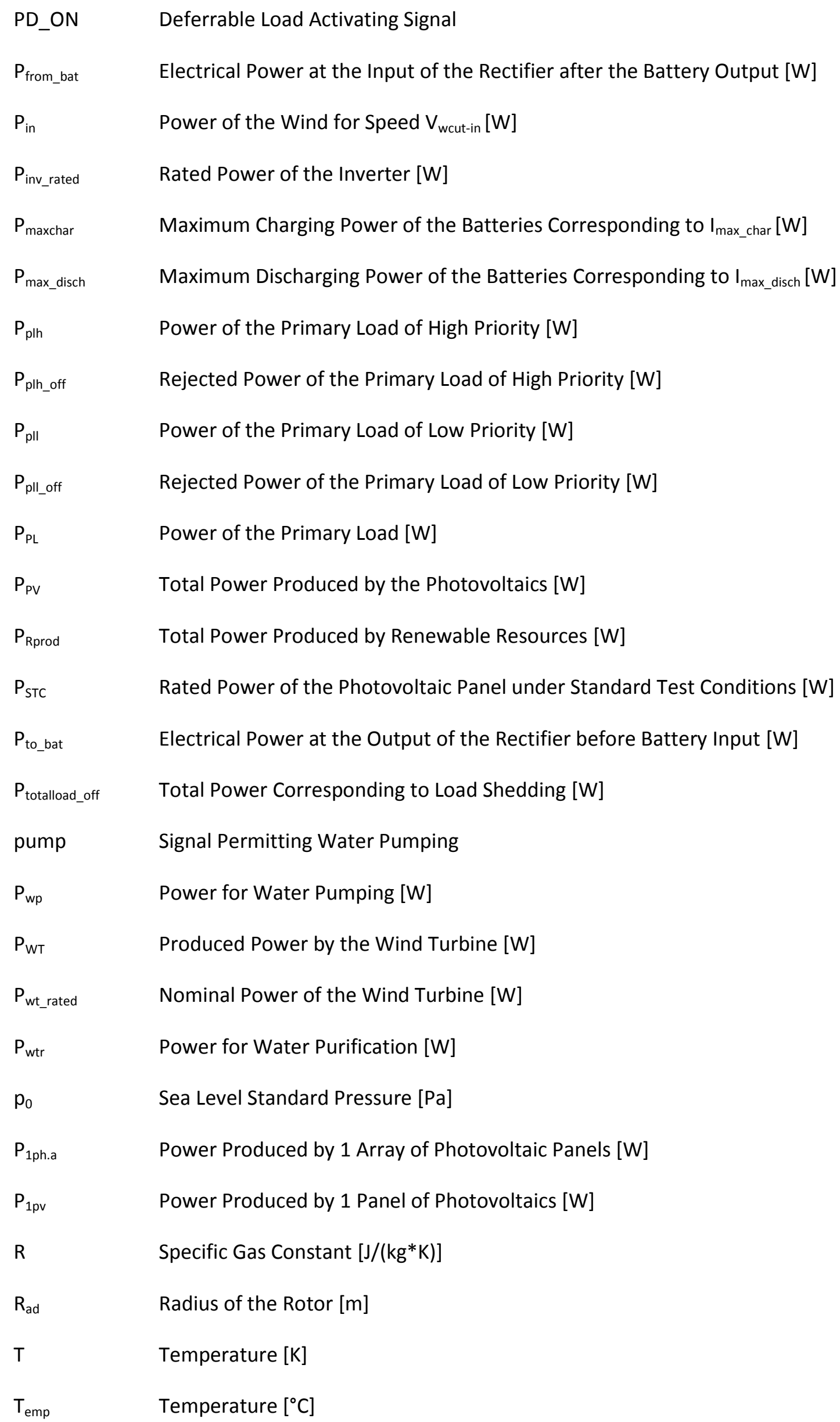




\begin{tabular}{|c|c|}
\hline $\mathrm{T}_{\text {STC }}$ & Temperature for Standard Test Conditions $\left[{ }^{\circ} \mathrm{C}\right]$ \\
\hline $\mathrm{V}_{\mathrm{dc}}$ & DC Voltage of the Battery Bank [V] \\
\hline $\mathrm{V}_{\mathrm{w}}$ & Wind Speed $[\mathrm{m} / \mathrm{sec}]$ \\
\hline $\mathrm{V}_{\text {wcut-in }}$ & Cut in Wind Speed for the Wind Turbine $[\mathrm{m} / \mathrm{sec}]$ \\
\hline $\mathrm{V}_{\text {wcut-out }}$ & Cut out Wind Speed for the Wind Turbine $[\mathrm{m} / \mathrm{sec}]$ \\
\hline $\mathrm{V}_{\mathrm{w} \_ \text {rated }}$ & Rated Wind Speed of the Wind Turbine $[\mathrm{m} / \mathrm{sec}]$ \\
\hline z & Altitude of the Wind Turbine [m] \\
\hline$\beta$ & Pitch Angle $\left[^{\circ}\right]$ \\
\hline$\eta_{c h \_b}$ & Efficiency Factor of Charging the Battery \\
\hline$\eta_{\text {convb }}$ & Efficiency Factor of the Battery Converter \\
\hline$\eta_{\text {disch_b }}$ & Efficiency Factor of Discharging the Battery \\
\hline$\eta_{\text {gint }}$ & $\begin{array}{l}\text { Efficiency Factor of the Interface between the Generator of the Wind Turbine } \\
\text { and the Inverter }\end{array}$ \\
\hline$\eta_{\text {inv }}$ & Efficiency Factor of the Inverter \\
\hline$\eta_{\text {p.e. }}$ & Efficiency of the Power Electronics for the Photovoltaics \\
\hline$\eta_{\text {round_trip }}$ & Round-trip Efficiency of the Battery \\
\hline$\eta_{\mathrm{w} . g} \cdot$ & Efficiency Factor of the Wind Generator \\
\hline$\lambda$ & Tip Speed Ratio \\
\hline$\rho$ & Density of the Air $[\mathrm{kg} / \mathrm{m} 3]$ \\
\hline$\omega_{\text {rotor }}$ & Angular Speed of the Rotor [rad/sec] \\
\hline
\end{tabular}




\section{Abbreviations}

$\mathrm{AC}$

Alternating Current

$\mathrm{CHP}$

Combined Heat and Power

COE

Cost of Energy

DC

Direct Current

DER

Distributed Energy Resource

DG

Distributed Generation

DNO

Distribution Network Operator

DS

Distributed Storage

EMS

Energy Management System

$M C$

Microgrid Central Controller

MO

Market Operator

NPC

Net Present Cost

PCC

Common Coupling Point

PMS

Power Management System

PV

Photovoltaics

rms

Root Mean Squared Value

SOC

State of Charge of the Battery

WT

Wind Turbine 


\section{Executive Summary}

This project was carried out at the Energy Department of KTH Royal Institute of Technology as part of the work of the Polygeneration Research Group.

The aim of this work is to design a hybrid autonomous power system for rural electrification, model and simulate its operation according to the chosen operational strategy.

The first chapter constitutes the introduction and describes the goals and objectives of the thesis, as well as the methodology followed to achieve them.

At the second chapter, the concept of microgrid is presented, along with their basic characteristics, operations, structure and possible configurations. Examples of already installed systems are cited and a literature survey is done.

The third chapter involves the design and techno-economic optimization of the hybrid power system for a remote village in Kenya. Some information about the electrification situation in the country is given and the electrical power needs of the inhabitants are determined. The microgrid consists of photovoltaics, wind turbine, diesel genset, batteries, a deferrable load and the primary loads. The techno-economical optimization is performed with the help of the HOMER software.

In Chapter 4, the microgrid is modeled in the Simulink environment of MATLAB. Each component is presented along with the model of the control for the operational strategy of the system. The three different case studies for the simulations are defined.

In Chapter 5, the simulations are carried out and their results are analyzed. Some alterations are proposed and additional simulations over longer simulation time performed and discussed.

Finally, some conclusions are drawn in relation to the system, its design and model and some aspects of it requiring further improvement in the framework of future work are indicated. 


\section{Introduction}

\subsection{Background}

The electrical sector was a profitable economic activity at its beginning in 1880, with the development of localized systems of electrical power production, distribution and sale at the local communities. Thus, the distributed generation of electrical energy is not a really new concept, even though it recently started appearing in the electrical power market bibliography. During the early stages of the electricity production development, the decentralized systems were the norm and not the exception, with the first power plants providing electricity to consumers, who were located in relatively small distances from them.

Later on, the national utility networks were developed with the establishment of massive central power plants and long transmission networks, under the state's supervision. The intense increase of the electrical energy demand reinforced the idea of scaling up the centralized production with big thermal, hydro-electric and nuclear power plants especially during the $20^{\text {th }}$ century. However, the energy crisis during 1970s, the rise of public concern over the environmental consequence during 1980s, the limitations on fossil fuel reserves and the influence from the liberalism principles contributed to a gradual alteration of energy policies and strategies [1].

The first electricity networks were $\mathrm{dc}$ and the voltage was limited as well as the distance between production and consumption point. The balance between them was partially achieved with the use of some kind of local energy storage, like batteries. With the expansion of the utility networks, the grid became ac and used high voltage in order to have higher capacity and reach longer distances. During the last decades though, the technological progress has contributed to the integration of the decentralized production related with the usage of renewable energy sources. This has increased the overall complexity of the grid, but has created many prospects for the access to electricity in many regions, where till now it was extremely difficult. Autonomous hybrid power systems comprising different energy sources and storage devices have been developed and have successfully served a wide range of applications, while continuing growing up and facing challenges.

\subsection{Goals and Objectives}

This project investigates the implementation of an autonomous hybrid power system to electrify a village near Garissa town in Kenya. The microgrid consists of photovoltaic arrays, a wind turbine, a diesel genset, battery bank as power storage and serves the needs of the households, the primary school, as well as the need of the inhabitants for clean water. It is represented by Figure 1.

The goal is to achieve a reliable and efficient operation of the microgrid, covering the consumers' needs and successfully managing the power inside it.

In order to achieve this, a representative model of the power system is essential. A valid, flexible and reliable model provides the basis for assessing the operation of a system like this, detecting its flaws, implementing different strategies and making the necessary adjustments to establish a system offering a good quality service to the people. 


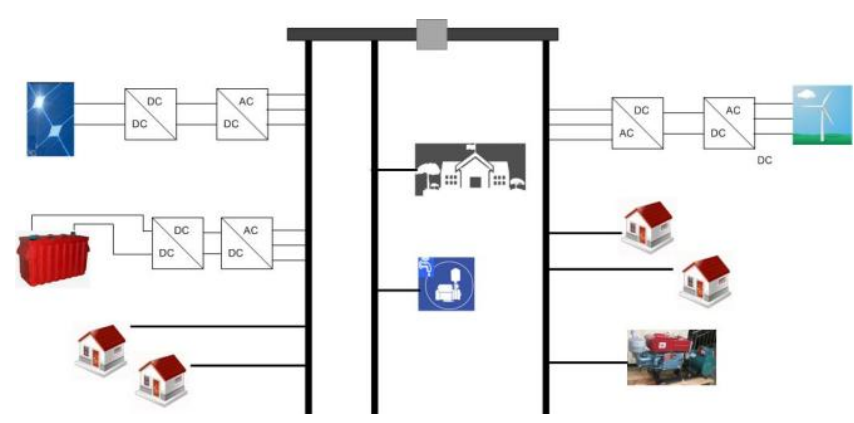

Figure 1. An indicative figure of the studied power system with the $p v$, the wind turbine, the batteries, the diesel genset and the different loads

\subsection{Methodology}

In order to design a power system, the first thing to be done is to decide on the power demand, the consumption the system should satisfy and the potential extra services it should provide. For cases like this, when the village is not electrified and is in a country the writer has not experienced, the estimation of the power demand can be done through extensive research of previous cases, similar systems and literature survey. The next step is to design the system which will be able to cover these loads; a process carried out in the HOMER software resulting in a techno-economically optimized configuration. This has as a prerequisite a thorough research for finding data about local costs and equipment that is being traded in the region, so that the result is as close to the real conditions as possible.

Subsequently, the defined system should be modeled and simulated, so that its operation can be monitored in smaller time slots and a power management strategy can be analytically tested in Simulink MATLAB; an option the HOMER software does not provide. This requires a literature survey on models regarding photovoltaics, wind turbine and batteries performance, as well as on the different control strategies. After the model is created in Simulink MATLAB, it needs to be tested under extreme conditions (e.g. without photovoltaics, with higher loads, etc) to ensure that it works properly and will give reliable results. The next step is the specification of different cases for which the operation of the microgrid will be simulated. The occurring results are analyzed and possible alternative solutions and improvements are considered. 


\section{Microgrids}

In this chapter, the concept of microgrid is described along with its main characteristics rendering it as an attractive alternative for electrification and setting it under the search light of many engineers, researchers, businessmen, organizations and communities all around the world. New York Prize awarded money to 83 projects for feasibility studies on microgrids [2]. The microgrid structure is presented, followed by some information on its operation. Subsequently, some examples of already installed microgrids and polygeneration systems are mentioned and the findings of the literature review on the topic are presented.

\subsection{Microgrids and their Significance}

According to Microgrid Institute [3], "microgrid is a small energy system capable of balancing captive supply and demand resources to maintain stable service within a defined boundary". A microgrid is a hybrid system composed by many different types of electrical energy sources such as renewable energy sources (photovoltaics, wind turbines, small hydro, gas turbines using biogas) but also generators using conventional fossil fuels (in a smaller scale), different kinds of energy storage (batteries, fuel cells, flywheels, water pumping) and loads of different types. Local energy assets, resources and technologies are used and combined inside the microgrid in order to satisfy the end users' requirements, which can vary from basic electrification to more advanced or complicated services. A representative idea of a microgrid can be given through Figure 2, where it is shown that a microgrid can possibly be interconnected with the utility network, include a variety of energy assets and resources in order to provide different services to a range of facilities.

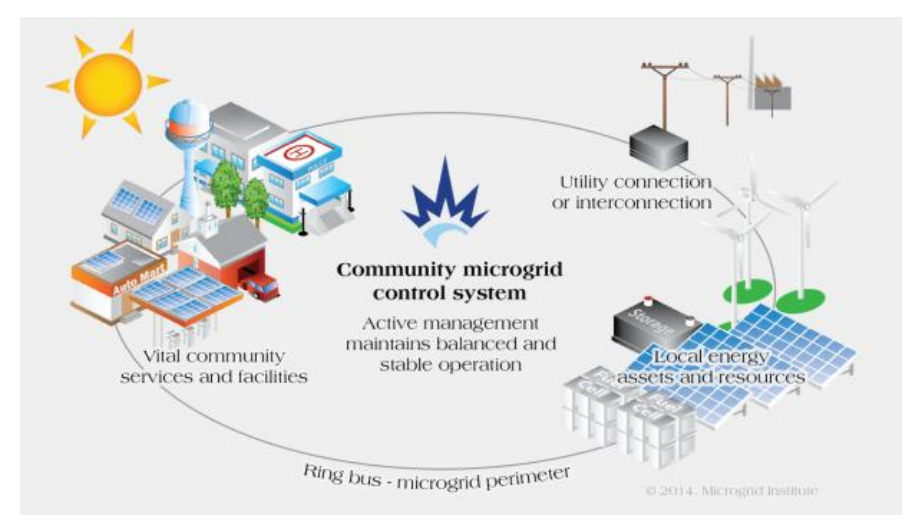

Figure 2. The concept of microgrid [3]

Some of the reasons for the increasing interest towards microgrids originate from the use of renewable energy sources and the decentralized, distributed character of the system. The environmental concerns (atmospheric, ground and water pollution, climate change) due to use of fossil fuels, the finite and limited amounts of conventional fuels, the increasing cost of electrical energy, the need for energy safety and independency of the countries strengthen the effort for adopting and developing the technology of renewable energy sources. The decentralization of electrical power production brings the generation closer to the consumption point, enhancing the reliability of the system, since if one fault occurs somewhere and a part of the grid gets isolated, then the other parts will not be affected. Moreover, it increases the efficiency of the overall system, since the transmission losses are decreased.

All the above acquire a higher significance due to the continuously increase of energy demand all over the world, with a rate that varies between the countries and the continents. Important 
incentives for the practical and scientific interest, the spread and support towards microgrid projects are the need for electrification in remote locations and developing countries, the user's need for sustainable, lower-cost energy, more reliable and resilient service, arising issues regarding grid security and survivability. The vast rise of electrical power demand makes urgent the need for actions towards grid optimization, congestions relief, integration of ancillary services. [3]

The importance and the character of the role of the microgrid differentiate in relation to the place where it is installed and the conditions there. In [4] there is a very interesting approach to this aspect, for which three different countries are used representing the developing economies, like Zambia, the rapidly industrializing economies, like India and the postindustrial economies, like Germany. The increase in the electricity supply and the existing electrification rate in each one of these countries create a totally different background for observing and assessing the necessity and usefulness of microgrid development. The level of electrification within a geographical region can be expressed through the length of transmission line per unit area of that region. At Figure 3, the circuit length of high voltage transmission line for a square kilometer of land area, the percentage of the population with access to electricity, the per capital energy use in 2000 and 2003, as well its increase during these three years are given.

\begin{tabular}{|c|c|c|c|c|c|}
\hline Country & $\begin{array}{l}\text { Circuit km of } \\
>132 \mathrm{kV} \\
\text { Transmission } \\
\text { Lines/sq km }\end{array}$ & $\begin{array}{l}\text { Percentage } \\
\text { with Access } \\
\text { to Electricity } \\
\text { in } 2000\end{array}$ & $\begin{array}{l}\text { Per Capita } \\
\text { kWh Use } \\
\text { in } 2000\end{array}$ & $\begin{array}{l}\text { Per Capita } \\
\text { kWh Use } \\
\text { in } 2003\end{array}$ & $\begin{array}{l}\text { Average Annual } \\
\text { Change in } \\
\text { Per Capita } \\
\text { kWh Use in } \\
2000-2003(\%)\end{array}$ \\
\hline Zambia & 0.0048 & 12 & 582 & 662 & 4.6 \\
\hline India & 0.021 & 43 & 402 & 435 & 2.7 \\
\hline Germany & 0.234 & 100 & 6,682 & 6,900 & 1.1 \\
\hline
\end{tabular}

Figure 3. Electricity access and use in illustrative countries [4]

In developing economies, the coverage of the transmission grid is severely geographically limited. The daily per capital electricity use is 1 to $2 \mathrm{kWh}$, when it is taken as the average over the whole country's population. The main barrier for the improvement of the situation there is the high capital investment required for an extension of the grid following the traditional centralized power system. The short purchasing power and the low levels of average consumption among the still unserved population set the microgrid to be a considerable alternative solution. This happens because for small scale microgrids there is no need for significantly subsidized large capital development support, especially if it is integrated within the community economic development. In this case, it can facilitate and contribute to better healthcare services, enabling the electrification of rural health clinics, better education and higher trade capabilities. In this case, the complexity of the microgrid and of the equipment should remain as low as possible, so that local technicians can maintain and observe its operation. If it is also combined with applying the intermediate technology [5] (like Hugh Piggot's wind turbine), the microgrid will be made with respect to the local techniques and resources and engage even more the local community.

In rapidly industrializing economies, like India, the transmission grid reaches a much wider area, but there are still significant parts of the population without access to electricity. Moreover, because of the intensity of the industrialization and the big population, the installed power is not sufficient to cover the continuously increasing demand. Thus, the main problems in this case are 
firstly the need of expansion of the main grid and secondly, the need of installing more power plants. This has a high cost, can be unreliable and most probably will not cover the end use of electricity for a long time. In this case, the microgrids are again a really attractive alternative, because they are less expensive, more flexible, easily expandable and reliable without any need of additional transmission lines. In addition, they may contribute to the improvement of the life in rural areas in the same way as before.

In post industrialized economies, all the population has access to electricity, consuming much more energy daily with an incremental rate during the years. There, an important effort towards increasing the energy efficiency in different domains is made and microgrids play a different role. They can be used again as an alternative for remote areas or islands. There are also many communities and cooperatives taking initiatives for developing microgrids in order to achieve some kind of self - management of energy. There are companies investing and setting up their own microgrids connected to the main grid, trading energy and making profit. Most importantly, though, they are used as a way of strengthening the power supply of a region, building or a hospital, etc, securing its reliable operation under bad weather conditions, problem or faults in the main grid. This is one of the reasons for the development of microgrid in United States of America [2].

Nevertheless, one cannot neglect the challenges and uncertainties faced by microgrids on various issues like "government policy, regulation, utility tariffs, contracting, financing, risk management, interconnection, resource planning, system operations, technology and fuel supply trends". [3]

Their most important features are their modularity, the redundancy of suppliers, the high existing standards and the simple interconnections required [6]. All these contribute firstly to the autonomy offered by them, since they include generation devices from a wide range of primary energy resources, frequently renewable, along with storage devices and controlled loads operating in an autonomous mode. Secondly, they contribute to the stability microgrids provide, because of the application of a control approach based mainly on droop in frequency and voltage at the terminal of each device, enabling the whole system to operate in a stable manner even during transient events.

The compatibility is another of their important characteristics, as they can act as complimentary fully functional units operating within the existing centralized legacy grid which is difficult to be expanded. Scalability and flexibility are significant as well and originate from their modularity and diversity of the composing elements. They can be easily expanded, connected with other microgrids or with the main grid, change the mixture of energy and adopt to different conditions, while at the same time they reinforce the flexibility. They perform within high efficiency levels and allow for engaging properties in response to costs, so that the operating protocol of the microgrid can integrate the market signals inside it [4]. Finally, resiliency and reliability are two crucial qualities of these systems enabling their expansion and usage.

\subsection{Microgrids Structure and Operation}

Microgrids can be divided in four categories:

i. The off -grid microgrids: they include islands, remote sites and other systems not connected to the local main grid 
ii. The campus microgrids: they are fully interconnected with a local electricity network, but at the same time, they can independently keep and provide some level of service in isolation from the grid, like in the case of a utility outage. Some examples of this category are university campuses, military bases.

iii. The community microgrids: they are integrated into utility networks, support multiple customers and services inside the community and secure a resilient power supply for vital community assets.

iv. The nanogrids: they consist of the smallest discrete network units with the capability of independent function, as it can happen in a single building.

A microgrid may or may not be connected with a local utility network, but for sure it can work in an island mode; otherwise it is not a microgrid, but a grid tied distributed generator system.

A general from of microgrid is presented in Figure 4, where it includes a wide variety of distributed energy resource (DER) units of rated power for each usually till $500 \mathrm{~kW}$, (but it can reach also $1 \mathrm{MW}$ ), usually connected through a low voltage grid with different types of end users (from residential buildings to industrial parks) of electricity and/or heat. The DER units involve distributed generation (DG) and distributed storage (DS) units with different characteristics and capacities. The microgrid can operate in connection with the main grid and in this case it actually 'follows' the main grid properties and exchanges power with it according to its needs. While working in autonomous mode though, it has to always regulate the voltage and frequency and maintain a power balance to secure a stable operation.

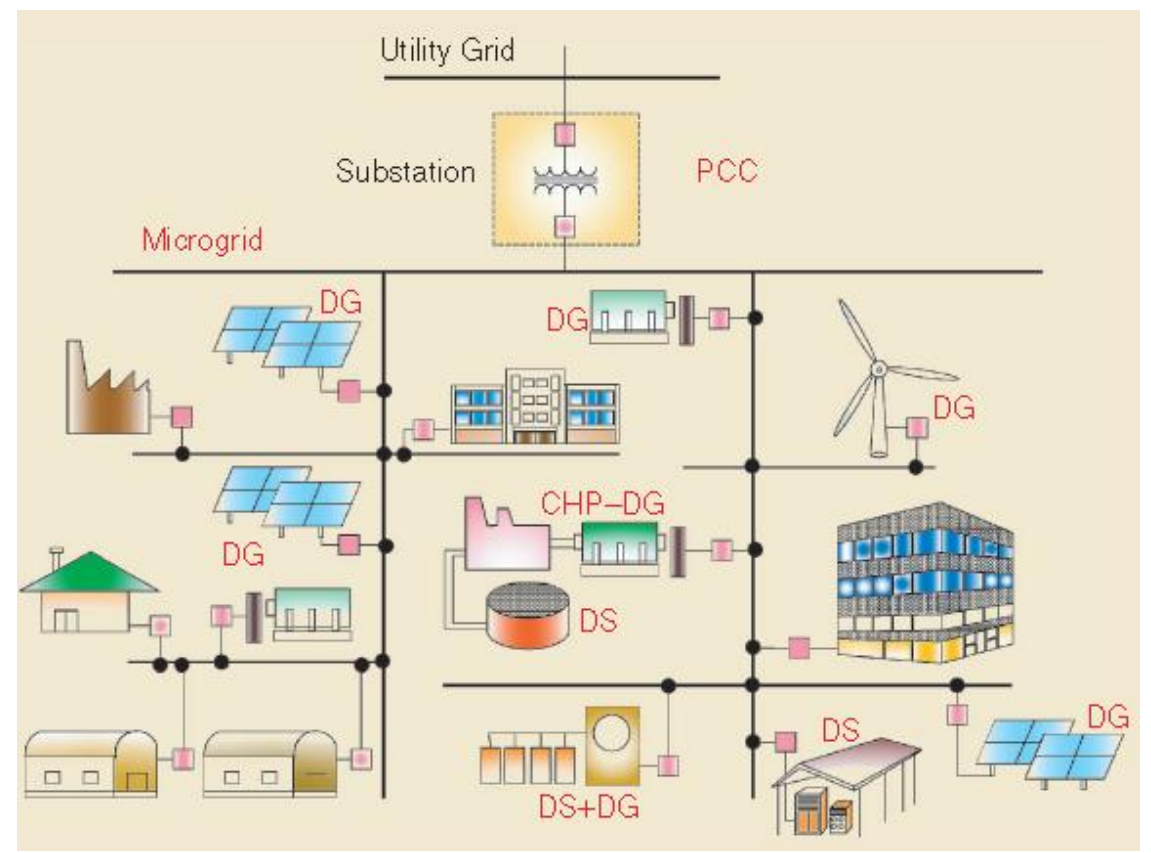

Figure 4. The general form of a microgrid [7]

The microgrid point of common coupling (PCC) is the electrical connection point of the microgrid to the utility network at the low voltage side of the substation transformer. As far as the DER units are concerned, in relation to their interface with the microgrid, they are categorized in two groups: the conventional or rotary units, which are interfaced to the microgrid through rotating machines and the electronically coupled units coupled with the host system through power electronic converters. At the conventional DG units (like a synchronous generator driven by a reciprocating engine, or a generator of a fixed speed wind turbine), the rotating machine 
converts the primary energy source to electrical power and functions as the interface between the source and the grid. At the electronically coupled DG units though, the coupling converter provides another level of conversion and control, and consists the interface with the microgrid. Each of these categories requires different kind of approach and control on both system and component level.

In terms of power management, the DG units are characterized as dispatchable or non dispatchable units. The power output of the first of them can be controlled externally, through set points indicated by an administrative control system; an example is the diesel generator in a system. The output power of the latter, though, is normally controlled based on the optimal operating condition of its primary energy source, in order to extract the maximum power of it; an example is the photovoltaics with maximum power point tracking. There are some qualities of the electronically coupled DER units improving the microgrid performance. These are the fast dynamic response of the interface converters, their capability to reduce the short circuit contribution of the unit to less than $200 \%$ of its rated current and the degree of electrical decoupling between the energy source and distribution system the converters provide, reducing the severity of dynamic interactions between two subsystems. However, they lack the intrinsic tendency of maintaining the microgrid frequency, since the converters do not exhibit any inertia in contrast to the conventional DG units. [7]

Regarding the microgrid loads, these can be electrical and/ or thermal and are usually characterized by different priority levels. The need for this categorization arises due to the autonomous mode of operation of the power system, where the preservation of a power balance may impose the act of load shedding. In this case, it must be ensured that the critical loads will receive service priority. Either way, the microgrid should facilitate the provision of more services, like customer service differentiation, power quality enhancement of certain loads and reliability improvement for specified load categories. In addition to that, load control involving lower priority loads that can be shifted in time during the day can be part of demand response control and contribute to reduce the peak load, smooth out the power demand curve and schedule the load serving for periods of time when excess of power is available.

The main DER controls aim to voltage/frequency control and active/reactive power control depending on the nature and type of DER and the configuration of the microgrid. There are two main categories: the grid following and grid forming control, each one being divided in two more kinds: the interactive and non interactive control methods, as it is described in more detail in [7]. Here, it will only be mentioned that the grid following approach is applied when direct control of voltage and/ or frequency at the PCC is not demanded. The grid forming control, though, is employed when the voltage and frequency control is demanded in the absence of the utility grid, when the DER units have to ensure the balance of power through voltage regulation and frequency stability in the autonomous microgrid. This is where the necessity for droop control [7] emerges, rendering it as a widely adopted and developed method in microgrid applications. 


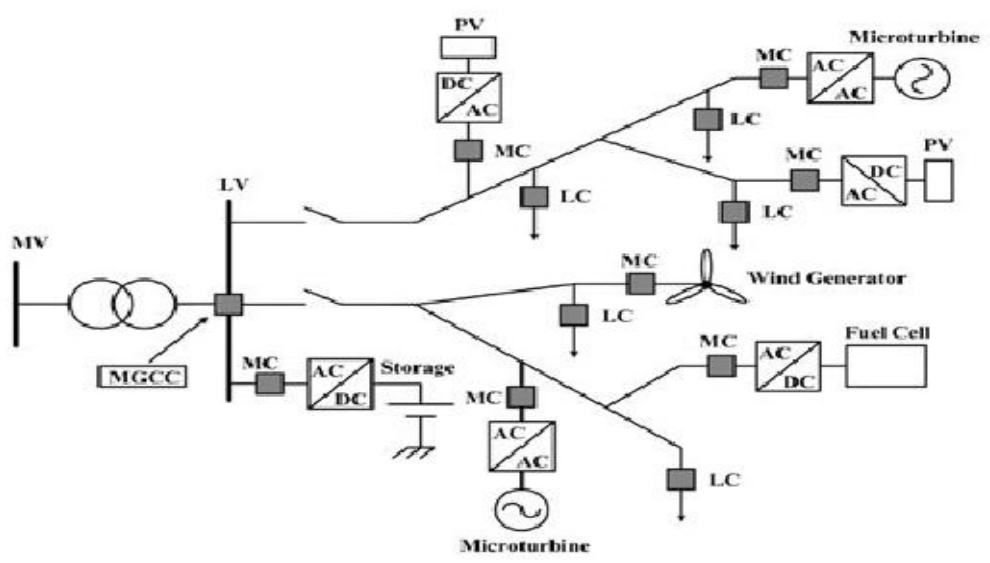

Figure 5. Typical structure of a microgrid [1]

The typical structure of a microgrid is depicted in Figure 5, where the extra elements (not discussed before) are the ones related with the architecture of control. The Microgrid Central Controller (MCC) can communicate with the Distribution Network (DNO) and Market Operator (MO) and its function extends from simple monitoring of the active and reactive power delivered by each microsource, till optimization of the overall system operation and maximization of its value through control signals to the generators and the loads. At the lower control level, one can find the Local Controllers (LC), which locally control a DG or DS or some controllable load. The LCs can communicate through signals between each other and the MCC [1]. As it is mentioned in [7], each LC may have a certain level of intelligence depending on the control approach. In a centralized operation, each $\mathrm{LC}$ receives set points from the corresponding MCC, which optimizes the power exchanged with the host system in the case the microgrid is not an off-grid one. The LCs follow the MCC's command during grid-connected mode operation, but keep the autonomy to perform local optimization on the power exchange of the DER units, as well as implement fast load tracking following transition to an autonomous mode. In a decentralized operation, the goal is to provide the maximum autonomy to the DER units and loads inside the microgrid. In this case, the LCs are intelligent, make decision locally and can communicate with each other to create a larger intelligent entity. The task of these controllers is not to maximize the performance of an individual unit, but to optimize the overall performance of the microgrid. This decentralized operation is often approached by researchers though multi - agent systems.

A microgrid can appear in different configurations as it is described in [8], according to the application and the requirements in each case. It is mainly categorized in series, switched or parallel hybrid energy systems with AC or DC coupling. In Figure 6, a series microgrid is shown, where all power generators feed DC power into a battery and then the power is again converted to $A C$ to be supplied to the loads. Both the diesel generator and the inverter should in this case be sized to cover the peak load, and each component is accompanied by an individual charge controller and in the case of diesel genset a rectifier. Some characteristics of this configuration are that it bears the danger of shutting the whole load down if there is a fault at the inverter and that it results in increased battery cycling and reduced system efficiency, being though the simplest configuration. 


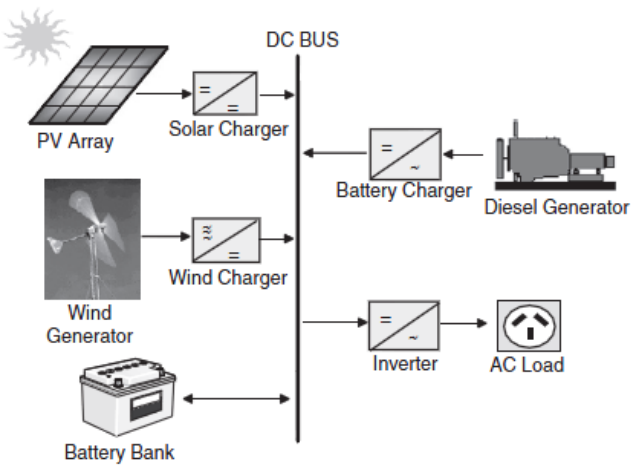

Figure 6. Series hybrid energy system [8]

The switched configuration of a PV - diesel hybrid energy system is depicted in Figure 7 and is broadly implemented in some developing countries. With this configuration, either the diesel genset or the inverter will act as the ac source without any main generation source being allowed to work in parallel. Both the diesel generator and the renewable energy source can charge the battery bank, but in this case the diesel generator can feed directly the load increasing the system's efficiency. Again the diesel generator and inverter should be sized to satisfy the peak load.

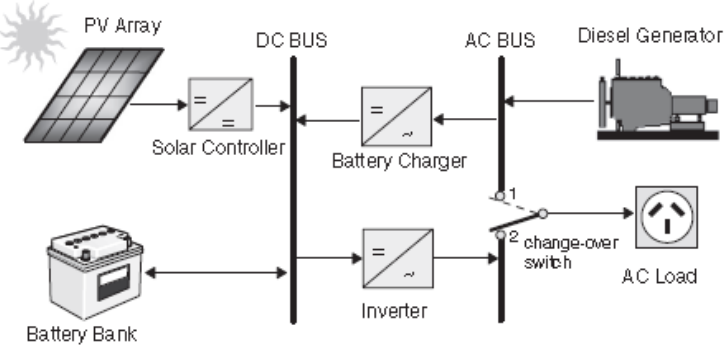

Figure 7. A PV-diesel hybrid energy system in switched configuration [8]

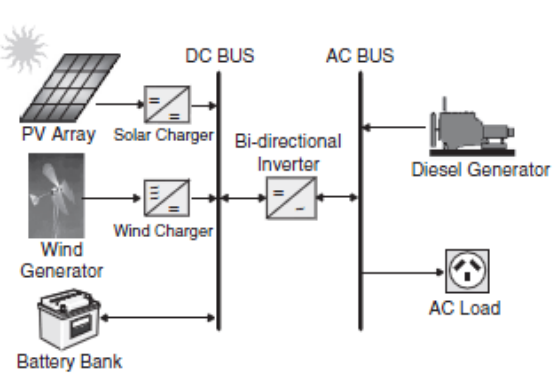

(a)

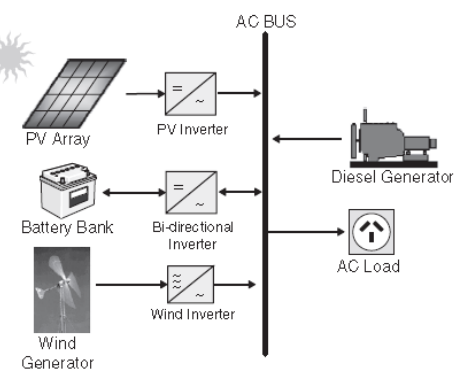

(b)

Figure 8. Parallel configuration of (a) a DC and (b) an AC coupled microgrid [8]

The third basic category is the parallel configuration with AC or DC coupling presented in Figure 8. This is the most efficient configuration with a more complex control though. In this case, the bi-directional inverter is used to link the battery with an ac source and can charge the battery when there is excess of power from the diesel genset or from the other sources in the system. Here, the sum of the power rating of the components needs to be sized to meet the peak demand, rather than the size of only two elements as before. Moreover, in the case of overload of the diesel engine, the bidirectional inverter can apply 'peak shaving' as part of the control strategy. 
The last aspect of microgrid operation discussed in this section is the power and energy management or the dispatch strategy of the microgrid. According to [9], "dispatch refers to the aspect of control strategy that pertains to energy flows among the major components of the system". The power and energy management systems' (PMS and EMS) fast response is more critical in microgrids compared to a conventional system. One of the reasons for that is also the lack of a dominant source of energy generation; the concept of infinite bus of the conventional systems does not exist here. They should accomplish both short-term power balancing and covering long-term energy management requirements. They assign real and reactive power references for the DER units to appropriately share power among the DER units, respond to microgrid disturbances and transients, balance the power and restore the frequency, as well as enable synchronization of the microgrid with local utility network, if needed [7]. In the case of off-grid microgrid for electrification of remote areas, where fueled back up power and energy storage devices keep the balance of the system, the dispatch strategy is strongly related with the consumption of fuel and prolongation of the lifetime of the equipment. In [9], there are four described dispatch strategies, which are related with the cooperation of the diesel generator and the batteries in the autonomous microgrid: the frugal dispatch strategy, the load following strategy, the state of charge $(\mathrm{SOC})$ set point strategy and full power/minimum runtime strategy.

\subsection{Microgrids as Part of the Polygeneration System}

The concept of polygeneration could be considered as an extension of the one of microgrid, including it at the same time. Polygeneration systems tightly integrate heating, cooling and electricity production processes. They include many different energy sources, like photovoltaics, wind turbine, storage devices, small scale hydro, micro-turbines, reciprocative engines, CHP resulting in much higher efficiency than the single-product systems, higher flexibility and profitability. They usually serve some additional services as well, like water purification and share the same benefits with microgrids, but more enhanced because of their wider character.

\subsection{Examples of Already Installed Systems}

In this section, some existing microgrids and polygeneration systems are presented.

One example of microgrid is the one installed on the island of Kythnos in Greece, having the form shown in Figure 9.This system was designed by the Athens based Center for Renewable Energy Sources and Savings, the Kassel University and SMA and it was installed in 2007 [10].

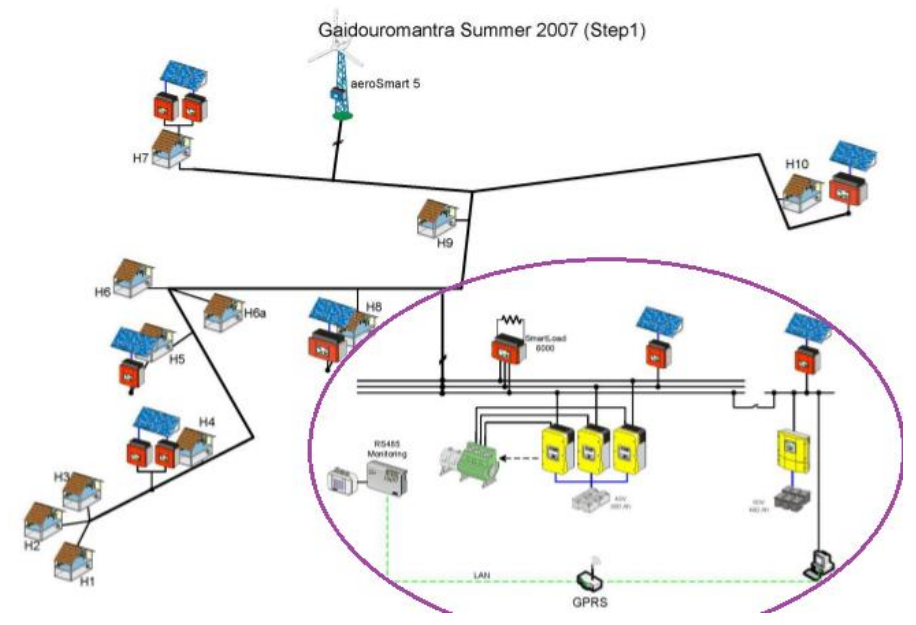

Figure 9. The microgrid installed at location Gaidouromantra in Kythnos [11] 
It is a single phase microgrid with overhead power lines and a communication cable running in parallel. It is supplying with electricity twelve houses located in a valley of the island. The grid and safety specifications for the house connections are set according to the technical solutions of the Public Power Corporation, which is the local utility grid. The establishment is located $4 \mathrm{~km}$ away from the closest pole of medium voltage grid and can be seen inside the purple circle of Figure 9. There is the prospect of getting connected with the main grid of the island, where there is already installed power from photovoltaics and wind turbines.

The microgrid consists of $10 \mathrm{kWp}$ of photovoltaics divided in smaller sub-systems, a battery bank of nominal capacity $53 \mathrm{kWh}$ and a diesel genset of nominal power output of $5 \mathrm{kVA}$. The three Sunny-island battery inverters are connected in parallel to form a robust single-phase in a master-slave configuration. In this way according to the consumers' power demand, the use of one or more battery inverters can be decided. The maximum power output of the battery inverter is $3.6 \mathrm{~kW}$, while the converter can work both in synchronous and droop mode. While operating under frequency droop mode, information can be transmitted to the switching load controllers in case the battery SOC is low, while the power output of the photovoltaic inverters can also be limited when the battery bank is fully charged.

Apart from the users' system mentioned above, there is a second system of $2 \mathrm{kWp}$ installed on the roof of the system house, coupled to a Sunny-island inverter and a $32 \mathrm{kWh}$ battery bank. This system is responsible for the monitoring and communication services needed for the coordinated operation of the system [12].

Another example of an off-grid installed microgrid for rural electrification is presented in [6] and is installed at Bulyansungwe in Uganda. The hybrid system is composed of $3.6 \mathrm{kWp}$ photovoltaic array, 2 Sunny Boy PV inverters of $1.7 \mathrm{~kW}$ each, a battery bank with nominal capacity of 21.6 $\mathrm{kWh}$, one Sunny Island battery inverter of $3.3 \mathrm{~kW}$ and one three phase gasoline generator of 4.6 kW power rate. It electrifies the school, the girls' and the boys' hostels and the convent. There is the prospect of a future expansion of the system to involve and integrate the existing system of the health clinic in the social center into the microgrid. The expansion includes also the installation of photovoltaic array at school, to enable the use of computers by the students; this will be a localized production, so no new storage will be added. In the system, there is also a kind of demand side management applied in order to use all the available energy before it is stored and reduce battery cycling. They have a pumping system for the peak production hours to improve the efficiency of their system.

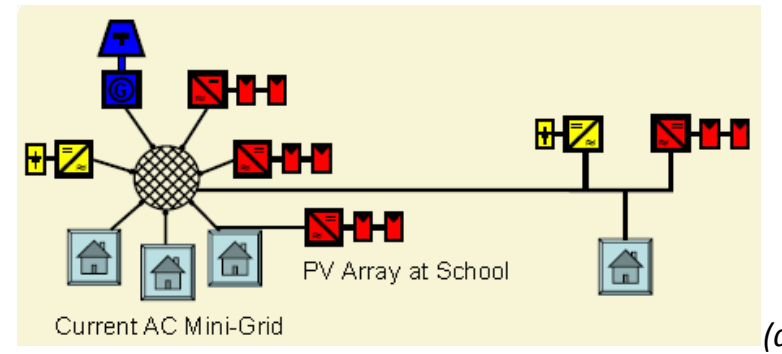




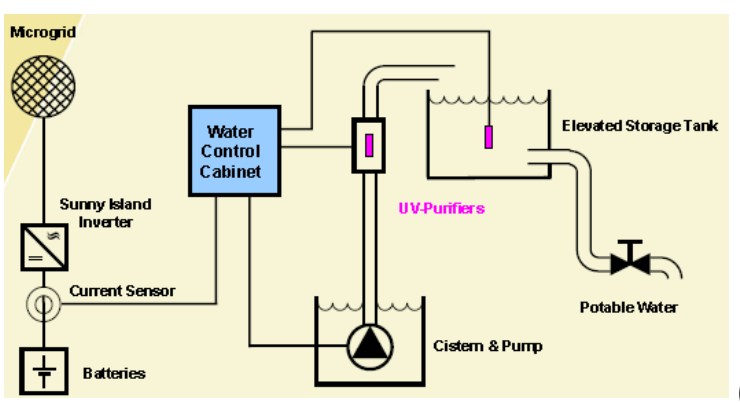

(b)

Figure 10. (a) The Bulyansungwe microgrid with its future expansion and (b) the pumping system architecture [6]

The last example involves polygeneration systems and more specifically the Polycity Project taking place in Turin, Stuttgart and Barcelona [13]. It is a project of the CONCERTO initiative, cofunded by the European Commission. During this project, the previously mentioned large urban areas will be developed, particularly in the field of energy optimization and the use of renewable energies. In Barcelona, eco-buildings are planned to be established for residential, industrial and service uses, which will be connected to a polygeneration system producing electricity, heating and cooling. The system will comprise natural gas cogeneration plants (CHP) with an electrical output of about $46 \mathrm{MWe}$, with thermal cooling facilities and a district heating and cooling network serving the Science and Technology Park. The system is complemented with a gasification biomass plant of $1 \mathrm{MWe}$, using wood waste from the furniture industry as fuel and with a solar thermal plant of $2000 \mathrm{~m}^{2}$ of collectors producing hot water for cooling purposes. The optimization of the overall system operation and the integration of supply and demand will be accomplished with the implementation of a Communal Energy Management System (CEMS).

\subsection{Literature Survey}

Because of the broad research and applied interest towards microgrids, there is a wide range of published literature and work carried out on this field. There are some studies which examine the feasibility of a microgrid for specific application or for different configurations with real case studies (some times) mainly using HOMER software, as it is done in [14] for a location in Bihar, in [15] for deciding on the optimal configuration for domestic lightning in countries of sub-Saharan Africa, in [16] where the feasibility of a wind-pv-diesel hybrid power system is investigated for a village in Saoudi Arabia and in [17] where HOMER has been used in the framework of a very detailed design of an off-grid microgrid for an Ethiopian region. There are also some works on size optimization of hybrid power systems without the use of HOMER software, but with using different ways of programming like in [18], [19] and [20].

There is also an extensive work carried out on modeling issues regarding microgrids to simulate their performance and assess the control methods. In [21], the modeling process of an autonomous solar -wind - hydro power system is described and its operation is simulated in Simulink / MATLAB. In [22], a microgrid composed of photovoltaics, critical and non-critical loads, fuel cells and intermediate storage connected to the utility network of medium voltage is modeled and simulated while transferred to islanded mode and controlled through droop control. In [23], the models of the photovoltaics, batteries, converters and their control are presented and used to simulate in ATP (alternative transients program) the operation of the microgrid under grid forming operation, droop control and grid following operation. Droop control is in the center of research carried out on the dynamic response of microgrids, like in [24] 
where an accurate load sharing method is implemented using droop control and the microgrid is modeled and simulated in PSCAD/EMTP.

Most of the published papers about microgrids focus on their control and in [25] there is a detailed description of control architectures, while in [26] a centralized control is implemented integrating the market price signals to optimize the power system's operation. There is also a lot of effort put on developing decentralized control methods and testing them, as in the case of multi - agent systems. Multi -agent systems is only one method among a lot that are being studied. In [27] the multi-agent approach is implemented and its design is described to simulate in Simulink the operation of a distributed smart grid under transient conditions, while in [28] the same method has been used to control the distributed energy storage in DC microgrids. It is quite interesting, that while multi agent control has been applied a lot in microgrid simulations regarding the voltage and frequency dynamic responses, it has not been applied in power management level.

Energy management has been the focus point of some research work too, with [29] presenting a review of power sharing control strategies in islanded microgrids and [30] carrying out a comparative evaluation of power management strategies of an autonomous pv/wind/fuel cells system, while using the multiperiod artificial bee colony theory to achieve an optimal energy management.

Finally, there are some works involving a complete approach and study of microgrids, starting with the design and size optimization, sometimes using HOMER software, continuing with detailed modeling of the components, the power electronics and their control and final simulations for short periods of time. One representative example of these works is [31]. In [32] the pre-feasibility study of an autonomous power system with photovoltaics, wind turbine, diesel genset and storage is done, followed by unit sizing and optimization, and finally modeling and simulation of the operation on the level of power management. A similar approach is adopted in [33], where a microgrid is designed for rural electrification purposes in Algeria, is modeled and simulated in Simulink MATLAB environment to assess the power management of the autonomous hybrid energy system. 


\section{Size Optimization in HOMER Software}

\subsection{Introduction}

In this chapter, the techno-economic optimization process is described focused on the electrification of a small village near Garissa in Kenya. The optimum configuration of the hybrid power system in terms of different generation capacities is assessed through the HOMER software and is compared with the alternative of a connection to the main grid. The aim of this simulation is to provide a basic but representative idea of the configuration of the microgrid, which will be further used to support the design of its model in MATLAB/Simulink.

Initially, some basic information about HOMER software will be presented, followed by a brief introduction about the electrification background in Kenya and the existing problems. Subsequently, the power demand in the village is estimated and the process of designing the model is described with the initial choice of the generators and batteries, as well as the considered constraints and parameters. Finally, the results of the analysis are shown. During the whole process, the main difficulty was to find reliable data about the costs of the equipment regarding purchase, transportation and maintenance because of their high volatility and variability between different places in even the same country, but also because the prices change for one year to the other.

The Hybrid Optimization of Multiple Energy Resources (HOMER) software is a tool to design, model and optimize stand-alone and grid connected power systems. [34] It is widely used for techno-economic analysis of microgrids, as it can simulate a range of different conventional as well as renewable energy technologies and assess the technical and economic feasibility of them. The inputs to the HOMER model are climate data, electrical load, technical and economic parameters of the equipment used for generation and storage, sensitivity variables, dispatch strategy, and some more constraints. Then the model performs a simulation of the operation of the system making the energy balance calculations for each one of the 8760 hours of the year, resulting in the optimal system size and control strategy based on the lowest net present cost (NPC).

However, there are certain limitations, as it happens with many softwares. Untill now, the basic free version of it does not easily allow to the user to include different kinds of controllers that accompany the micro-sources, does not simulate the charge controllers and transmission loses, ignores some external costs like the ones for wiring and mounting of systems and does not calculate accurately the real lifespan of batteries according to their usage. [35] Moreover, it does not offer much flexibility in terms of the micro-grid configuration, which can only be set up as centralized. A higher flexibility on the configuration could have considerable effects on the adequacy, energy efficiency, safety, and expansion potential of an autonomous hybrid energy system. [36]

\subsection{Kenya Background}

Since the topic of this thesis has been chosen to be about rural electrification and more specifically a case study about a village in Kenya, including some information about the situation in this country regarding the access to electricity and the related difficulties could be useful for the reader to understand better the approach of this work to the important aspect of electrification of isolated areas. 
Kenya is a country of $580,370 \mathrm{~km}^{2}$, being in this way the $49^{\text {th }}$ biggest country in the world and the $23^{\text {rd }}$ biggest in Africa. It has $45,925,000$ people, while more than $43 \%$ of them live under the poverty line [37]. The total electricity generation increased by $3.9 \%$ from 7,560 GWh in 2011 to $7,850 \mathrm{GWh}$ in 2012 [38]. The installed effective capacity is around 1,660 MW, with hydro being the main source, followed by thermal and geothermal power, while there is a small part coming from wind power plant [39]. The total penetration of renewable energy sources is more than 80 $\%$, but the fluctuating character of the hydro source, especially during the summer months when the water level is low, leads to increased consumption of fossil fuels.

Increasing economic activities in the country along with the higher domestic energy demand result in a situation where the unsuppressed demand is calculated to be at $1700 \mathrm{MW}$ while the power generation is $1664 \mathrm{MW}$ [35]. The apparent gap between production and demand creates instabilities in the system and necessitates imports of foreign energy, whose high cost further slows down the economic growth of the country. According to the World Bank [40], only $19 \%$ of the total population has access to electricity; more specifically, $6.7 \%$ of the rural population and $58 \%$ of people living in urban areas. The extension of the grid itself is not the solution, since the production capacity should be increased at the same time, the cost of extension is very high and the reliability of electricity supply rather low. On average, Kenyan companies lose nearly $10 \%$ of their production due to power outages and fluctuations [38]. This has lead to the need of diesel power plants installation, which have a significant cost of energy generation.

In the framework of the development plant of Kenya VISION 2030 and the initiative SE4ALL (Sustainable Energy for All) the country takes more and more measures to secure a safe, reliable, cost effective and environmentally friendly coverage of the people's energy needs both in urban and rural areas, by increasing the generation capacity, upgrading the grid, augmenting the share of renewable sources in the energy mix and supporting interconnections with the neighboring countries. To satisfy the energy needs of the citizens in isolated areas, several autonomous microgrids have been installed (like in lake Victoria Islands [35]) and the bureaucratic procedures have been reduced; an example for this is the direction that the Renewable Energy projects under a capacity of $1 \mathrm{MW}$ do not need license and those between $1 \mathrm{MW}-3 \mathrm{MW}$ need a streamlined Electricity Permit from the Energy Regulatory Commission [38]. Still, much more remain to be done.

\subsection{Power Demand Estimation}

For the size optimization to be done, the load curve during the day and the year should be determined. Generally, this has been a difficult task, as the uncertainty around it is high. An accurate prediction on how people without previous access to electricity will behave is hard. The common practice when a microgrid is to be installed to an unelectrified area, is to interview its inhabitants about their needs, what they currently use and what they would mostly like to add on that and then interview the citizens of another currently electrified village, to investigate what and how much they really use. Subsequently, these models are compared and a representative combination of the two of them is hopefully reached, in relation also with how much money the people can afford to pay for this service.

The case study of this thesis involves the electrification of a hypothetical small village of 100 households ( 5 people per household) located $50 \mathrm{~km}$ from Garissa. The estimation of the power demand was done after a research on previously made case studies of rural electrification in developing countries [35], [36], [41] , [42]. The loads the microgrid would feed are domestic and 
public loads. The public loads include the streetlights, the primary school and water pumping and treatment. In [34], they define four different service levels for the design of a microgrid in Senegal:

\begin{tabular}{|l|l|}
\hline Service Level & Loads included \\
\hline $\mathbf{1}$ & 2-3 lamps, radio \\
\hline $\mathbf{2}$ & 3-5 lamps, radio, black and white TV or radio-cassette \\
\hline $\mathbf{3}$ & 6-8 lamps, radio, black and white TV or radio-cassete, 1 device \\
\hline $\mathbf{4}$ & More than lamps, radio, colour TV, video, more devices \\
\hline
\end{tabular}

As far as Kenya is concerned, according to [35], when the SE4ALL - UN global tracking framework was launched, the energy access of households was categorized in five different tiers both for electricity and cooking based on two distinctive criteria: the first one was out peak available capacity, duration, evening supply, affordability, legality and quality, while the second one was relevant to the provided energy services, as shown at Table 1.

Table 1. The five different Tiers of energy access in Kenya according to SE4ALL [35]

\begin{tabular}{|l|l|l|l|l|l|l|}
\hline Attributes & Tier $\mathbf{0}$ & Tier $\mathbf{1}$ & Tier $\mathbf{2}$ & Tier $\mathbf{3}$ & Tier $\mathbf{4}$ & Tier 5 \\
\hline Power (up to Watts) & - & 1 & 50 & 200 & 2,000 & Unlimited \\
\hline Duration (hrs) & - & 4 & 4 & 8 & 16 & 22 \\
\hline Evening supply & - & 2 & 2 & 2 & 4 & 4 \\
\hline Affordability & - & - & Yes & yes & yes & yes \\
\hline Legality & - & - & - & yes & yes & yes \\
\hline Quality & - & - & - & yes & yes & yes \\
\hline
\end{tabular}

These Tiers, though, do not impose strict criteria on designing the energy service. At the framework of this thesis, the energy service provided in the Kenyan village has been developed as a combination of all the above, following a higher level than usually, without examining in depth the factor of citizens' ability to pay, but nevertheless, trying to keep the cost as low as possible. The supply of electricity will last during the whole day and the load curve has resulted from the following assumptions:

i. The loads of each household are:

- Lighting: with maximum load of 3*11 W Compact Fluorescent Lamps (CFL), scaled up from 17:00 till 23:00 and with one lamp for safety till 06:00

- Radio : $15 \mathrm{~W}$ [43], during morning and afternoon

- Colour TV : $70 \mathrm{~W}$ [44], during the evening

- Small fridge: $30 \mathrm{~W}$, the whole day

- Fan: $35 \mathrm{~W}$, around noon and afternoon

- Mobile charging: $7.5 \mathrm{~W}$ in the evening

ii. The primary school, that will also be connected to the microgrid, has evening courses during the weekdays and morning classes during weekends [44], but does not operate at all during their holidays in April, August and December [45]. The school has 8 classes and its loads are:

- Radio : $15 \mathrm{~W}$

- Lighting : $3 * 11 \mathrm{~W}$ CFL for each classroom (during the evening classes)

- External lighting : $2 * 11$ W CFL (during the evening classes)

The load of the school is considered as a low priority load. 
iii. In calculating the streetlights' demand, is assumed that one light of equivalent $100 \mathrm{~W}$ per 15 households is enough [41]. That counts for 5 CFL of $30 \mathrm{~W}$ [46] from 18:00 till 05:00.

iv. The load for water pumping and purification has been defined as a deferrable load and has been designed in order to secure water storage for three days.

In Table 2, the analytic electric energy consumption of the village corresponding to a weekday with open schools is presented and at Figure 11 the load curve of this day is depicted.

Table 2. Electric energy demand of one household and the whole village for a weekday with open school

\begin{tabular}{|l|r|r|}
\hline Appliance & $\begin{array}{c}\text { Electricity demand per household } \\
\text { (kWh/day) }\end{array}$ & $\begin{array}{c}\text { Total electricity demand for } \\
\text { 100households (kWh/day) }\end{array}$ \\
\hline \hline Light & 0.231 & 23,1 \\
\hline Radio & 0.120 & 12 \\
\hline TV & 0.350 & 35 \\
\hline Mobile Charging & 0.380 & 3,8 \\
\hline Fan & 0.210 & 21 \\
\hline Small refrigerator & 0.720 & 72 \\
\hline Primary School & & 0,21 \\
\hline Streetlights & & 1,7 \\
\hline Water purification & & 4 \\
\hline system & 1.669 & 1,2 \\
\hline Water Pumping & & 174 \\
\hline Total & & \\
\hline
\end{tabular}

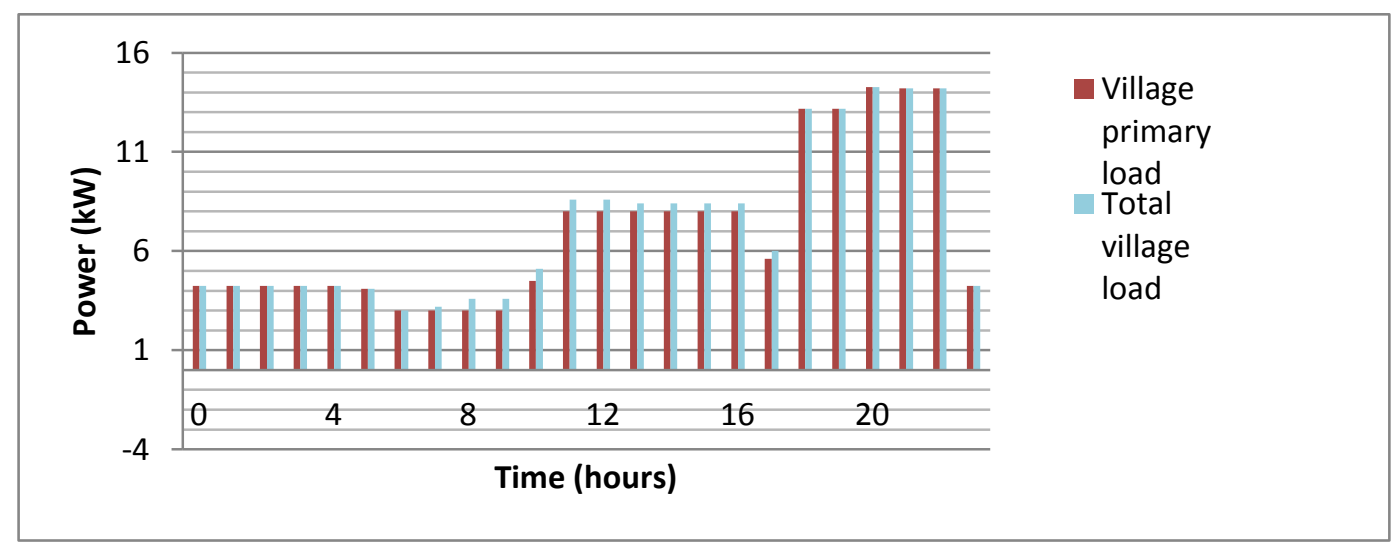

Figure 11. The load curve during a weekday with open school

For the Primary Load input to HOMER, a day to day random variability of $5 \%$ and time-step-totime-step variability of $5 \%$ was used.

\subsection{Building the Model}

In this section, the process of building the model of the hybrid power system is described in relation with the structure of the grid, the selection of power sources, basic costs, the possibility to extend the main grid and other constraints and control parameters needed from HOMER software to run the simulation.

Kenya is a country of great potential in Renewable Energy Sources, mainly hydro, geothermal and solar, but also wind and biomass in some parts of the country [35], [38]. In this case the 
power sources will be a photovoltaic generator and wind turbine along with a diesel genset as a back up and batteries for storage all connected in a AC-coupling parallelly configurated hybrid system [47]. The temperature, clearness index for solar radiation and wind speed data were acquired through TRNSYS software, used as input to HOMER and are presented in Figure 12 and Figure 13, as they were extracted later on from the latter. TRNSYS software uses multiple databases regarding all these data, as well as Typical Meteorological Year (TMY) data [48] [49] for simulating and extracting the resulting data for the location to be studied. One of the meteoroligical databases used in TRNSYS is Meteonorm providing actual measured data from stations located in the region, also in Garissa (which is really close to the village of this study) [50] [51].

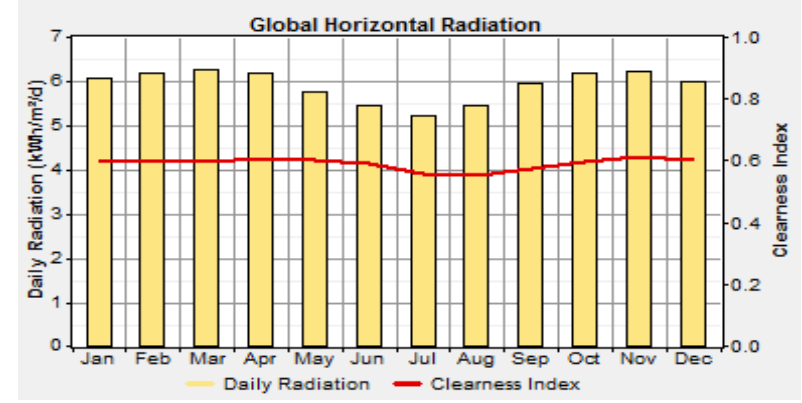

Figure 12. Average monthly radiation data over a year for a village near Garissa
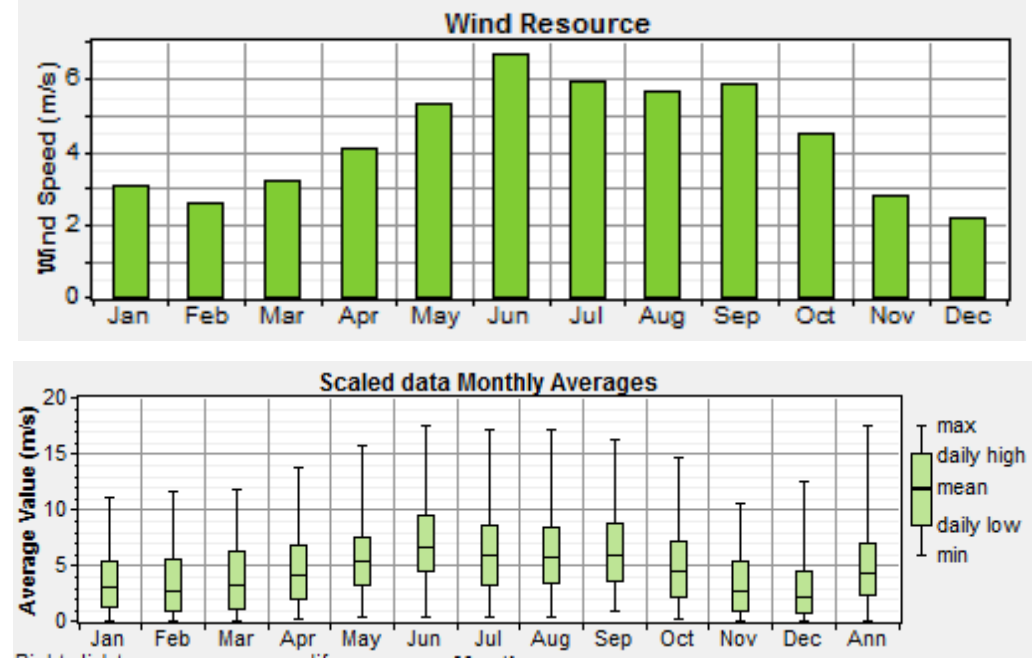

Figure 13. Average wind speed data over a year for a village near Garissa

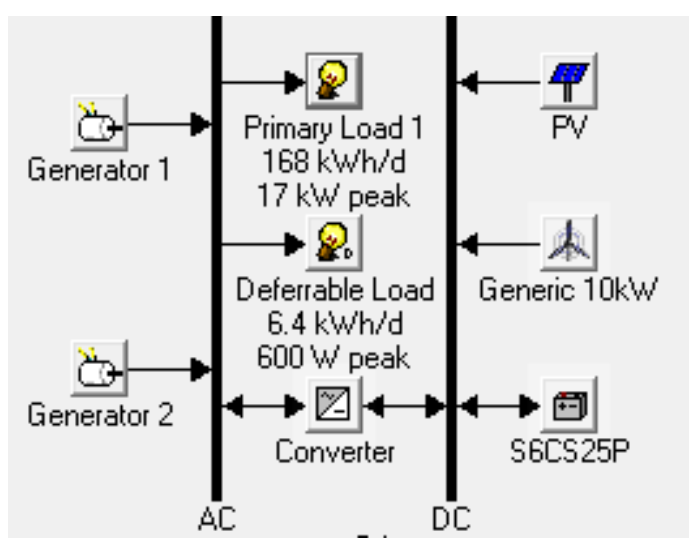

Figure 14. The scheme of the hybrid power system as it was made for HOMER simulation

In Figure 14, the reader can see the scheme of the microgrid as it was created in the HOMER software. There are two points that should be noted. Firstly, the two diesel generators used in 
the system; one of them (Generator 1 ) was rated at $9.5 \mathrm{~kW}$ and the other one at $15 \mathrm{~kW}$. That was done in order to cover efficiently all the possible levels of the load and avoid working the diesel generator under a low load. The second point that should be noted is the wind turbine placed beside the DC bus, even though the generator intended to be used has AC output. As it was mentioned before, the different controllers cannot really be simulated in HOMER, while the wind turbine will be connected to the $A C$ bus of the microgrid through an AC/DC/AC converter and the photovoltaic generator through a DC/DC converter and an inverter. The costs of the power electronics needed were more easily simulated with this arrangement.

Representative costs were difficult to determine, because they change rapidly with time, country and area. In order, though, to use reliable economic inputs, a literature survey was done related to previous case studies [16] , [35], [36], [42] , [44], [52], [53] and [54], general research in the internet about the cost of diesel fuel and equipment in Kenya, transportation, maintenance and operation costs. As a comparative measure for the validity of the relative values, the findings of the writer's supervisor's research on the topic were used.

Additionally to that, as far as the cost data for photovoltaics is concerned, [55] - [56] gave initially multiple and quite differentiated directions, before the final cost values were decided. What is more, regarding the wind turbine, a locally manufactured one following the Hugh Piggot's model was initially selected using information from [57], but then considered as a not so good choice, because of the relatively weak wind potential of the site, where this low cost but also low efficiency could not offer much to the microgrid. [58] was used to give an idea of the cost of a converter used for wind turbines, using one of the common choices for such an application, like Windy Boy from SMA. As for batteries, the Surrette 6CS25P with nominal capacity of 1156 Ah was introduced, connected in strings of $48 \mathrm{~V}$ ( 8 batteries per string). The cost was finally estimated according to [44]. The price of diesel in the main Kenyan market was taken from [59], but then extra amount was added on top of that to count for transportation and other relevant costs arising for fuel sold in isolated rural areas. The detailed cost inputs are given in Table 3.

Table 3. The cost data introduced to HOMER model for the main components

\begin{tabular}{|c|c|c|c|c|}
\hline Equipment & $\begin{array}{c}\text { Size (kW) [or number of } \\
\text { batteries] }\end{array}$ & $\begin{array}{c}\text { Capital Cost } \\
\mathbf{( \$ )}\end{array}$ & $\begin{array}{c}\text { Replacement } \\
\mathbf{( \$ )}\end{array}$ & $\begin{array}{c}\text { Operation \& Maintenance } \\
\text { Cost (\$/hour) }\end{array}$ \\
\hline Generator 1 & 9.5 & 1210 & 1100 & 2.5 \\
\hline Generator 2 & 15 & 3000 & 2500 & 4 \\
\hline PV & 1 & 3000 & 2000 & 327 \\
\hline $\begin{array}{c}\text { Wind } \\
\text { Turbine }\end{array}$ & 10 & 20000 & 15000 & 15 \\
\hline Batteries & 1 of 1156Ah and 6V & 1000 & 900 & 0 \\
\hline Converter & 5 & 2640 & 2640 & 3 \\
\hline
\end{tabular}

An annual interest rate of $6 \%$ is assumed and the project lifetime has been set to 20 years. Regarding the control parameters, both kind of dispatch strategies the cycle charging (with the setpoint state of charge at $80 \%$ ) and load following has been selected to be simulated in order to conclude in the optimal. Multiple generators are allowed to operate simultaneously on the same bus and with capacity less than the peak load. The only constraint set is the maximum annual capacity shortage, which cannot exceed the percentage of $3 \%$. 
Table 4. Grid extension inputs to HOMER model

\begin{tabular}{|c|c|c|}
\hline Capital Cost $\mathbf{( \$ / \mathbf { k m } )}$ & Operation \& Maintenance Cost $\mathbf{( \$ / y e a r} / \mathbf{k m})$ & Grid Power Price (\$/kWh) \\
\hline 10,000 & 160 & 0.119 \\
\hline
\end{tabular}

The grid extension inputs are shown in Table 4 and were determined based on [35]. According to that, the establishment of Medium Voltage lines in Kenya has an average cost of 10,000 \$ per $\mathrm{km}$. Moreover, four categories of electricity consumption schemes are defined: domestic, small commercial, interruptible and street lighting. There is a fixed charge of 1.41 US\$ for all schemes and consumption up to $15,000 \mathrm{kWh}$ per month. In addition to that fee, there are three tiers of consumption for domestic consumers, 0-50 kWh, 51-1500 kWh, higher than 1,500 kWh per month, adding an extra cost of $\$ 0.024, \$ 0.096$ and $\$ 0.22$ USD per $\mathrm{kWh}$ respectively. For small commercial, interruptible and street lighting schemes, the extra cost of $\mathrm{kWh}$ is $\$ 0.11, \$ 0.06$ and $\$ 0.09$ USD respectively. In this case, the monthly electricity consumption of each household is $50 \mathrm{kWh}$, so they pay $1.41 \mathrm{USD}$ plus $0.024 \$ / \mathrm{kWh}$. For schools, streetlights and water treatment the charge is 1.41 USD per month plus the $0.06,0.09$ and $0.06 \$$ respectively. (The price used for school is the same with the one for interruptible load, since it is considered as a low priority load.) If the weighted average is used, the grid power price will be $0.119 \$ / \mathrm{kWh}$.

\subsection{Results}

In this section of Chapter 3, the results of the techno-economical optimization will be presented and further adjustments and considerations will be discussed.

After running the simulation in HOMER software, the resulting optimal solution has the parameters of Table 5, with the only difference of converter power rating. According to HOMER the optimum power rating is $40 \mathrm{~kW}$, but after the photovoltaic power production graph was seen, it seems more reasonable (from the technical point of view) to have converter of at least $30 \mathrm{~kW}$.

Table 5. The resulting from HOMER system architecture

\begin{tabular}{|l|l|}
\hline Photovoltaic & $40 \mathrm{~kW}$ \\
\hline Wind Turbine & $1 * 10 \mathrm{~kW}$ \\
\hline Diesel Generator & $1 * 9.5 \mathrm{~kW}$ \\
\hline Surrette 6CS25P & 48 batteries (6 strings*8 batteries) \\
\hline Converter & $20 \mathrm{~kW}$ \\
\hline Dispatch Strategy & Load Following \\
\hline Total NPC & $\$ 315,220$ \\
\hline Levelized COE & $\$ 0.434 / \mathrm{kWh}$ \\
\hline Operating Cost & $\$ 10,066 / \mathrm{yr}$ \\
\hline
\end{tabular}

The load following dispatch strategy implies that whenever a generator operates, it produces only the needed amount of power to meet the primary load. The deferrable load, as well as charging the batteries are of lower priority and are served only by the renewable power sources. The deferrable load is ahead in priority of charging the batteries. According to HOMER help, though, "regardless of dispatch strategy, when the level of the storage tank drops to zero, the peak deferrable load is treated as primary load". 
With this configuration, there is excess electricity of around $17,680 \mathrm{kWh} / \mathrm{year}$ ( $19.5 \%$ of the annually produced energy), while the capacity shortage is only $0.4 \%$, much less than the maximum value, which was given as input to the software. In Figure 15 - Figure 18, the writer can observe the cost summary for all the components, the cash flows, the monthly average production as well as the graph relating the electrification cost with grid extension. From Figure 15 , it is obvious that the net present cost of photovoltaics prevails, since they acquire the highest installed power too, because of the significant solar potential of the region.

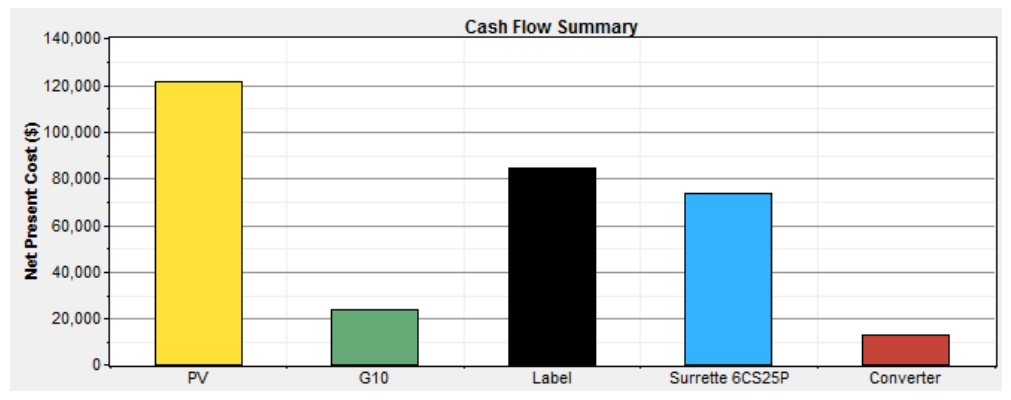

Figure 15. The net present cost of all the power system components

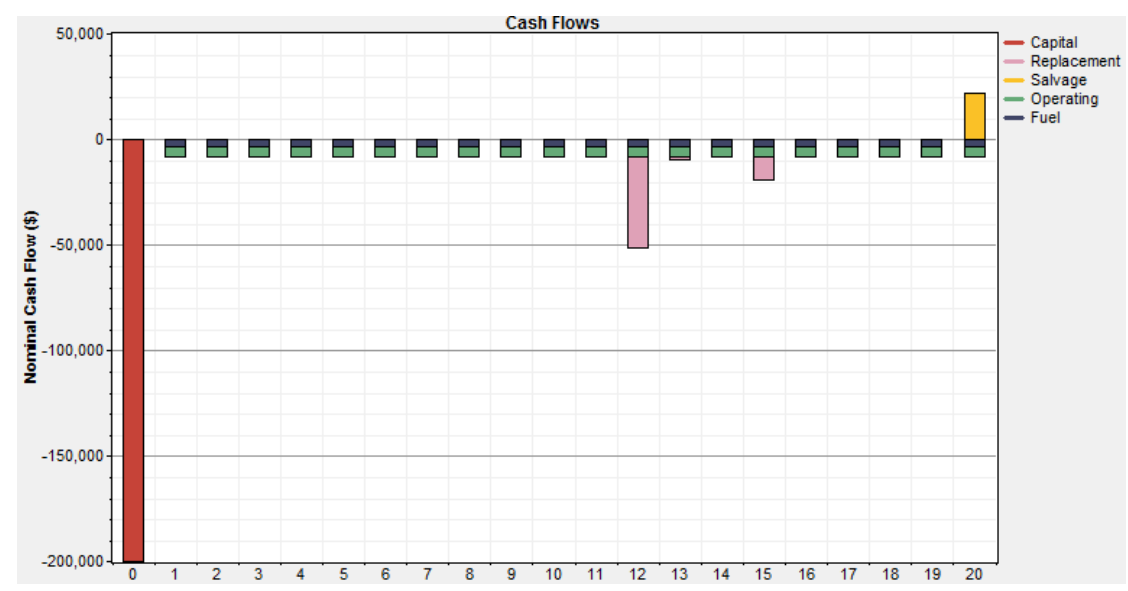

Figure 16. Nominal Cash Flow in relation with the time (years) of operation

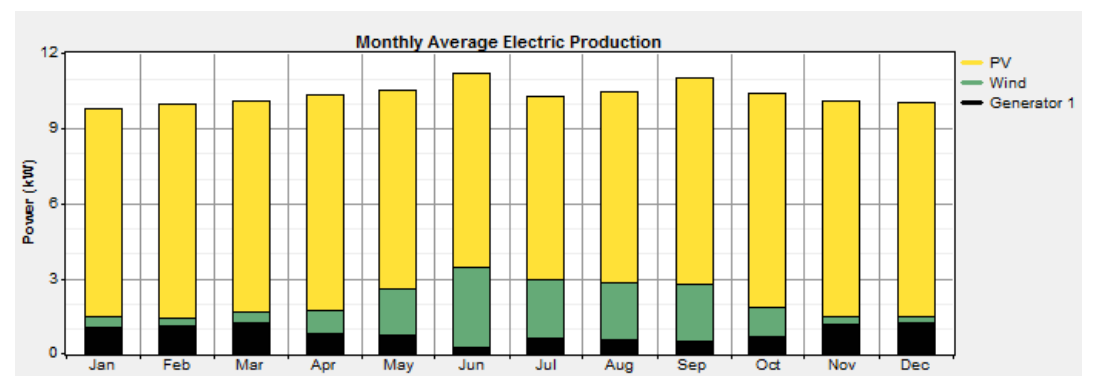

Figure 17. The monthly average electric production 


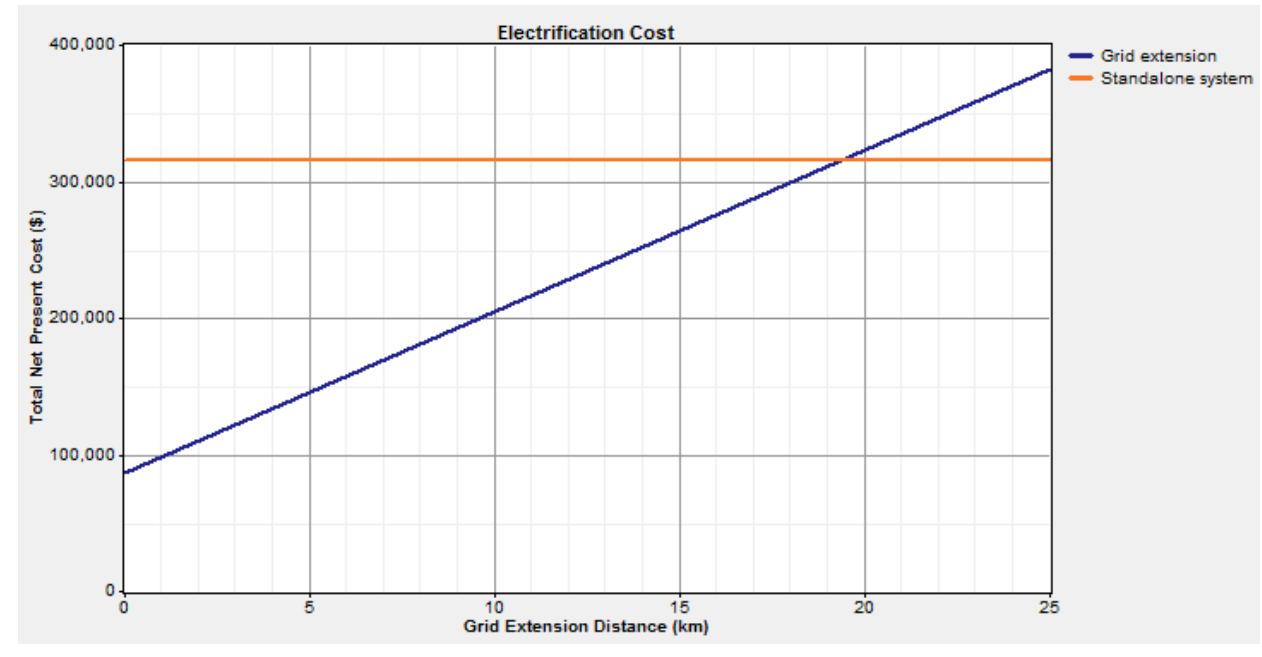

Figure 18. Comparison of the electrification cost with the autonomous power system in relation to the grid extension cost. The breakeven grid extension distance is at $19.3 \mathrm{~km}$

After having considered all the above, there are certain points requiring a bit more attention. The net present cost of the proposed hybrid power system is higher than the grid power price, cited in Table 4, but as one can observe in Figure 18, the autonomous microgrid is actually a more feasible solution in terms of the added cost from grid extension, because the village is 50 $\mathrm{km}$ from Garissa. In addition to that, the quality of service would be much more satisfying in this way, because of the unreliability of the main grid. Nevertheless, the excess electricity is around $18 \%$, which is not favorable, as this energy is not used anywhere. Moreover, the state of charge of the batteries as it is presented in Figure 19 at $40 \%$ for quite a long time, which could shorten their life. Further measures to reduce both of the previous issues are considered in the following chapter, where the operational strategy is studied using MTLAB/Simulink.

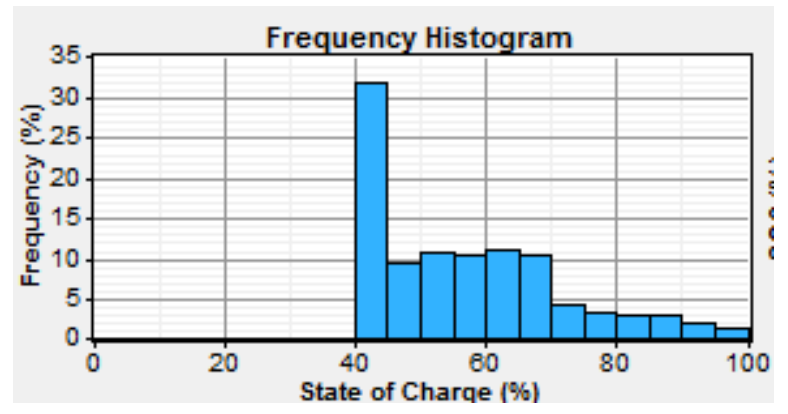

Figure 19. Frequency histogram of the State Of Charge of the battery bank

In this case it happens for the optimal solution to have null capacity shortage. This not the common situation though. Usually the less is the capacity shortage, the higher is the cost. It could be interesting to examine the difference in the cost and probably the optimal architecture, in the case were additional loads were to be fed; a rural health clinic with specific range of power demand could be one of these loads, where high reliability is mandated. Another load could correspond to a production process like a flour mill, which is common in these regions; then, the distribution of the load during the day and the week would be significant to reduce a hardly managed high peak. Both of these loads could be important for the village, since they could act like a core of further social and economic development of the community. Finally, perhaps, more accurate results could be obtained if local companies could be contacted to provide prices and cost data for all the equipment needed. In these countries, though, the selection of these data is 
complicated and harsh even for international organizations like International Renewable Energy Agency. 


\section{Modeling and Simulation}

\subsection{Introduction}

By definition, "modeling is the process of representing a real-world object or phenomenon as set of mathematical equations". It can be used to describe all the different kinds of systems, like mechanical, hydraulic, chemical, electrical systems (etc) and while used for simulations, it can give a reliable and representative idea of their performance, characteristics and operation. It occupies an important part in engineering science, because it provides the means for testing systems, assessing their response, strengths and potential weaknesses, before they are actually constructed or at the level of the first tests, reducing the possibility of unfortunate events and failures of design and operation.

In this thesis, modeling is used to represent the operation of an autonomous power system using SIMULINK MATLAB. Even for this, though, there are many different ways to approach it, depending on the scope of the study and the objective. For someone who aims to study the transition phenomena or the quality of power and stability issues, the modeling is being done on a very detailed electrical level, with analytic models of the photovoltaics, the generators, the batteries, the power electronics, (etc) and the simulation time is usually quite short on the order of seconds, as for example in [60]. On the contrary, if power management is the focus of the work, the system can be modeled on a 'higher level', as the power production and distribution between the different components are used, and the simulation time can be longer on the order of days, like in [61]. Different outcomes arise from these simulations and it is important that the model conforms to and can comply with the research question each time.

The aim of this work is to examine how the autonomous power system works and performs in terms of power management, as well as to assess how efficient it is and how well it can satisfy the needs of the inhabitants of the village on a day to day basis, while exploring different possibilities; something that could not be done only through HOMER. So, none of the components are represented with every electrical detail and no power electronics appear individually in the model. What counts here is the produced power in relation to the consumption and how they are going to be harmonized. There are, though, some thoughts for future developments of the model mainly in terms of the operational control that could produce different outcomes and equip it with different potentials.

In this chapter, the power system will be initially and shortly presented on the level of the model. The main logic behind it will be presented and subsequently, all the elements' models will be provided using mathematical equations and simple ready to use Simulink blocks and components. The important part of the model of the control and operational strategy will be analyzed and finally the characteristics and conditions of the different case studies for the simulation will be defined.

\subsection{Description of the System}

The autonomous power system consists of the photovoltaic array (installed power of $40 \mathrm{~kW}$ ) connected to the main ac bus of $230 \mathrm{~V}$ (phase voltage) through a DC/DC converter and inverter, the wind turbine of $10 \mathrm{~kW}$ nominal power connected to the grid through a rectifier and an inverter, the battery pack of total nominal capacity 6936 Ah connected to the ac bus of the microgrid through a DC/DC converter and an inverter, the diesel generator of $9.5 \mathrm{~kW}$, primary load and the deferrable load. The primary load consists of two components: the high and low 
priority. This categorization serves at the handling of power deficit in the system. The deferrable load includes the power spent on water pumping and purification, and can be thought as an additional storage application, as it will be described further on in this chapter. All the loads are considered as ac and the system follows a predefined and deterministic operational strategy. Even though each micro-source is interconnected to the system through its own power electronics, which are responsible for their smooth operation and the maximum power extraction, the overall system operation control is centralized, like there is a central converter responsible for the power distribution inside the microgrid.

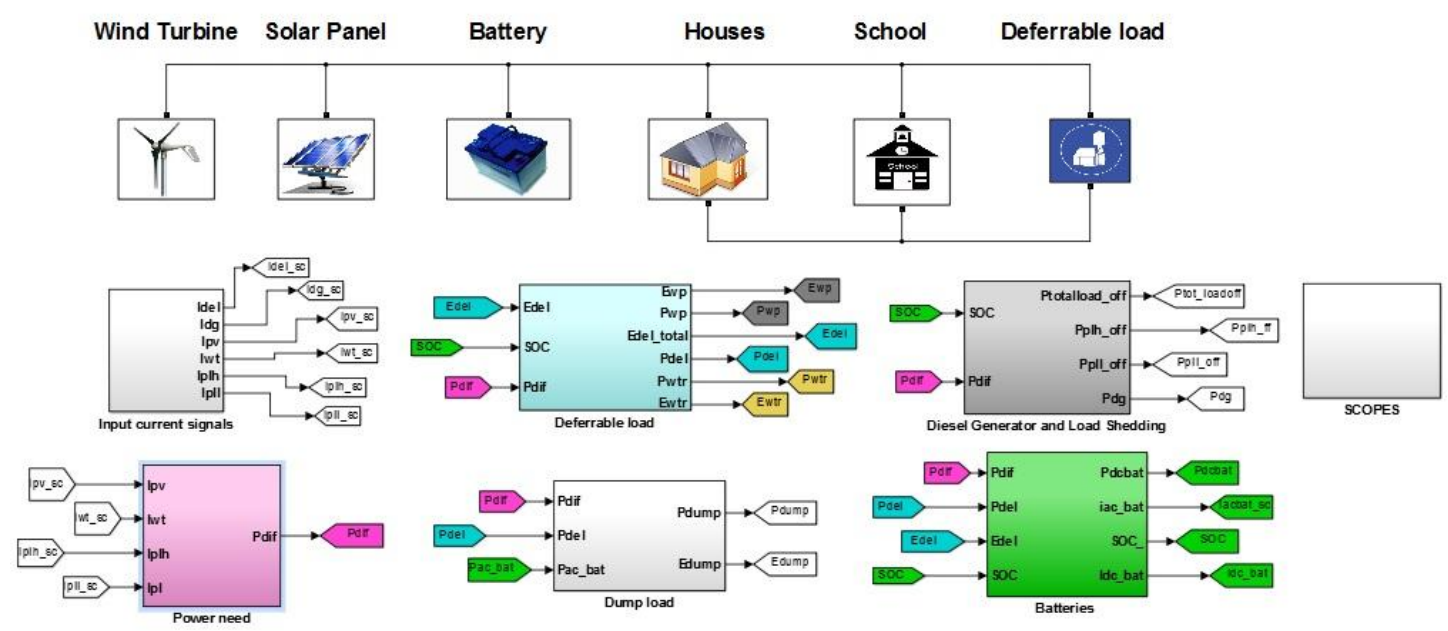

Figure 20. A general view of the model in Simulink-MATLAB

Figure 20 presents the microgrid as well as the individual subsystems of the model. After having defined the installed power from each energy source, the main inputs of the model are the solar irradiance hourly values $G$, the wind speed hourly values $V_{w}$, the temperature hourly values $T_{\text {emp }}$, the high and low priority primary load hourly values $\mathrm{P}_{\mathrm{plh}}$ and $\mathrm{P}_{\mathrm{pll}}$ respectively, as well as the initial value of the SOC of the batteries. The outputs are the power produced by the different sources, and the power consumed by all kinds of load during the simulation time, as well as the energy production and consumption, information on the battery operation and the amount of power that may not be used or at other moments may not be covered. This will be explained further in section 7 of this chapter.

Noticing Figure 20, one can see that the model consists of:

- the microgrid,

- the Input Current Signals subsystem,

- the Power Need Subsystem,

- the Deferrable Load subsystem,

- the Dump Load subsystem,

- the Diesel Generator and Load Shedding subsystem,

- the Batteries subsystem and

- the Scope subsystem.

The model has this form, similar to [62], in order to be able to facilitate a possible future development by integrating phasors, further measurements in the grid and probably an application of droop control based on the characteristic curves of the inverters without their detailed models. Thus, at the Input Current Signals subsystem, the produced power by the 
photovoltaics and the wind turbine, the current of each source and load, except for the batteries are calculated. At the Power Need subsystem, the difference between the power production and the power demand at every moment is computed and corresponded to the signal $P_{\text {dif }}$ indicating if there is surplus or shortage of electrical power in the system. The Deferrable Load subsystem is where it is decided if and which parts of the deferrable load will be fed. The power and energy consumption for water pumping and purification are also calculated there. The Dump Load subsystem is where it is found if there is an excess of power that cannot be used by the system, called dumped power; this power and the corresponding energy are calculated. The Diesel Generator and Load Shedding subsystem decide if the diesel genset should start to operate and at which power rate or if load rejection needs to be done and how much of the power demand will be shut down. The Batteries subsystem controls if the battery bank should be charged or discharged, calculates the power exchanged between it and the system, the energy, the rms value of the current, as well as the state of charge (SOC) of the batteries, which is an important parameter. Finally, the Scope subsystem includes all the necessary graphs to visualize the results regarding the microgrid's operation.

\subsection{Photovoltaics}

As it was mentioned in the first section of this chapter, there is a wide variety of ways one can model a system and the photovoltaics, as its components, depending on the aim of the work, the chosen method, the focus point of the analysis and many other factors. This is also the case for modeling a solar photovoltaic system. In [63] six methods of modeling a photovoltaic cell are explained and two of them are focusing mainly on producing voltage and current as outputs. However, here, the attention is placed on the power production from the photovoltaic array. For all the calculation and the choice of parameters, real datasheets from the manufacturers have been used both for the photovoltaic panel and the power electronics.

Initially, the power generated by one panel $\mathrm{P}_{1 \mathrm{pv}}$ is calculated according to equation (1):

$$
P_{1 p v}=f_{v} * P_{S T C} \frac{G}{G_{S T C}}\left[1+k_{p}\left(T_{e m p}-T_{S T C}\right)\right]
$$

where

$f_{v} \quad:$ a derating factor around 0.9 to account for some of the losses in the system, such as shading, aging or wire losses

$P_{S T C} \quad$ : rated power in Standard Test Conditions, $P_{S T C}=255 \mathrm{~W}$

G : instantaneous solar irradiance

$G_{S T C} \quad$ : solar irradiance for Standard Test Conditions, $G_{S T C}=1000 \mathrm{~W} / \mathrm{m}^{2}$

$k_{p} \quad:$ temperature coefficient related to power, $k_{p}=-0.43 \% /{ }^{\circ} \mathrm{C}$ for the CS6P-255 | 260P photovoltaic panel from Canadian Solar [64]

$T_{e m p} \quad$ instantaneous temperature

$T_{S T C} \quad$ : temperature for Standard Test Conditions, $T_{S T C}=25^{\circ} \mathrm{C}$

The total number of photovoltaic panels is $N_{p}=156$ to reach an installed power of approximately $40 \mathrm{~kW}$. The inverters used are of nominal power $20 \mathrm{~kW}$ and taking into account also the open circuit voltage and the short circuit current of the solar panels, the panels are separated in two different teams and connected to two different converters and inverters. 
So, the power output of each photovoltaic array is: $\quad P_{1 p h . a .}=\frac{N_{p}}{2} P_{1 p v}$.

This power enters the converter and then the inverter. The power electronics' efficiency factors vary with the ratio of the power they transfer $\mathrm{P}_{1 \text { ph.a }}$ over their rated power $\mathrm{P}_{\text {inv }}$ rated. Here, the Sunny Tripower Inverter of SMA Solar Technology is used as a source for this dependence and the efficiency changes with the ratio of output power $\frac{P_{1 . \text { ph.a }}}{P_{\text {inv_rated }}}$ according to Table 6 [65]. This is integrated in the model through a look-up table.

Table 6. Efficiency profile of the photovoltaics' inverter according to [65]

\begin{tabular}{|l|l|}
\hline Output power ratio (\%) & Efficiency (\%) \\
\hline 5 & 94.0 \\
\hline 10 & 96.6 \\
\hline 20 & 97.8 \\
\hline 25 & 98.0 \\
\hline 30 & 98.1 \\
\hline 50 & 98.2 \\
\hline 75 & 98.1 \\
\hline 100 & 98.0 \\
\hline
\end{tabular}

So, the final power output of the photovoltaics is equal to $P_{p v}=2 * \eta_{\text {p.e. }} * P_{1 . p h . a}$. In this case, the implementation of the above described model in Simulink is indicatively depicted at Figure 21. The same happens for the wind turbine in the following section, but the rest of the model figures are placed in Appendix I.

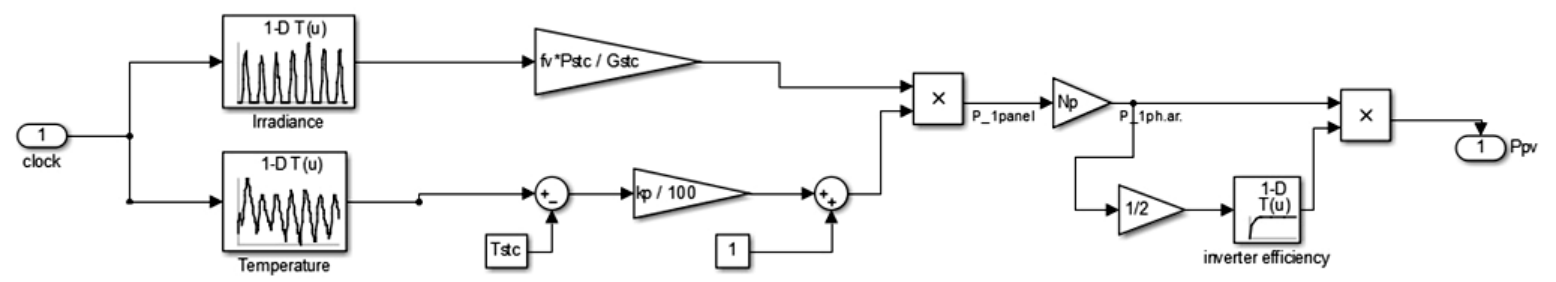

Figure 21. The calculation of Ppv at the model in Simulink

\subsection{Wind turbine}

Following a similar logic as before, the wind turbine power output is calculated and inserted in the model. The wind turbine has a horizontal axis, a nominal power of $10 \mathrm{~kW}$ and includes a permanent magnet synchronous generator, as it was specified considering cost and robustness reasons. The model used here as a source for data is SW-10 kW from Senwei (a Chinese company manufacturing small wind turbines) [66] and can easily be found in Kenya too. The power curve of this wind turbine as it appears in the datasheet is given in Figure 22. This kind of curve is usual in small wind turbines, where, the rated power is achieved in a slightly higher value at wind of $11 \mathrm{~m} / \mathrm{s}$. In this model, though, the power of the wind turbine for wind speeds higher than the nominal is considered steady. 


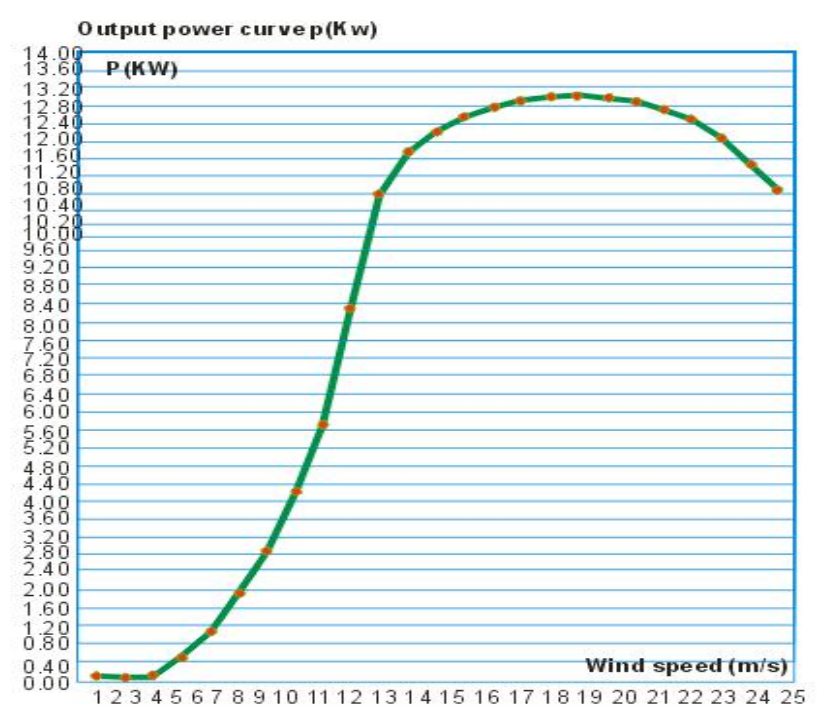

Figure 22. Power curve of SW-10kW according to the datasheet [66]

The mechanical power output of the wind turbine is estimated using the equations (2), in a common line with [67]:

$$
\begin{aligned}
& P_{w t}=0 \\
& P_{w t}=\frac{1}{2} c_{p}(\lambda, \beta) * \rho(z) * A * V_{w}{ }^{3}-P_{\text {in }} \\
& \text { when } \quad V_{w}<V_{\text {cut-in }} \\
& P_{w t}=P_{w t_{-} \text {rated }} \\
& \text { when } \quad V_{\text {cut-in }} \leq V_{w} \leq V_{\text {rated }} \\
& P_{w t}=0 \\
& \text { when } V_{\text {rated }} \leq V_{w} \\
& \text { when } \quad V_{\text {cut-out }} \leq V_{w}
\end{aligned}
$$

where

$V_{w} \quad: \quad$ instantaneous wind speed

$V_{\text {cut-in }} \quad: \quad$ cut-in wind speed, $\quad V_{c u t-i n}=3 \mathrm{~m} / \mathrm{sec}$

$V_{\text {rated }} \quad: \quad$ rated wind speed, $\quad V_{\text {rated }}=10 \mathrm{~m} / \mathrm{sec}$

$V_{\text {cut-out } \quad: \quad \text { cut-out wind speed }}$

$\lambda \quad: \quad$ tip speed ratio

when

$$
\lambda=\frac{\omega_{\text {rotor }} * R_{a d}}{V_{w}}=\frac{2 \pi * n_{\text {rotor }} * R_{a d}}{60 * V_{w}}
$$

where

$$
\begin{aligned}
& \omega_{\text {rotor }} \quad: \quad \text { angular speed of the rotor in } \mathrm{rad} / \mathrm{sec} \\
& n_{\text {rotor }} \quad: \quad \text { rotational speed of the rotor in } \mathrm{rpm} \\
& R_{a d} \quad: \quad \text { radius of the rotor, } \quad R_{a d}=3.5 \mathrm{~m} \\
& \text { A : } \quad \text { the area swept by the rotor, } A=\pi R_{a d}^{2} \\
& \beta \quad \text { : } \quad \text { pitch angle, here it is steady and equal to zero } \\
& c_{p} \quad: \quad \text { aerodynamic power coefficient, which is calculated according to [68], } \\
& \text { from eq. (4) }
\end{aligned}
$$


$c_{p}=0.73 *\left(\frac{151}{\lambda_{i}}-0.58 * \beta-0.002 * \beta^{2.14}-13.2\right) * \exp \left[\frac{-18.4}{\lambda_{i}}\right]$

where

$$
\lambda_{i}=\frac{1}{\frac{1}{\lambda-0.02 \beta}-\frac{0.003}{\beta^{2}+1}}
$$

$\rho(z) \quad: \quad$ the density of the air in $z$ height above the sea level, calculated from eq. (6)

$$
\rho(z)=\frac{p_{0}}{R * T} * \exp \left[-\frac{g * z}{R * T}\right]
$$

where

$\begin{array}{llll}p_{0} & : & \text { sea level standard pressure, } & p_{0}=101325 \mathrm{~Pa} \\ R & : & \text { specific gas constant, } & R=287 \mathrm{~J} /(\mathrm{kg} * \mathrm{~K}) \\ g & : & \text { gravitational constant, } & g=9.8 \mathrm{~m} / \mathrm{sec}^{2} \\ T & : & \text { temperature in Kelvin, } & T=T_{\text {emp }}+273\end{array}$

The power curve occurring as a result of the above equations is plotted in Figure 23 and is quite close to the one from the datasheet for the wind speeds up to $10 \mathrm{~m} / \mathrm{sec}$, because of the previously mentioned difference.

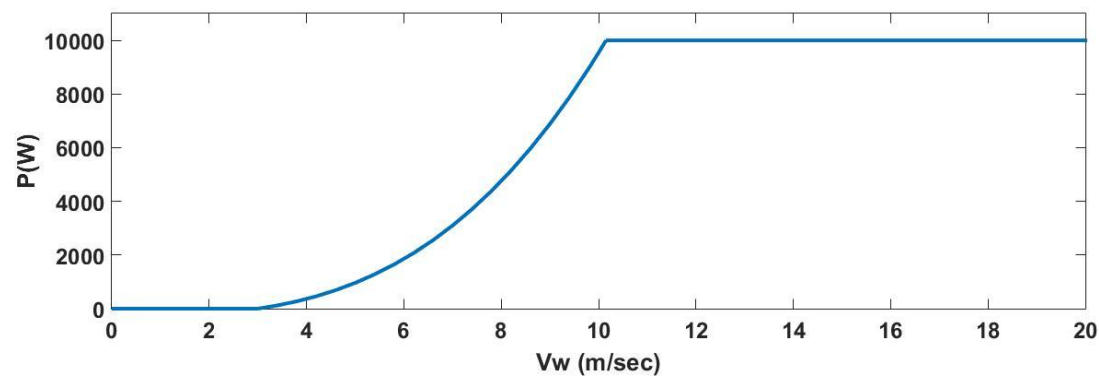

Figure 23. Wind Turbine Power Output Curve according to eq. (4)

This power is then multiplied with the efficiency factor of the generator $\eta_{w g}=0.9$ and then with the efficiency factor of the power electronics, serving as the interface between the wind turbine and the main bus of the microgrid. The output of the wind turbine is first rectified and then inverted again. Their efficiency factors are calculated similarly as in section 3 of this chapter, based also on their datasheets, and are considered as in Table 7, where $\eta_{\text {gint }}$ is the efficiency of the interface between the generator and the inverter, whose efficiency is $\eta_{\text {inv. }}$.

Table 7. Efficiency profile of the power electronics of the wind turbine

\begin{tabular}{|r|r|r|}
\hline \multicolumn{1}{|l|}{$\boldsymbol{n}_{\text {gint }}(\%)$} & $\mathbf{n}_{\text {inv }}(\%)$ & $\begin{array}{l}\text { Loading } \\
\text { percentage }\end{array}$ \\
\hline 95 & 93 & 0.05 \\
\hline 97.7 & 95.6 & 0.1 \\
\hline 98.9 & 96.8 & 0.2 \\
\hline 99.1 & 97 & 0.25 \\
\hline 99.2 & 97.1 & 0.3 \\
\hline
\end{tabular}




\begin{tabular}{|r|r|r|}
\hline 99.4 & 97.2 & 0.5 \\
\hline 99.3 & 97.1 & 0.75 \\
\hline 99.2 & 97 & 1 \\
\hline
\end{tabular}

In Figure 24, the part of the model responsible for the computation of the power produced by the wind turbine is presented.

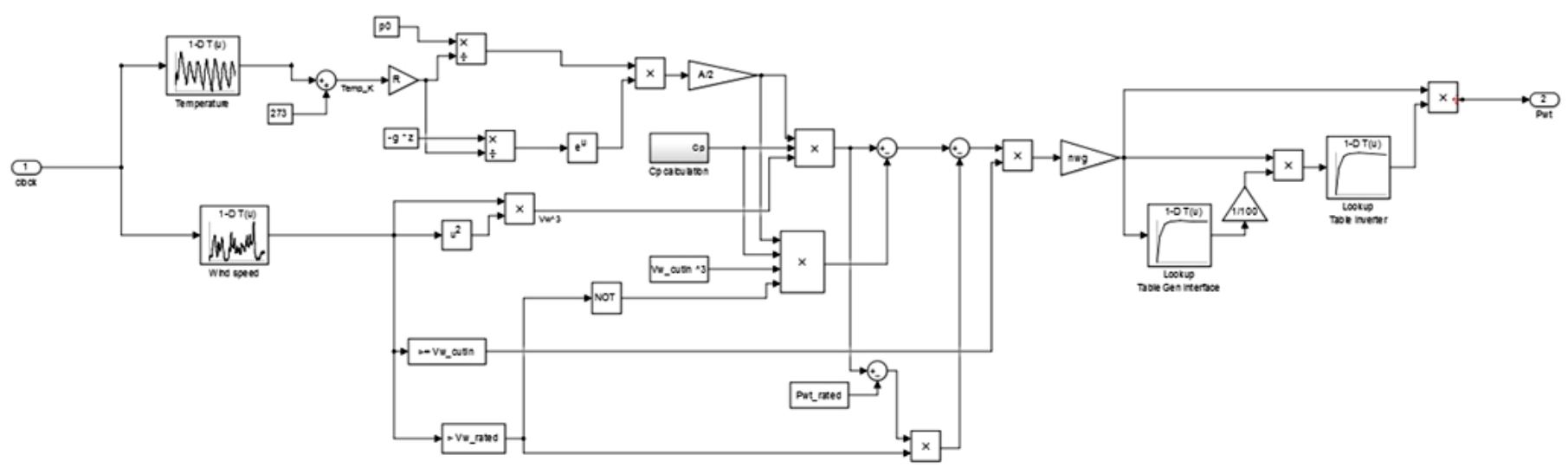

Figure 24. The calculation of Pwt at the model in Simulink

\subsection{Batteries}

The battery bank has a total nominal capacity of $6.936 \mathrm{kAh}$ and consists of 6 parallel strings of batteries, each one of which includes 8 batteries connected in series. The model used in this case, as it was also shown in Chapter 3, is the S6CS25P Rolls/Surrette of Rolls Battery Engineering [69].

In the battery model, some conditions are examined in order to control if the batteries should start charging, discharging or do neither of them. The control conditions will be described in section 7 of this chapter, but the signals they produce BAT_CH and BAT_DISCH are boolean variables (taking values 1 or 0 ). It should be noted that this model is not for only one battery, but for the description of the total battery bank together.

In order to achieve a safe operation and a long life time of the batteries, there are established maximum charge and discharge rate corresponding to the power values $P_{\text {max }}$ ch and $P_{\text {max _disch }}$ respective since the $d c$ voltage of the battery bank is $V_{d c}=48 \mathrm{~V}$. The limits have been set to $P_{\text {max }}$ ch $=15.18 \mathrm{~kW}$ and $P_{\text {max_disch }}=12.14 \mathrm{~kW}$ for a maximum dc current for one battery of $50.84 \mathrm{~A}$ and 15 hour rate.

Then, there is the amount of power $\mathrm{P}_{\mathrm{e}}$ the system needs to be exchanged with the storage bank and this is compared with the previous limits in order not to exceed them. The power exchanged with the battery is $\mathrm{P}_{\text {ac } \_ \text {bat }}$, because this is how it is measured on the ac bus. $\mathrm{P}_{\mathrm{e}}$ originates from the power difference singal $P_{\text {dif }}$ and when it is positive there is an excess of power in the system which needs to be stored, so the battery is being charged. The opposite happens when $P_{e}$ is negative.

A converter is located in between the storage bank and the ac bus of the grid and its efficiency factor $\eta_{\text {convb }}$ changes with the load percentage similarly to the previously mentioned inverters. Then, the power stored and the one extracted from the battery are differently calculated, as shown in eq. (7)-(10). 
For battery charging:

$$
\begin{gathered}
\eta_{\text {convb }}=\frac{P_{\text {to_bat }}}{P_{\text {ac_bat }}} \Rightarrow P_{\text {to_bat }}=\eta_{\text {convb }} * P_{a c_{-} b a t} \\
\eta_{\text {ch_b }}=\frac{P_{\text {charge }}}{P_{\text {to_bat }}} \Rightarrow P_{\text {charge }}=\eta_{c h \_b} * P_{\text {to_bat }}
\end{gathered}
$$

where

$$
\begin{array}{ll}
P_{\text {to_bat }} & \text { : electrical power at the output of the rectifier before the battery } \\
P_{\text {charge }} & : \text { amount of charge added in the battery } \\
\text { to } & \text { : the charging efficiency of the battery, which is considered to be equal }
\end{array}
$$$$
\eta_{c h \_b} \cong \sqrt{\eta_{\text {round_trip }}}
$$

where

$\eta_{\text {round_trip }} \quad$ : the round trip efficiency of the battery, $\eta_{\text {round_trip }}=80 \%$

For battery discharging:

$$
\begin{aligned}
& \eta_{\text {convb }}=\frac{P_{a c_{\_} b a t}}{P_{\text {from } \_ \text {bat }}} \Rightarrow P_{\text {from_bat }}=\frac{P_{a c \_b a t}}{\eta_{\text {conb }}} \\
& \eta_{\text {disch_b }}=\frac{P_{\text {from } \_b a t}}{P_{\text {disc }}} \Rightarrow P_{\text {disch }}=\frac{P_{\text {from } \_b a t}}{\eta_{\text {disch } \_b}}
\end{aligned}
$$

where

$$
\begin{array}{ll}
P_{\text {from_bat }} & : \text { electrical power at the input of the rectifier after the battery } \\
P_{\text {disch }} & : \text { amount of charge removed from the battery } \\
\eta_{\text {disch_b }} & : \text { the discharging efficiency of the battery, which is considered to be } \\
& \text { equal to } \\
& \eta_{\text {disch_b }} \cong \sqrt{\eta_{\text {round_trip }}}
\end{array}
$$

This amount of power is then used to find the charging and discharging current value, which is used for the calculation of the exchanged ampere hours (Ahs) and the SOC of the battery bank. For the whole battery bank, the current $I_{d c \_b a t}$ is equal to the ratio of $P_{\text {charge }}$ of $P_{\text {disch }}$ over the voltage $48 \mathrm{~V}$. For one battery string and one battery, the current is equal to one sixth of it. Integrating $I_{\mathrm{dc}}$ over the time results in the Ahs still stored in the battery, if the initial value of the integral is the initial capacity of the battery. When this is divided by the initial capacity of the battery, the state of charge (SOC) of the battery is found.

The figure of the Battery Subsystem can be found in the Appendix I and it includes several smaller subsystems. The Battery Charging Conditions and Battery Discharging Conditions subsystems decide on if the batteries should be allowed to interact with the grid. The Battery Parameters subsystem involves the calculation of $I_{d c}$, the SOC and the total exchanged Ahs, which is a measure useful to count their lifetime. The calculation of the converter efficiency is done inside the subsystem with the same title. The subsystems Battery Charges and Battery Discharges involve the calculation of $P_{\text {charge }}$ and $P_{\text {disch }}$ respectively, while the last subsystem with the calculation of $I_{r m s}$ has been made in order to facilitate the extension of the model to 
incorporate phasors. The $I_{r m s}$ is the root mean squared (rms) value of the alternating current at the output of the converter. Except for the part of the calculations related to $I_{r m s}$, in all the other calculations, the power and current of the battery are positive when the batteries get charged and negative when they get discharged.

\subsection{Loads}

In this system, two main categories of loads exist: the primary and the deferrable load.

The primary load $P_{\text {prim_load, }}$ whose hourly values are given as inputs in the model through a look up table, is the one forming the power demand curve that represents all the main end uses of electrical power and have to be satisfied at certain times during the day. The power demand for the village was specified in section 3 of Chapter 3 . It is separated in the high priority $P_{\text {plh }}$ and low priority load $\mathrm{P}_{\mathrm{pll}}$, which represent applications of different importance. This categorization is actually put in use, when there is power shortage in the system that the batteries and the diesel generator fail to completely cover. Then, some part of the load will be rejected, since there should always be a balance of power in the system, and the first loads to be shut down are the low priority ones. Only if the low priority load is not enough to cover the deficit, a part of the high priority will be also shed.

On the other hand, the deferrable load has a different function acting mostly as an additional storage application enhancing the flexibility and efficiency of the system. Depending on the application, it may cover certain ranges of power values and a defined value of daily energy consumption, but the main characteristic is that it is shifted whenever there is surplus of power. In this case, the deferrable load is related with the water service in the village; it includes water pumping $\left(P_{w p}=200 \mathrm{~W}\right)$ and water purification $\left(P_{w t r}=400 \mathrm{~W}\right)$ with a determined daily energy demand of $E_{\text {del_daily }}=5.19 \mathrm{kWh}$. They can be done both at the same time and separately according the control strategy described in section 7 of this chapter.

\subsection{Control and Operational Strategy}

In this section, the logic of the operational strategy and its control will be described. It is designed in order to follow the load following dispatch strategy proposed by HOMER and simulate the occurred system configuration. This implies that the diesel generator operates only to cover the primary load, but neither the deferrable load nor to charge the batteries. This is a strategy often used in systems based on renewable energy sources, according to the same software designers.

Apart from the produced power $P_{p v}, P_{w t}$ and demand power $P_{p l h}, P_{p l l}$, the following parameters are the most significant variables in the control of the microgrid:

- $P_{\text {dif }} \quad$ : the signal of the difference between the produced power by the photovoltaics and the wind turbine, and the primary load.

- SOC : the state of charge of the batteries

- $P_{\text {ac_bat }}$ : the exchanged power with the batteries (measured at the ac bus) at the simulation time

- $\mathrm{E}_{\mathrm{del}} \quad$ : the electrical energy consumed by the deferrable load from the start of the day till the time that the next state appears in the simulation time

- $P_{\text {del }} \quad$ : the power consumed by the deferrable load, can be equal to $0, P_{w p}, P_{w t r}$ or $P_{w p}$ plus $P_{\text {wtr }}$ 
There are also some signals with boolean values activating or deactivating the deferrable load, the water pumping, the battery charging or discharging: PD_ON, pump, BAT_CH and BAT_DISCH respectively.

In more detail, the operational control is as follows:

Initially, the difference between the produced and consumed power by the primary load is calculated, according to eq. (11). If it is positive, there is surplus of power in the system, which may be directed to the deferrable load, charge the batteries and/or be dumped. If it is negative, there is power deficit to the system which will be covered by discharging the batteries, turning in the diesel generator and/or rejecting part of the load.

$$
P_{\text {dif }}=P_{\text {Rprod }}-P_{P L}=\left(P_{\text {PVout }}+P_{\text {WTout }}\right)-\left(P_{\text {plh }}+P_{\text {pll }}\right)
$$

In case there is excess of power in the system $\left(P_{\text {dif }}>0\right)$, the energy consumed by the deferrable load $E_{\text {del }}$ is the parameter to be firstly checked. There is a minimum value $E_{D_{-} \min }$, corresponding to certain time of water pumping and purification and this is defined like that, in order to ensure that there will always be enough clean water for the people. Of course for the deferrable load to be activated, the $P_{\text {dif }}$ should be more or equal to the power needed for water pumping. There is a predefined value for its daily energy consumption $E_{\text {del_daily, }}$ after which the deferrable load does not get activated any more. Is important to note here that $E_{\text {del }}$ is reset every 24hours, so that it starts each day with value 0 . Water pumping precedes water purification. The next parameter to be checked is the current SOC of the batteries. There is a maximum allowed value $\mathrm{SOC}_{\max }$, minimum allowed value $\mathrm{SOC}_{\min }$ and an intermediate one approximately around $60 \%$. It is not allowed to violate the defined limits and it is preferable if it stays more time above the intermediate value. It should also be notes, that there are certain (pre-mentioned) limits for the charge rate of the batteries and maximum power and current; these limits cannot be violated neither. So, either only the deferrable load will be activated, either only the batteries will get charged or both of them will be provided with electrical energy. In the worst case of excess power, where $\mathrm{P}_{\mathrm{dif}}$ is too high, so that it cannot be covered by the above actions, the rest of the produced power is dumped $\mathrm{P}_{\text {dump }}$.

In case there is deficit of power in the system $\left(P_{\text {dif }}<0\right)$, the first parameter to be checked is the SOC of the batteries. If it is higher that its minimum value, then batteries can cover a part of the demand up to the maximum specified discharge rate. If though the deficit of power is too much or the SOC of the batteries too low, then the possibility of activating the diesel genset is examined. In order for it to be turned on, there is a minimum limit of power output set on $40 \%$ of its nominal power $P_{d_{\mathrm{d}} n}$, to ensure efficient operation and long life time of the diesel genset. So, if the power needed is lower than this threshold or if it exceeds the nominal power of the diesel genset, then part of the load needs to be shut down with total value $P_{\text {totalload_off. }}$ First the low priority load will be rejected (with power $\mathrm{P}_{\text {pll_off }}$ ) and if it is not enough, the part of the high priority load $\mathrm{P}_{\text {plh_off }}$ will follow.

A more detailed description in the form of algorithm can be found in the Appendix II. The above described operational strategy is depicted in the flow chart of

Figure 25. This is the main logic guiding the control of the operation of the autonomous power system, showing which components are activated in each case. While here it appears to be centralized, when it is integrated inside the model it disperses inside the different subsystems. What is more, many subsystems have some additional control functions, as it happens with the 
deferrable load and the case of load shedding. The more detailed description of the individual controls of deferrable load and load shedding are also presented in Appendix II. The figures for the subsystem generating the batteries activating signals, the subsystem calculating the amount of dumped power, the model of the deferrable load and the one diesel genset and load shedding are given in Appendix I, in case the reader desires to follow closer the design of the model. 


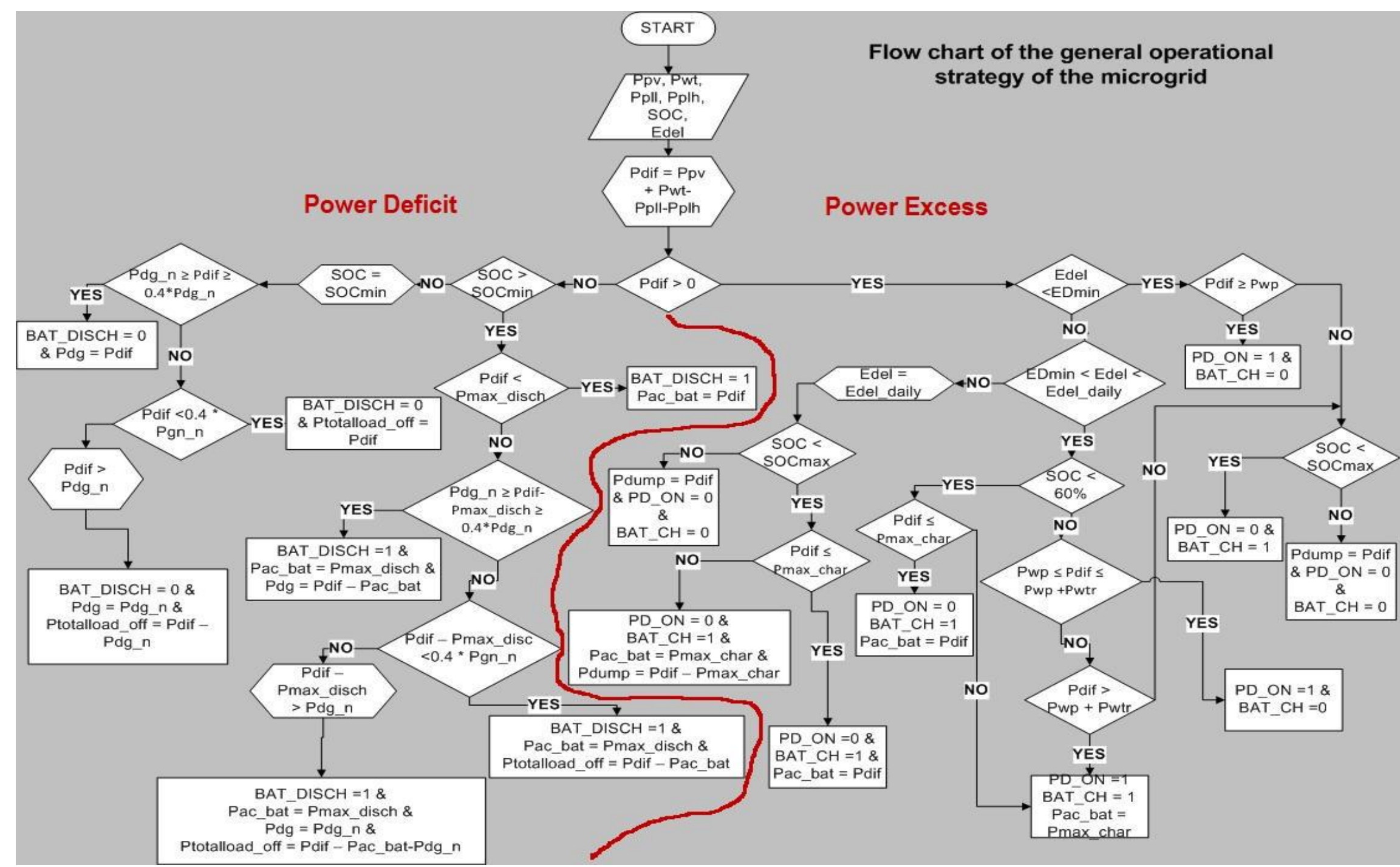

Figure 25. Flow chart of the main operational strategy 


\subsection{Description of the Different Cases for the Simulation}

In order to understand the system behavior under different circumstances, different conditions can be simulated. In this section, different cases are specified in a way that covers a range of different conditions with different potentials for power production by the renewable sources.

There are several weather data available that represent the temperature, the irradiance and the wind speed throughout the year. This data can be used as a base to specify the case studies. Two diagrams from HOMER provided a base for this choice and are shown again in Figure 26 and Figure 27.

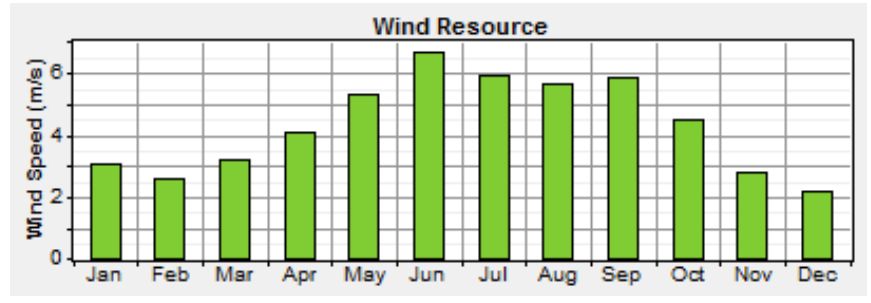

Figure 26. The average monthly values of wind speed at the village in Kenya

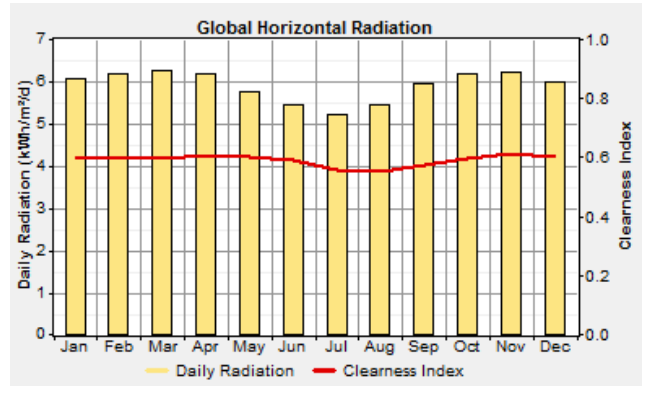

Figure 27. The average values of daily irradiation for every month in the village in Kenya

Comparing the two diagrams, one can see that the fluctuation of solar energy is much more than the wind speed during one year, meaning that the variation of electrical power produced by the wind turbine is much more intense than that from the solar photovoltaics. Ideally, for the sake of having a wide range of different cases, it would be profitable to find four different time slots during the year: one with high production both from photovoltaics and wind turbine, one more where both of them would have low production levels and two others where one of them would produce a lot and the other not. However, the second option cannot be supported in this application context, since the weather data does not favor it; there is no month where both the irradiance and the wind speed are weak.

The simulation will cover a period of two days (48 hours) with a change in irradiance, temperature, wind speed and primary load inputs for different cases. The latter one, though, does not vary a lot throughout the year because of the way it has been defined.

The first case study (Case i) represents two days in September, when the energy yield by both sources reaches its highest values. More precisely a time period from $15^{\text {th }}$ till $16^{\text {th }}$ under the weather conditions shown in Figure 28 and the power demand of the values shown in Figure 29 is investigated. 


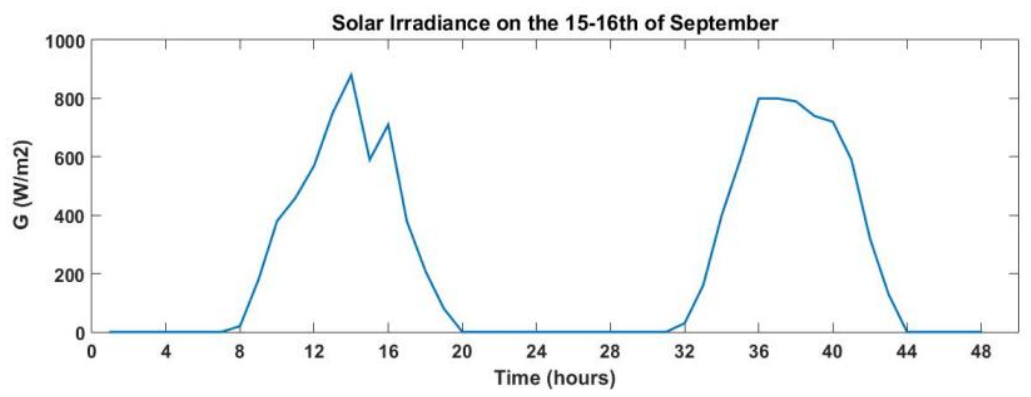

(a)

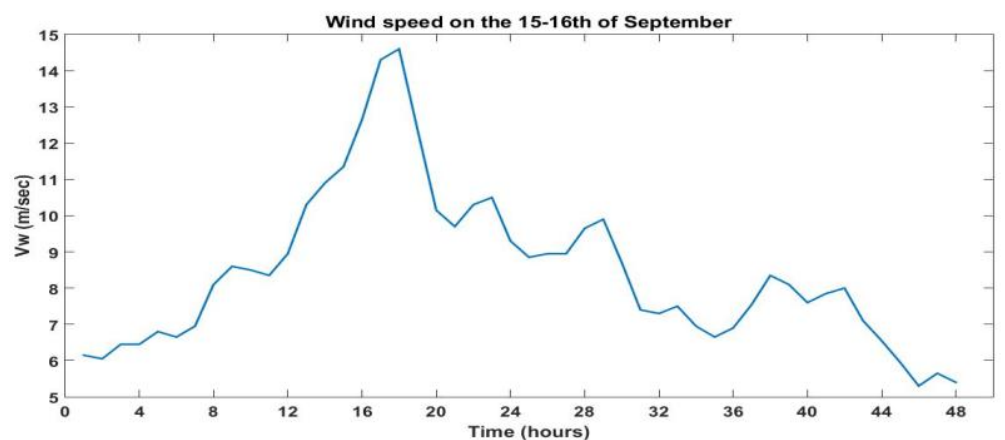

(b)

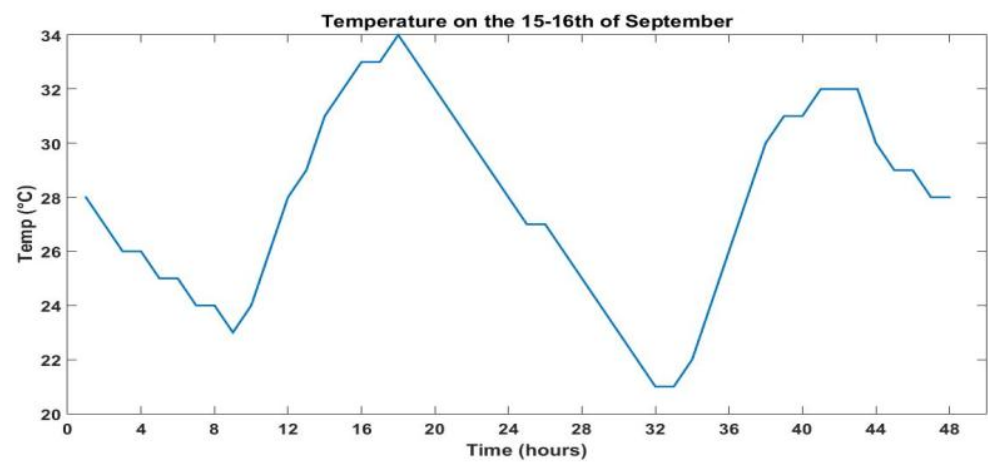

(c)

Figure 28. The (a) solar irradiance, (b) wind speed and (c) ambient temperature on the $15^{\text {th }}-16^{\text {th }}$ of September

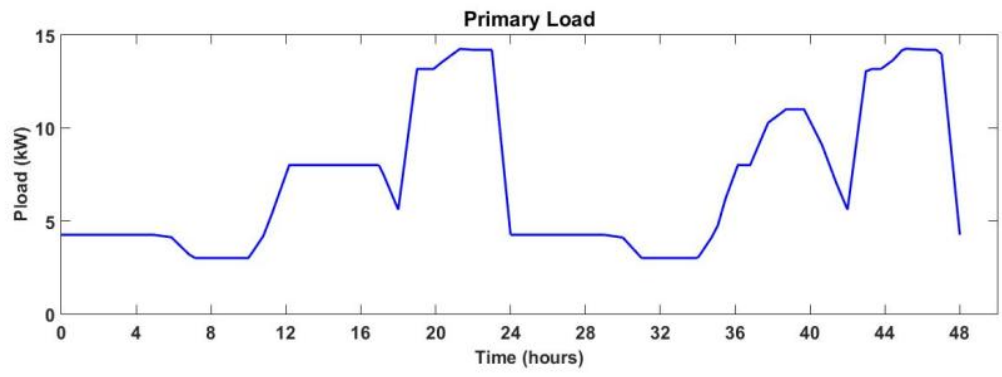

Figure 29. The primary load during $15-16^{\text {th }}$ of September

The second case represents two days in July, from $20^{\text {th }}$ till $21^{\text {st }}$, with high wind potential and low solar irradiance, as it is shown at Figure 27. The power demand for the primary load is almost the same as in Figure 29, but the weather data related with power production are given in Figure 30. 


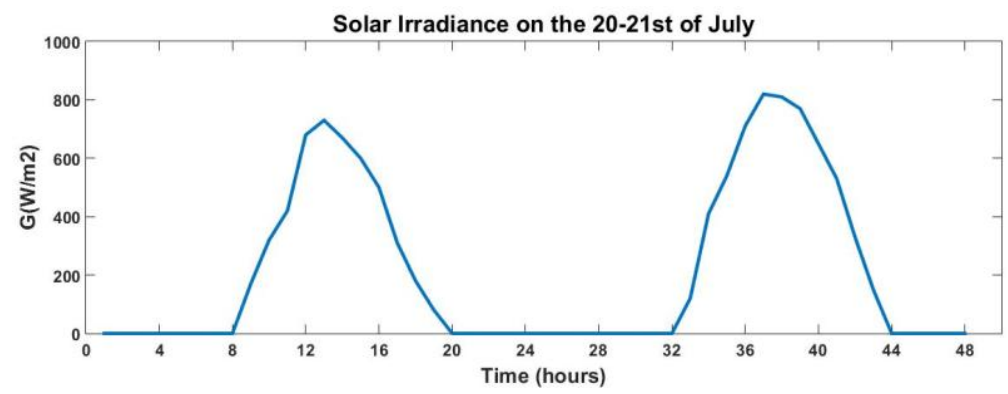

(a)

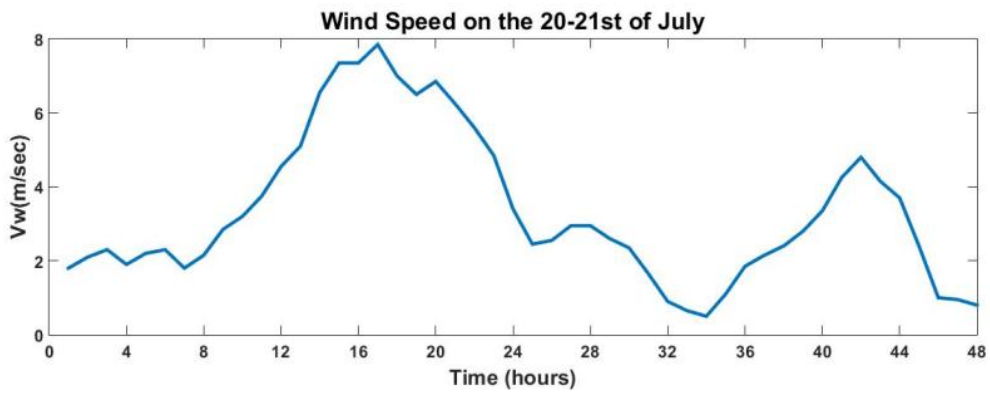

(b)

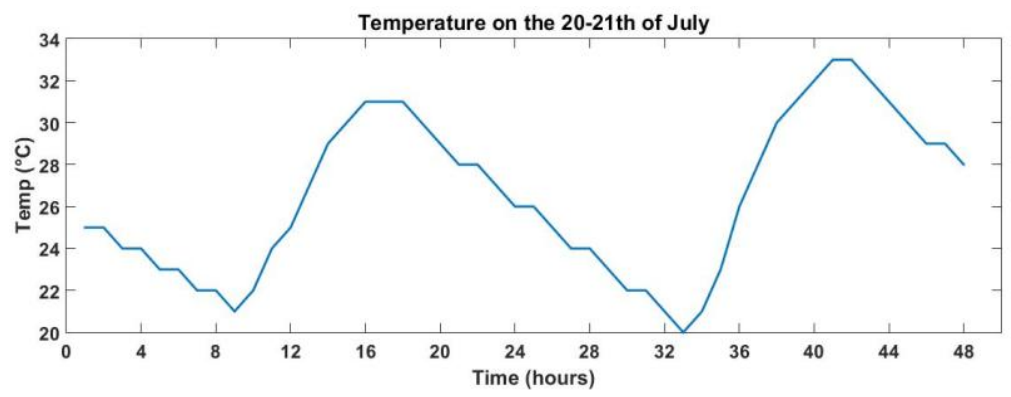

(c)

Figure 30. The (a) solar irradiance, (b) wind speed and (c) ambient temperature on the $20^{\text {th }}-21^{\text {st }}$ of July

The third case (Case iii) represents two days in early December (from the 3rd till the 4rth of the month), when the power production from the wind turbine is modest, but the photovoltaics perform really well under really high irradiance levels. During this month, the primary school is closed, so the primary load is slightly reduced. The weather data related with power production are given in Figure 31 and the load curve for these two days in Figure 32.

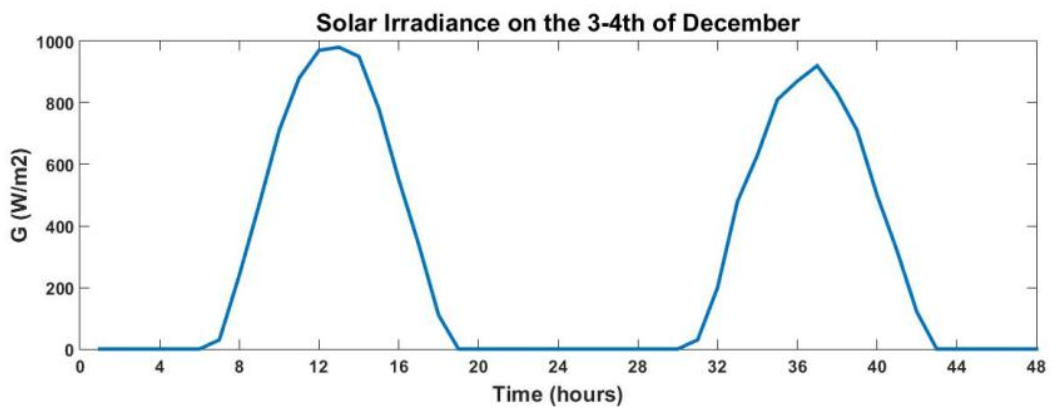

(a) 

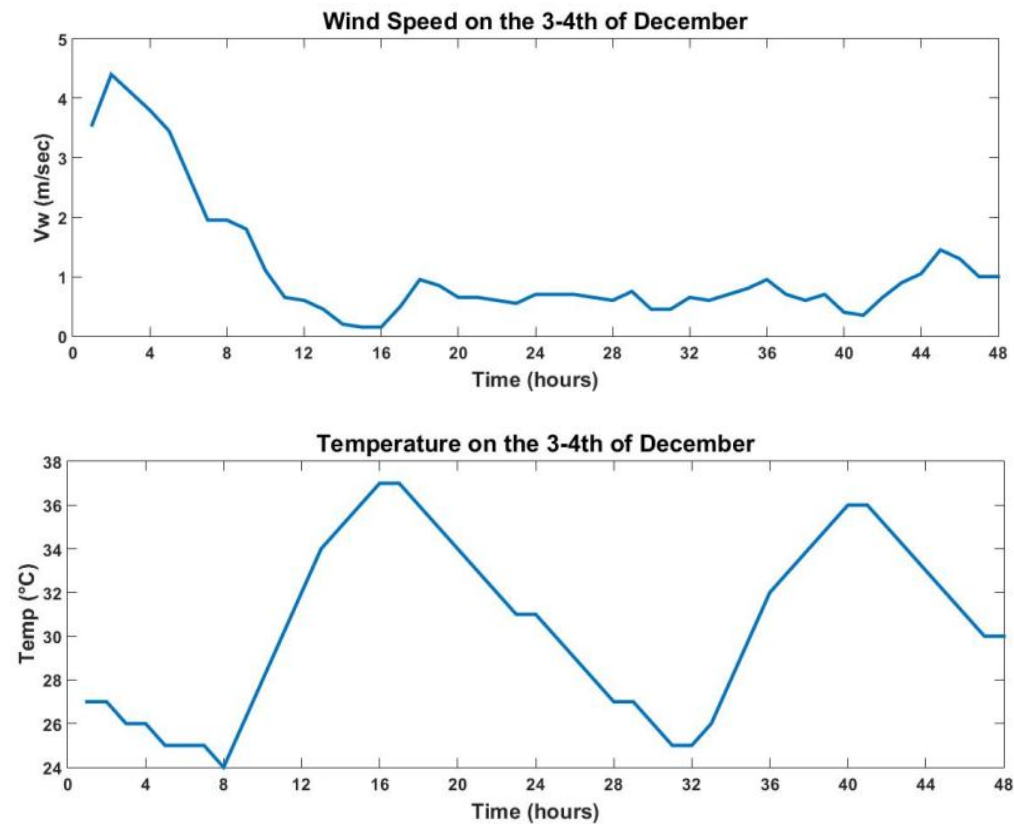

(c)

Figure 31. The (a) solar irradiance, (b) wind speed and (c) ambient temperature on the $3^{\text {rd }}-4^{\text {th }}$ of December

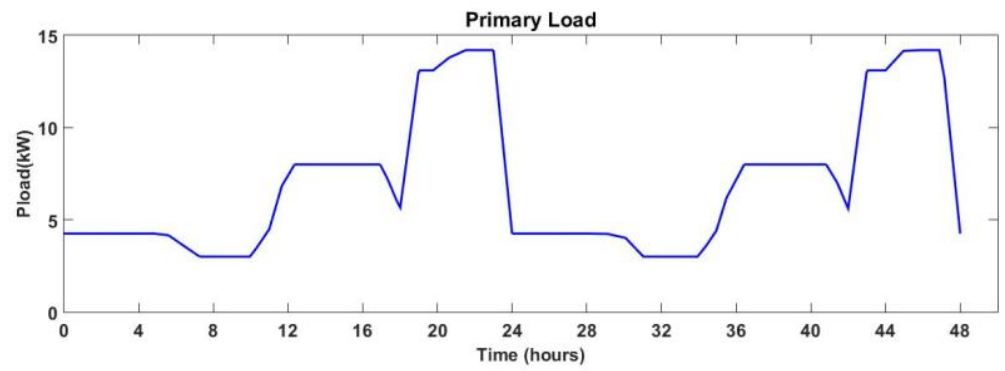

Figure 32. The primary load during 3-4 ${ }^{\text {th }}$ of December 


\section{Simulation Results}

\subsection{Introduction}

After describing the model structure and specifying the different simulation cases in Chapter 4, this chapter involves the study of the simulation results. The three basic cases are simulated and their results are presented. In the first simulation, the comments include also some explanations connecting the results and plots with the designed operational strategy. Subsequently, there is a brief discussion on the initial findings which lead to the secondary analysis. Then, some additional simulations are conducted and analyzed, along with some alterations or extensions with the potential of improving the overall performance of the system and the model.

The description of the simulation results will be analytical mainly for one case (Case (i) September) with all the related graphs in Section 5.2.1. The other cases are also described but their detailed graphs are cited in Appendix IV in order to make the report more easily readable.

\subsection{Initial Analysis}

\subsubsection{Case (i)}

Case (i) involves two days (48 hours) in the mid of September, when the electrical power production reaches one of the highest levels of the year. At time $t=0$ hours, the storage bank is at $80 \%$ of its nominal capacity, the diesel generator does not operate and the deferrable load is off.

Firstly, the graphs related with power production are given in Figure 33. One can see that the wind turbine reaches its peak power (equal to the nominal) around the noon of the first day of the simulation and that also the photovoltaics have quite high production. In Figure 33(b), the power demand corresponding to the primary load $\mathrm{P}_{\text {load }}$ is displayed, while in Figure 33(c), the signal of power difference $P_{\text {dif }}$ is plotted. This parameter represents the difference between the produced power by the renewable sources $\left(\mathrm{P}_{\mathrm{pv}}+\mathrm{P}_{\mathrm{wt}}\right)$ and the power demand $\left(\mathrm{P}_{\text {load }}\right)$.

At Figure 33(c), the light green line crossing $y$-axis at $P=0$ 'separates' the conditions of power excess and power deficit. When $\mathrm{P}_{\text {dif }}$ is positive, the produced power is higher than the one consumed by the users. On the contrary, when $\mathrm{P}_{\text {dif }}$ is negative, then the power produced at that time is not enough to cover their needs. Each one of these conditions triggers a series of different actions (described in detail in Chapter 4), aiming towards the better and stable management of power in the system. Nonetheless, it is visible in Figure 33(c) that during this month, when the performance of both energy sources is high enough, the magnitude of $P_{\text {dif }}$ is significant and potentially problematic in terms of management and stability issues. 


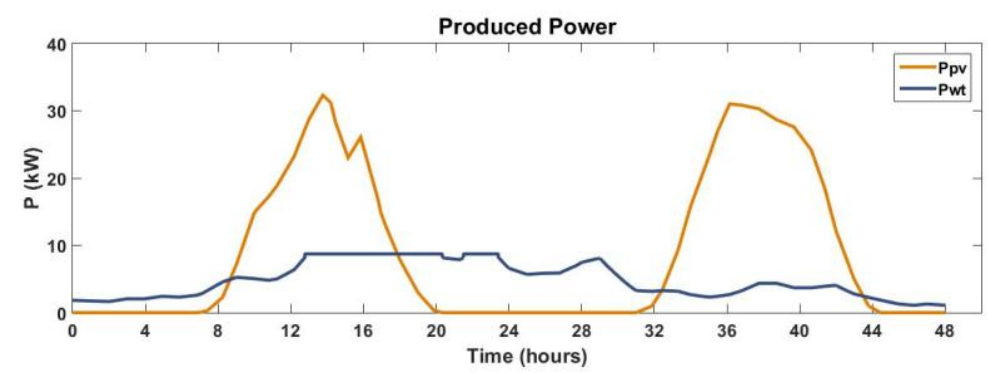

(a)

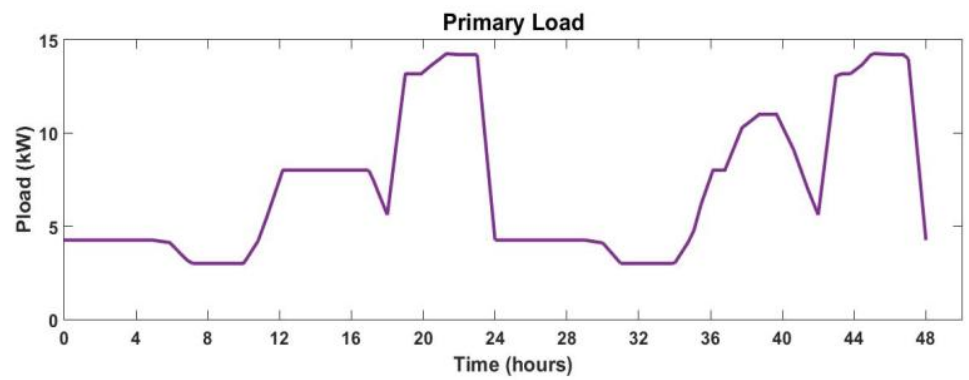

(b)

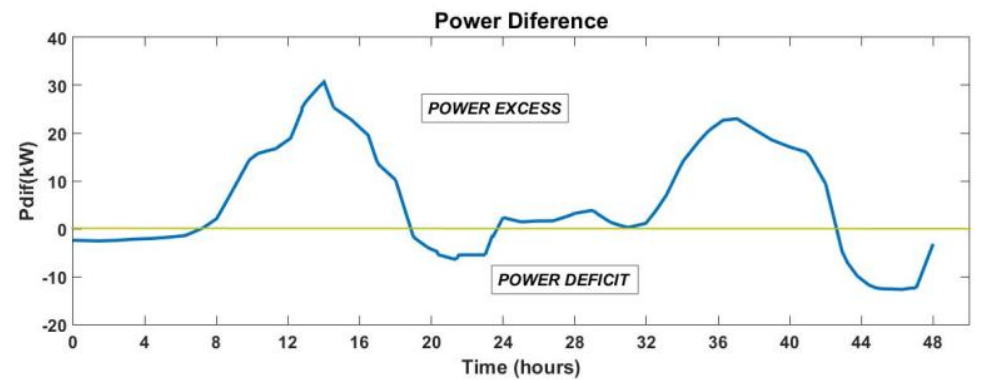

(c)

Figure 33. (a) Power produced by the photovoltaics and the wind turbine, (b) Power demand and (c) Power difference signal for Case (i)

At Figure $34(\mathrm{a})$, all the plots related to the actions taken in case of power excess are presented; one can follow the absorbed and provided power by the battery $\mathrm{P}_{\text {bat }}$ as it is measured on the ac bus of the microgrid (red line), the deferrable load $P_{\text {del }}$ (orange line), as well as the power that is being dumped $\mathrm{P}_{\text {dump }}$ because it can neither be stored nor be used on that time (green line).

While observing Figure 34(a), one should focus on the positive side of the $y$-axis in order to follow the behavior of the system when there is surplus of power. This happens mainly during morning till early evening hours (around $08-19$ ). At 8 o'clock of the first day, excess power appears in the system. This is when the photovoltaics start their production, while the wind turbine has been operating since the previous night. When this happens, the load is completely served, and the batteries start to absorb the extra power with an increasing rate, till they reach their maximum allowed charge rate at around 9 o'clock. After that time, they keep charging but with steady rate till 14:00, when they get almost fully charged and they are disconnected to get protected from overcharging. These can also be noticed in Figure 34 (d) and (e). Even before that time, though, at around 10 o'clock, dumped power begins to increase, since the primary load, the batteries and deferrable load are not enough to consume all the produced power. In few occasions, the dumped power gets even equal to the power difference, meaning that almost all the excess power is thrown away. 


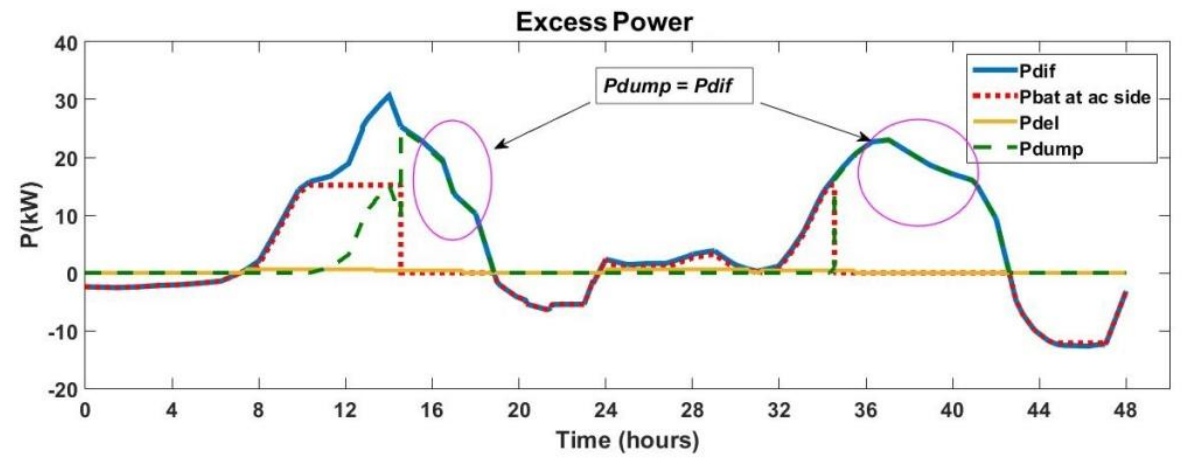

(a)

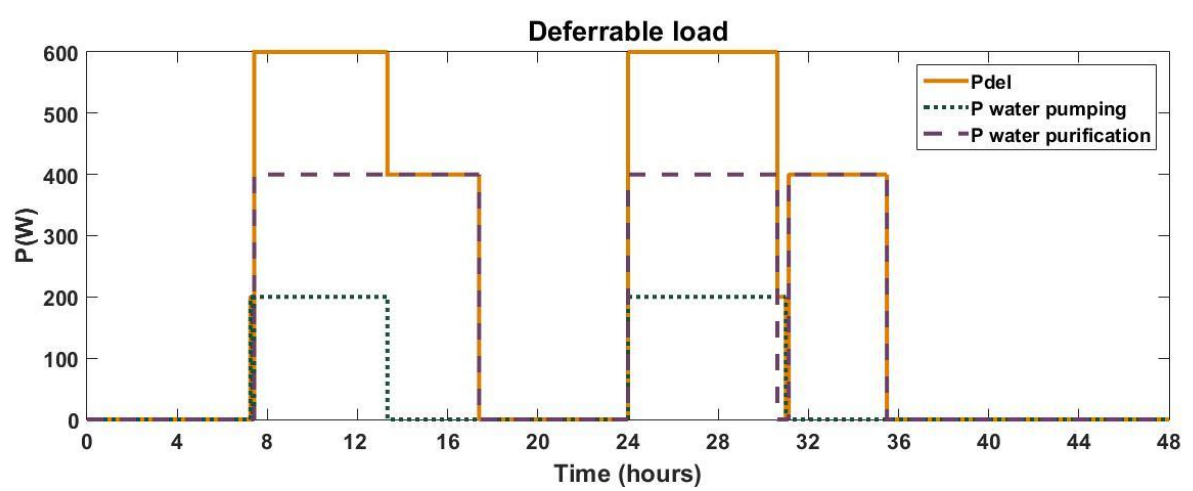

(b)

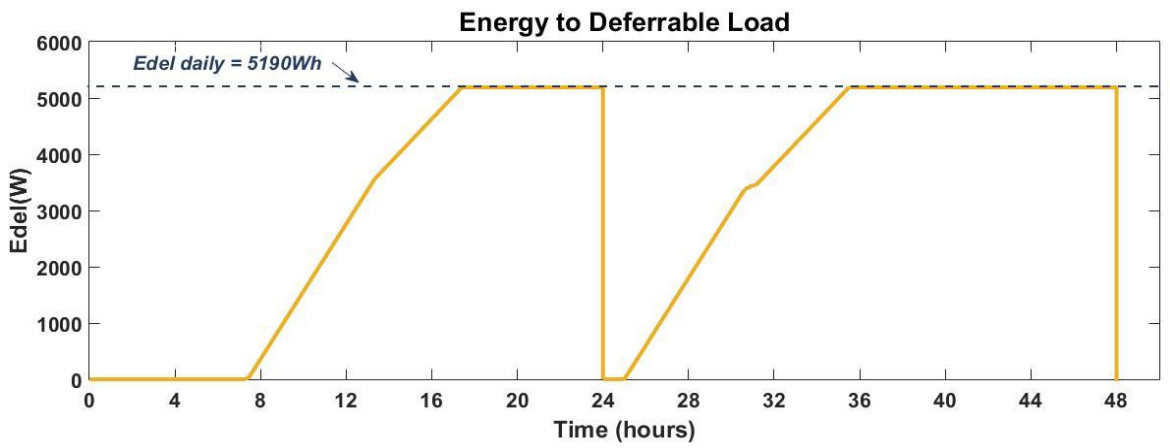

(c)
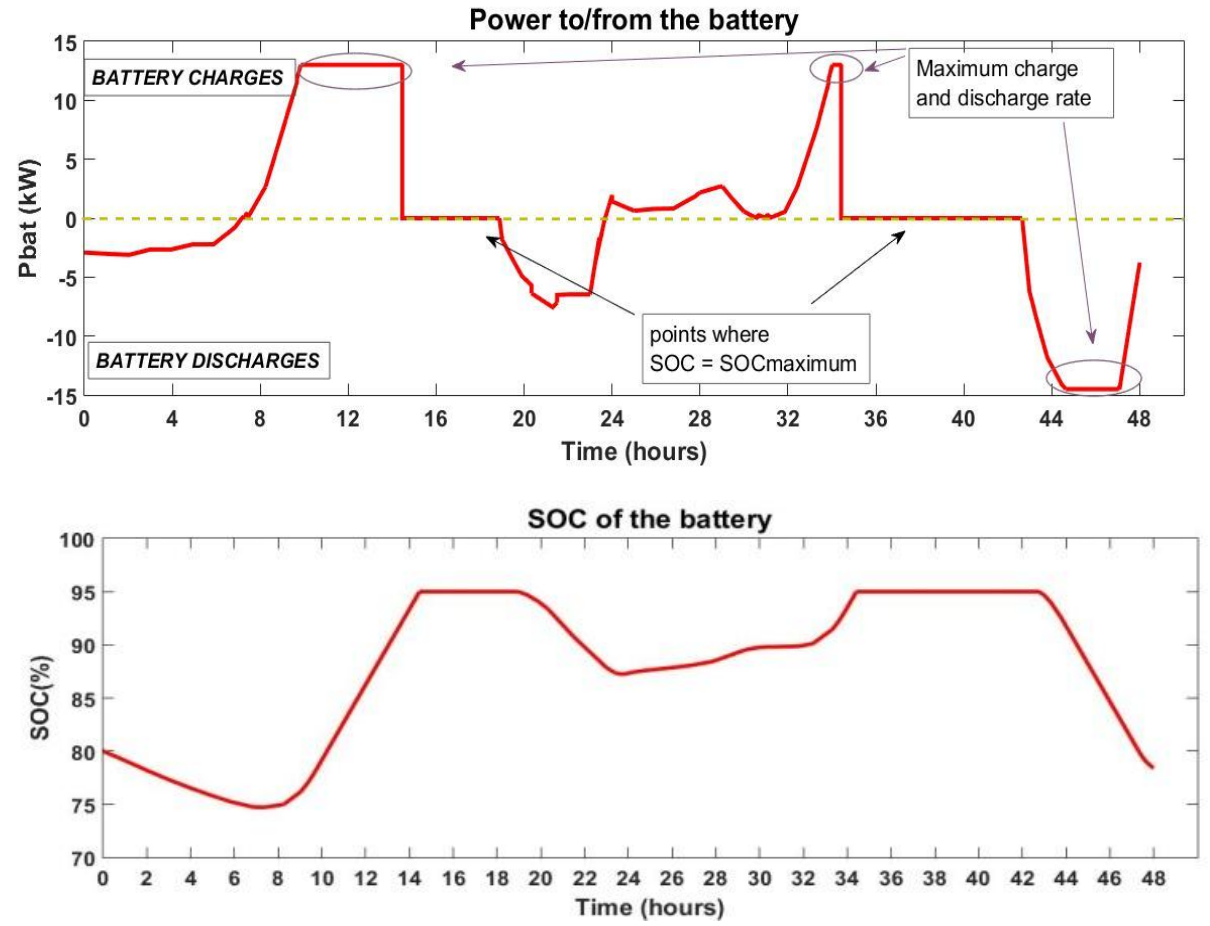

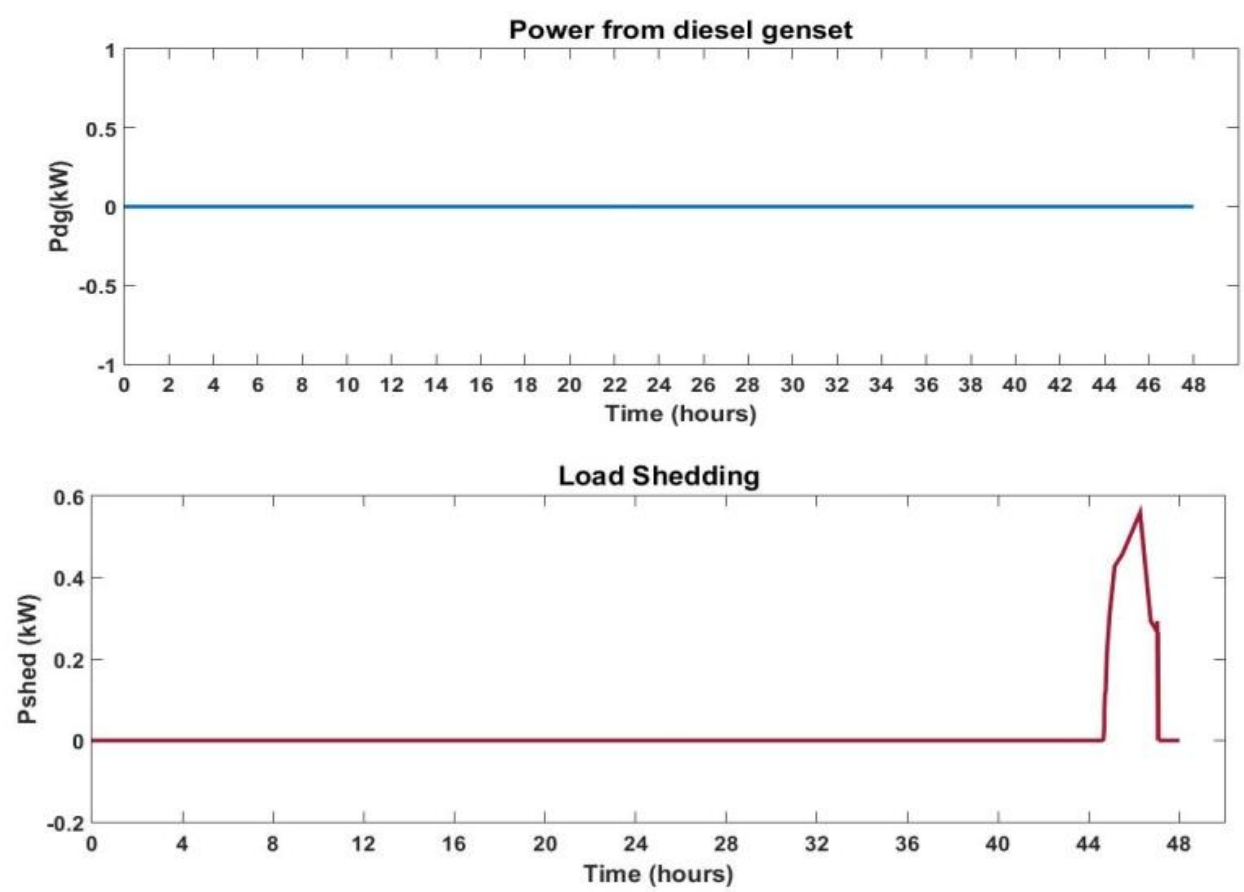

(g)

Figure 34 (a) Power plots describing mainly the condition of power excess in the system, Deferrable load (b) detailed power consumption and (c) energy consumption, (d) Power absorbed and provided by the battery and (e) the SOC of the battery, (f) Power output from diesel genset and (g) Load that was rejected because of deficit of power for Case (i)

One component of the system getting activated during excess power conditions is not clearly shown in Figure 34(a) and this is the deferrable load. It involves water pumping and purification and is being activated depending on the SOC of the battery, the excess power and the energy consumed by itself, as it was described in Chapter 4 and Appendix II. Its operation is presented in Figure 34 (b) and (c). At around $8 o^{\prime}$ clock there is enough power to cover the need for both water pumping and purification. At 13:00, all the amount of needed water is pumped, but it remains to be purified, which is completed at 17:30. The next day, the excess of power enough to cover this extra load occurs much earlier, only at 24:00 (at midnight), since the batteries remain almost always highly charged. At Figure 34 (c), the energy absorbed by the deferrable load is plotted in the way it is measured and controlled in the model. At the end of each day it gets nullified, but before, it needs to have reached the amount of $5190 \mathrm{Wh}$, which corresponds to the daily need of clean water for this village.

Focusing on the negative $y$-axis part of Figure 34 (a), though, the reader can take a quick idea of what happens when there is not enough produced power in the system to cover the users' demand. In this case, it seems that the batteries are mostly able to cover the existing demand during the evening and night. However, at the end of the second day, they reach the maximum allowed discharge power, without feeding the total primary load. At that moment, the remaining power to be covered is less than the allowed minimum value to trigger the diesel generator $\left(0.4^{*}\right.$ $\left.P_{d g \_n}=3.8 \mathrm{~kW}\right)$. Consequently, a part of load is shut down and its peak value is $0.5 \mathrm{~kW}$. All these are depicted in the following graphs; there, in Figure 34(d) the power transferred to and from the battery is plotted, as well as the SOC during the simulation time in Figure 34(e), the power output from the diesel genset and the total load that's been switched off in Figure 34(f) and (g) respectively. 
Following the presentation of the results from the September simulation and their description in correspondence to the system operation, there are certain facts that have to be considered. These facts are related with the system and also with the model itself.

The first aspect which needs to be examined is the amount of dumped power. At Figure 35, the produced electrical energy is plotted over the dumped electrical energy, the energy demand and the energy stored either in the batteries or through the deferrable load. Here it is clear how important this problem is, as approximately $38 \%$ of the produced power is being wasted affecting the performance of the system.

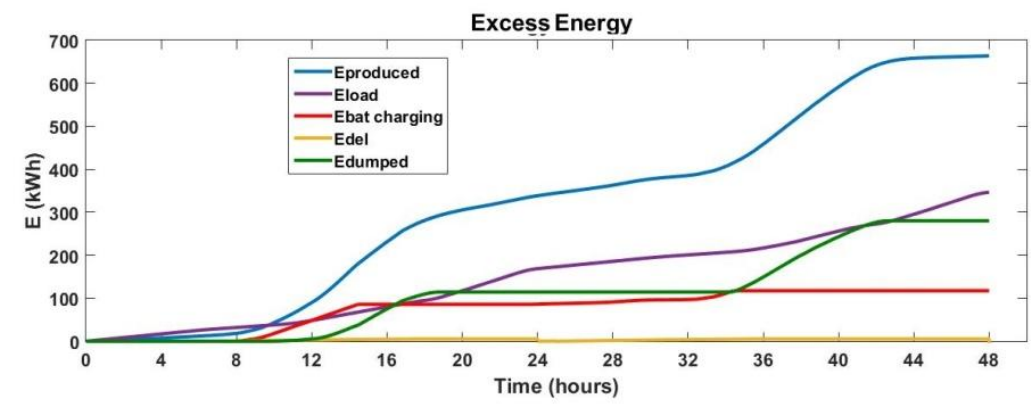

Figure 35. Plots of energy describing the management of the surplus of power in the system for Case (i)

During the two days of September, the battery bank cannot absorb any more power, since it has reached its maximum allowable SOC and the deferrable load is also turned on; still the value of excess power is high. One possible reason might be an oversized installed photovoltaic capacity calculated by HOMER or differences in the way the produced power is calculated in the two individual cases (i.e. in the HOMER software and in this model), since the weather data are exactly the same. At this point, it should be reminded that HOMER indicated the existence of $18 \%$ excess of electricity throughout a whole year.

Another aspect requiring further consideration is the case of load shedding at the end of the second day, while the SOC of the battery is still around $80 \%$. Under these circumstances, while the SOC of the battery is high enough, the power provided by the batteries has reached its maximum allowed limit. So, they keep discharging but without covering all the primary load. Then, the difference Prprod $+P_{\text {batdisch-Pload }}$ is negative but less than $40 \%$ of the nominal power of the diesel generator. This implies that it is not efficient to turn it on and the only possibility is to switch off a part of the load equal to this explicit deficit. The peak value of load shedding is $P_{\text {shed_peak }}=550 \mathrm{~W}$ and the total energy remaining uncovered is around $1.1 \mathrm{kWh}$.

This battery response is based on two factors: firstly, the power limits as they are set according to the datasheet of the manufacturer and HOMER specifications for the same battery model, and secondly, the way the battery control is designed without an advanced integration of the different rates of discharge in the model after a certain threshold. Providing the discharge current ( $\left.I_{\text {dc_bat }}\right)$ of the battery was allowed to increase to $59.45 \mathrm{~A}$ from $50.84 \mathrm{~A}$ at a 12 hour rate, the battery would cover this section of the load too. It would result in a final SOC equal to $75 \%$ at the end of the 48 hours and the maximum measured discharge power of one battery string would be equal to $2650 \mathrm{~W}$ (dc side). The curves for the SOC of the battery under the originally defined limitations and the SOC for a higher allowed charge rate are shown at Figure 36. However, one should consider that the limitation of $I_{\max }$ for the battery has been set like this for safety reasons and to prolong its lifetime. 


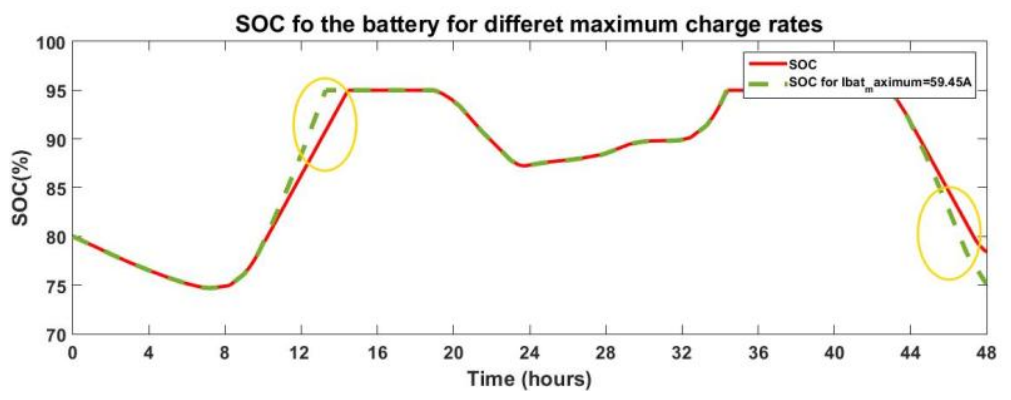

Figure 36. Comparison of the battery bank operation in terms of SOC for different allowed charge rates for Case (i)

\subsubsection{Case (ii)}

Case (ii) involves two days in late July with strong wind speeds but low irradiation values. The results of this simulation are characterized by some similarities with case (i), as it will be further realized.

The reader can obtain a general idea of the system function during these days observing Figure 37. Initially, the power production by the photovoltaics and the wind turbine are presented in Figure $37(a)$ and the primary load curve at Figure 37(b). Subsequently, the focus turns on the management of excess of power in the system, which is described by the Excess Power diagram in Figure $37(c)$. It can be easily noticed that signal $P_{\text {dif }}$ is following a similar pattern as in September case (i), with high amounts of extra power during the day and relatively smaller power shortages during the night. The problem of dumped power has already started appearing as a significant possibility. In this case, the batteries reach their maximum allowed state of charge every noon, but they can satisfactorily cover the power deficit during night and yet not falling under $80 \%$ of their nominal capacity. Their operation is described in more detail by the corresponding graphs in Appendix IV. These days, neither the diesel generator is activated, nor is the load shedding needed.

What appears to be once again as an ineffectiveness of the system is the significant amount of power that remains unexploited. In Figure 37(d), the produced energy in relation to the used energy by the batteries and the loads, as well as the dumped energy are depicted. Around one third of the produced electrical energy by the renewable energy sources is being dumped even during July when the solar irradiance is at its lowest levels throughout the year. 


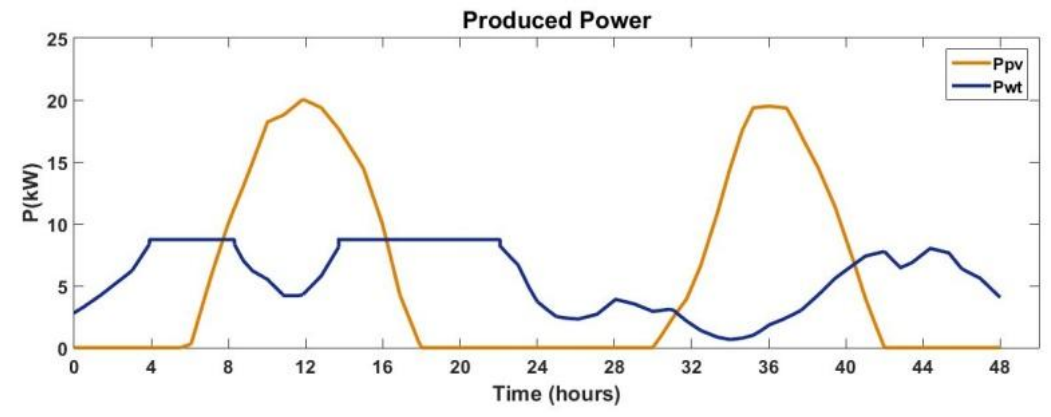

(a)

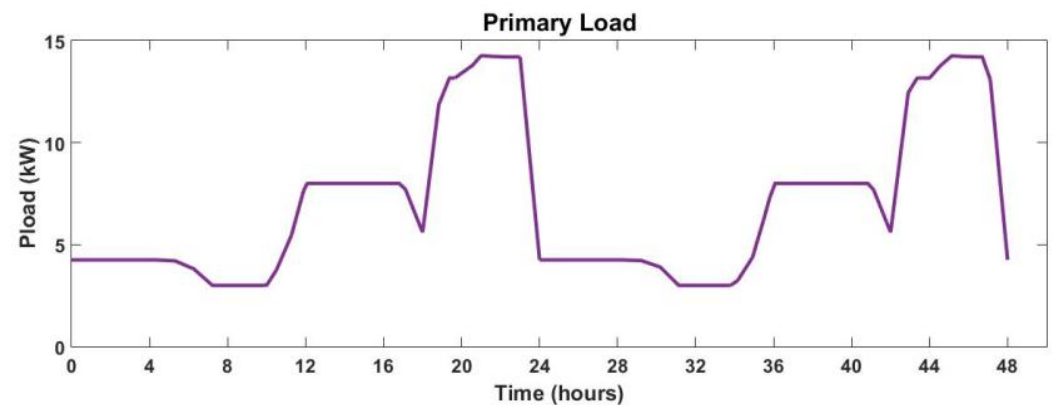

(b)

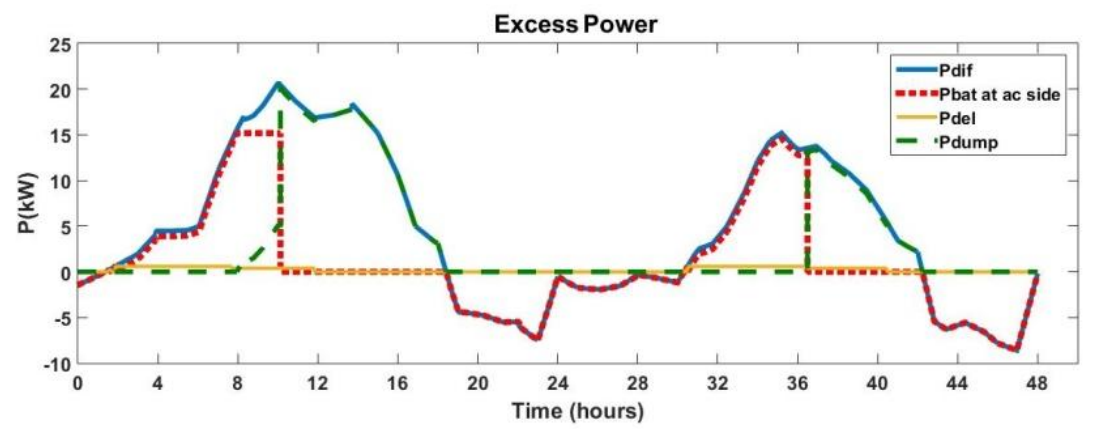

(c)

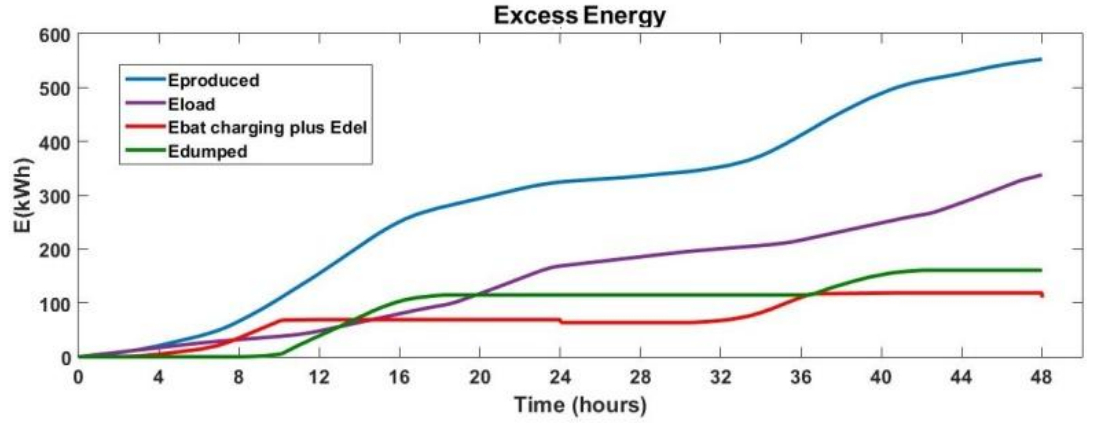

Figure 37. (a)Power produced by the photovoltaics and the wind turbine, (b) Power demand, (c) Power plots describing mainly the condition of power excess in the system, (d) Plots of energy describing the management of the surplus of power in the system for Case (ii)

\subsubsection{Case (iii)}

The third case involves two days in early December when the wind speed is very low, but the solar irradiation reaches some of its highest values throughout the year. The produced power by each of these sources is depicted on Figure 38(a), where it is clear enough that the wind turbine does not really contribute in power production during this period of time. The power demand is shown in Figure 38(b) and is similar to the previous examples, except for the fact that during December the low priority primary load is null (because of the way it is defined in this project).

Excess power management is being also assessed at this point and the corresponding familiar graph with the signals $P_{\text {dif, }}, P_{\text {dump }}, P_{\text {bat_at_acside }}$ and $P_{\text {del }}$ is in Figure 38(c). The signal of power difference of the system follows the same pattern as before with positive values during the daytime and negative during the nights. Its maximum positive values are quite close to those in 
July but less than in September, while its negative values are higher than in July and very close to those in September. The 'Excess Power' graph of December case is considerably differentiated from the respective previous ones, because in spite of the presence of dumped power, its magnitude is smaller than in case (i) and (ii) and less than the power absorbed by the batteries most of the time.

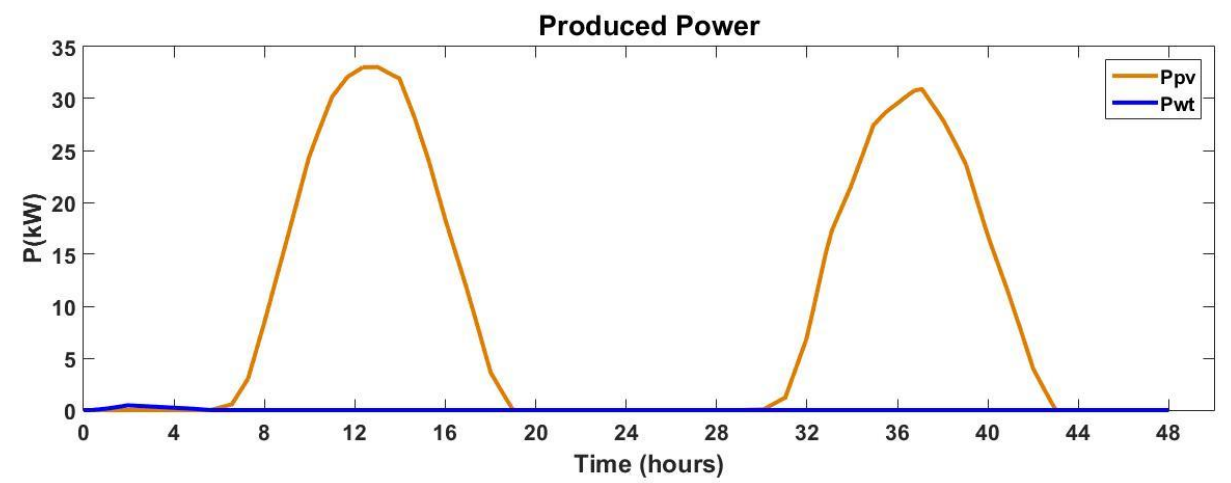

(a)

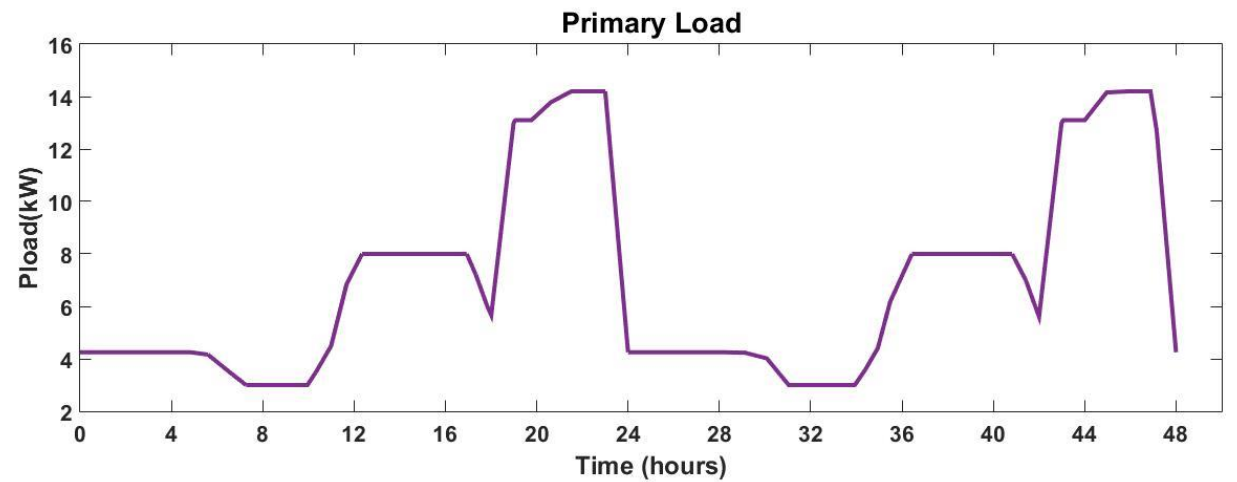

(b)

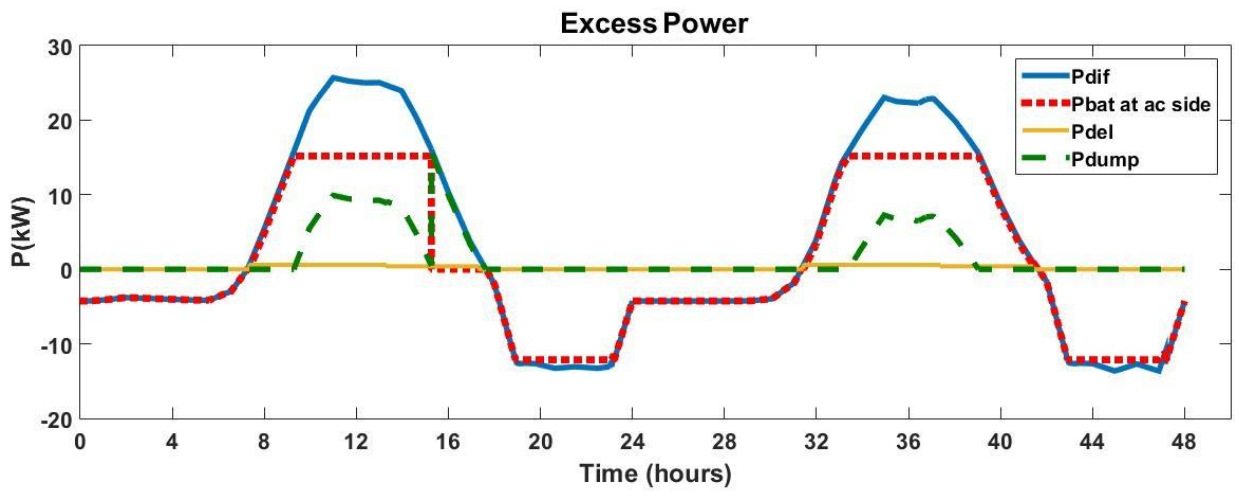

(c)

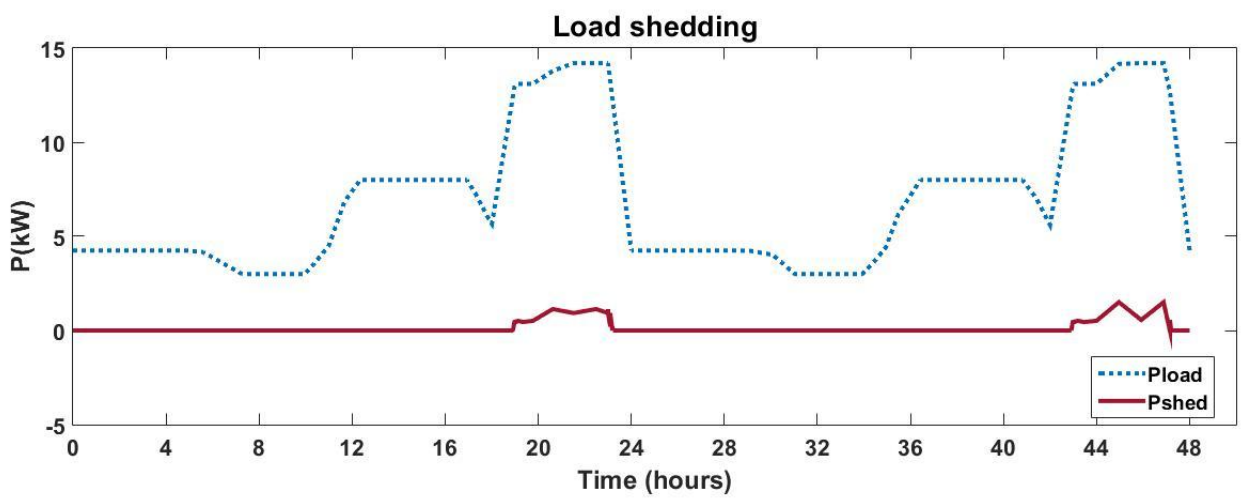

(d)

Figure 38. (a)Power produced by the photovoltaics and the wind turbine, (b) Power demand, (c) Power plots describing mainly the condition of power excess in the system, (e) Load failed to be satisfied in comparison with the total primary load for Case (iii) 
As far as the evening time is concerned, it is also apparent in the 'power excess' graph that the deficit of power is more than the power provided by the batteries; this will inevitably lead to an activation of the diesel generator or shutting down a load section. The diesel generator is not turned on, because the remaining power to be covered $P_{\text {dif }}-P_{\text {disch }}$ is less than minimum load of allowed operation for the diesel genset $P_{\text {min_dg. }}$. As a result, the equivalent amount of power is taken off the primary load and leads up to a total of $7.7 \mathrm{kWh}$ of uncovered energy demand $(2.27$ $\%$ of the total energy demand) at the end of the second day. The load shedding signal is shown in Figure 38(d).

Regarding the batteries operation, they absorb the biggest percentage of the excess of power in the system and cover most of the deficit, with their SOC expanding from $65 \%$ till its highest allowed value. In case (iii), it is the first time the SOC of the battery falls down to $65 \%$ and at the end of the second day is less than $80 \%$; this fact could make interesting and useful the conduction of one more simulation of the system during the same time, but with a lower initial state of charge of the battery, since this can be one real case during December. At the end of the first day (19-23 hours), the battery is reaching its maximum allowed discharge power without being extremely discharged and as a consequence it is incapable of covering the whole demand.

As in September case, if a higher discharge rate of the battery was allowed (12 hour rate with $\mathrm{I}_{\text {bat }}$ $=59.45 \mathrm{~A}$ ), there would be no load shedding and the SOC at the end of the second day would be around $67 \%$. The power output from the storage bank and its SOC would vary in a wider range, while a higher discharge current would be allowed, but an interesting fact regarding this possibility is its effect on the amount of dumped power, which would have a higher peak, around $28 \mathrm{~kW}$. Nevertheless, as it was mentioned before, the limits of the charge rate of the battery were chosen so that they would prolong the battery lifetime and ensure a safer operation. A closer look at the battery bank performance for both the real and the hypothetical case could be taken through the graphs of the power transferred to and from the battery during the simulation time and of its state of charge in Appendix IV.

As a last step of this basic analysis of the results from the third case, the energy plots are given in Figure 39 , where the $E_{l o a d}$ is the energy demand of the inhabitants without the load shedding. Almost one quarter of the produced electric energy is being dumped.

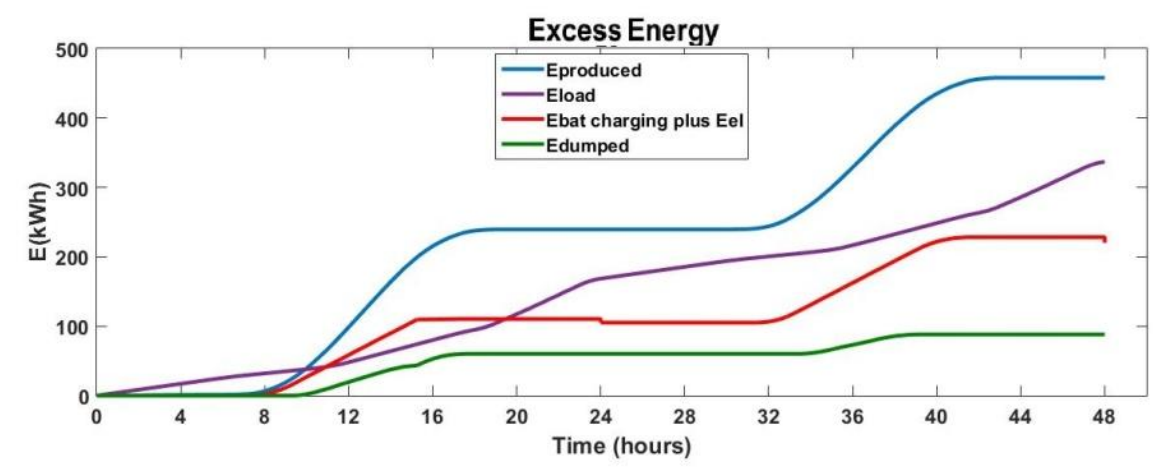

Figure 39. Plots of energy describing the management of the surplus of power in the system for Case (iii)

\subsection{Discussion on the First Results}

Having reconsidered the results from the simulations of the different cases, the author concludes that further and deeper consideration is required in certain parts. At the same time, some extra simulations are worth being carried out under different initial conditions (like the initial SOC of 
the batteries) or under possibly beneficiary alterations of the system, in order to obtain a broader understanding of the system's behavior and its weaknesses (also on the modeling level).

i. The main drawback of the system arising from the simulations of the previous section is the high amount of excess power that cannot be used and is being dumped.

ii. Secondly, the control of the charging rate of the battery is a topic which could be developed contributing to a more efficient operation of the microgrid and a more representative model.

iii. What is more, although an initial SOC of $80 \%$ is used for the simulation of all the cases, some days may start with less charged batteries especially in months with lower production rates.

iv. The diesel generator was not activated in these simulations, because the power remaining to be covered was less than the threshold defined for its activation. Consequently, a part of the load was not fulfilled.

v. The load shedding, as it is expected, usually happens during the night time, when there is not production of power from the renewable sources, and the battery bank and the diesel genset should cover the demand. Here, the main/primary load has been divided in high priority and low priority load, as it has been described in Chapter 4.6. The low priority load is the first one to be cut off and this is why it should be carefully chosen, for the load shedding to be efficient and as less disturbing as possible. The chosen as low priority load should be on during these time slots when an important deficit of power is expected, it should belong to a convenient power range (so that its value can mostly cover the total power of load shedding) and of course be of lower importance in comparison with the other end uses of electric power.

vi. The importance and function of the deferrable load (here, involving water pumping and treatment) imposes different criteria for assessing the model and its results. Considering it as an extra but not vital service aiming to improve the performance of the overall system and operating as one more storage application is different from expecting every day to have a certain amount of electrical energy provided to it.

\subsection{Alterations and Additional Simulations}

In this chapter some of the mentioned aspects in the previous section will be more closely investigated with the conduction of a few additional simulations with longer duration or different initial conditions.

Having an excess power is a common phenomenon in autonomous power systems with high penetration of renewable energy. Nevertheless, it was not expected to arise with this magnitude, since a techno-economical optimization was pre-conducted with HOMER software; a tool with high reliability. So, while a different way of calculating the power production from the photovoltaics by the two models could explain light deviations, a conclusion that the photovoltaics are oversized could be one possibility. On the other hand, the short time focus of the former simulations could justify a statement like this and it is really important to point out the difference between the simulation which is run here and the one which is run by HOMER software. To be more elaborate about the difference in calculations, this is rooted in the calculation of the incident radiation on the solar panel, taking into account the components of beam and diffusion radiation separately [70]. Far more importantly though, HOMER has assessed the behavior of the system throughout a whole year, when the weather conditions and 
consequently the produced electrical energy vary and the excess or deficit of power of every day formulates the initial conditions for the next day in row.

\subsubsection{Case (i)}

To achieve a better understanding, the operation of the system for 4 days in September is being also simulated, with the first two of these days being the same as in case (i) in section 5.2.1. At Figure 40 , the power production is given, followed by the signal $P_{\text {dif }}$ showing the time periods with excess or deficit of power in Figure 40(b). It can be seen in Figure 40(b) that there is a varying excess of power during these four days of September and lower amounts of power deficit during the night time.
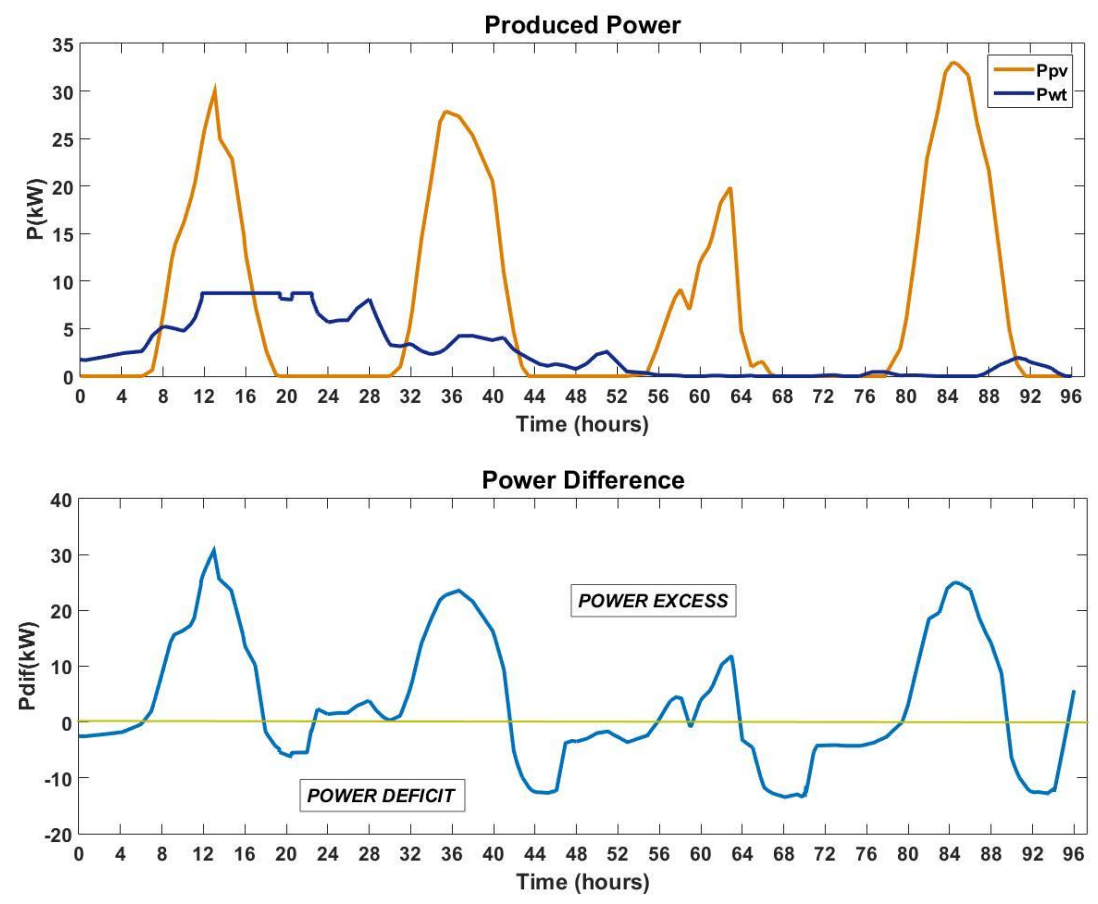

(b)

Figure 40. (a) Power produced by the photovoltaics and the wind turbine and (b) Power difference signal during the 4 days for the extended Case (i)

At Figure 41(a), the graph indicates how the excess power is managed by the autonomous system. There is an amount of dumped power, reaching its highest value the second day, when it equates with $\mathrm{P}_{\mathrm{dif}}$ for some hours. Taking a closer look to the same graph, one can also notice that for the negative part of $y$-axis, related with power shortage in the system, the batteries (red line) can cover the biggest part of it. Again, the diesel generator does not operate, since the power demand is lower than the minimum power limit justifying its efficient operation. Thus, parts of the load need to be shut down, as shown in Figure 41(b); nevertheless, the amount of energy demand for the primary load that remains unmet is really small in comparison with the whole energy consumption, as it is shown in Figure 42. In the first day there is no load shedding at all, but during the third day, when it happened to have lower power production, the taken off the system load reaches its peak. 


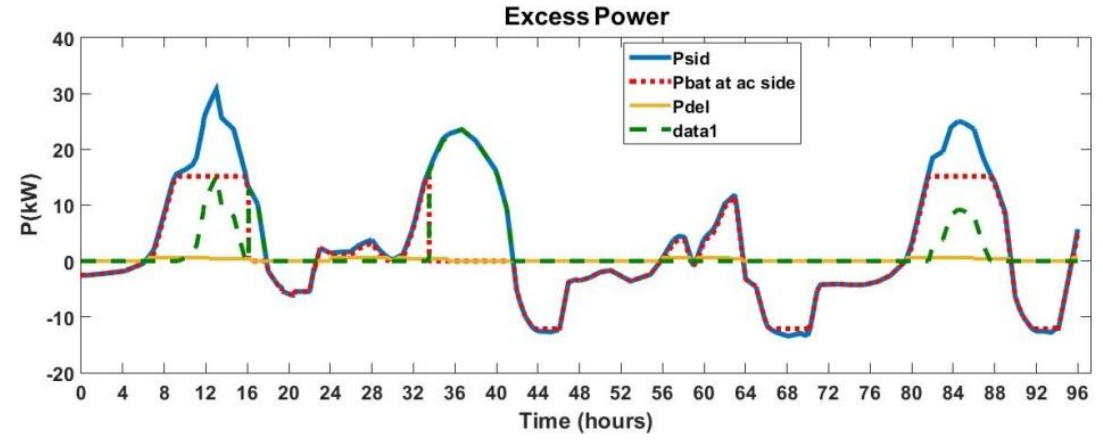

(a)

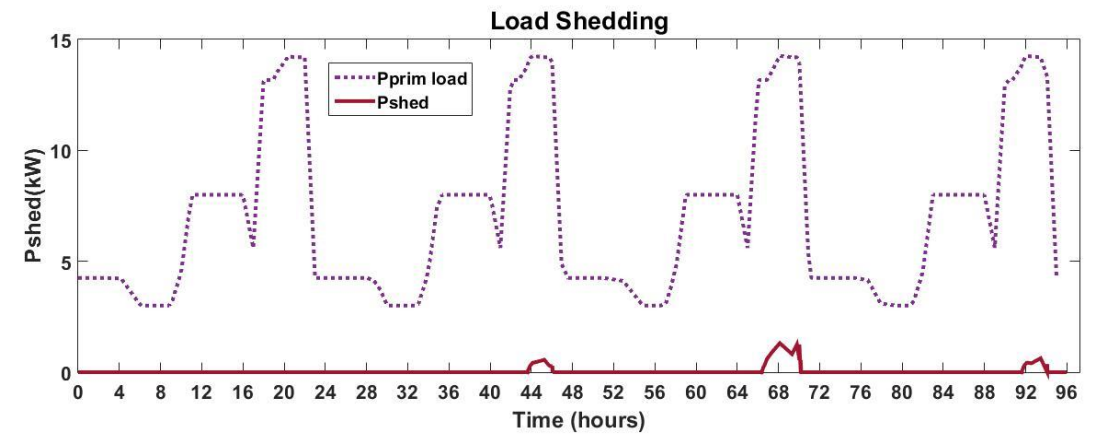

(b)
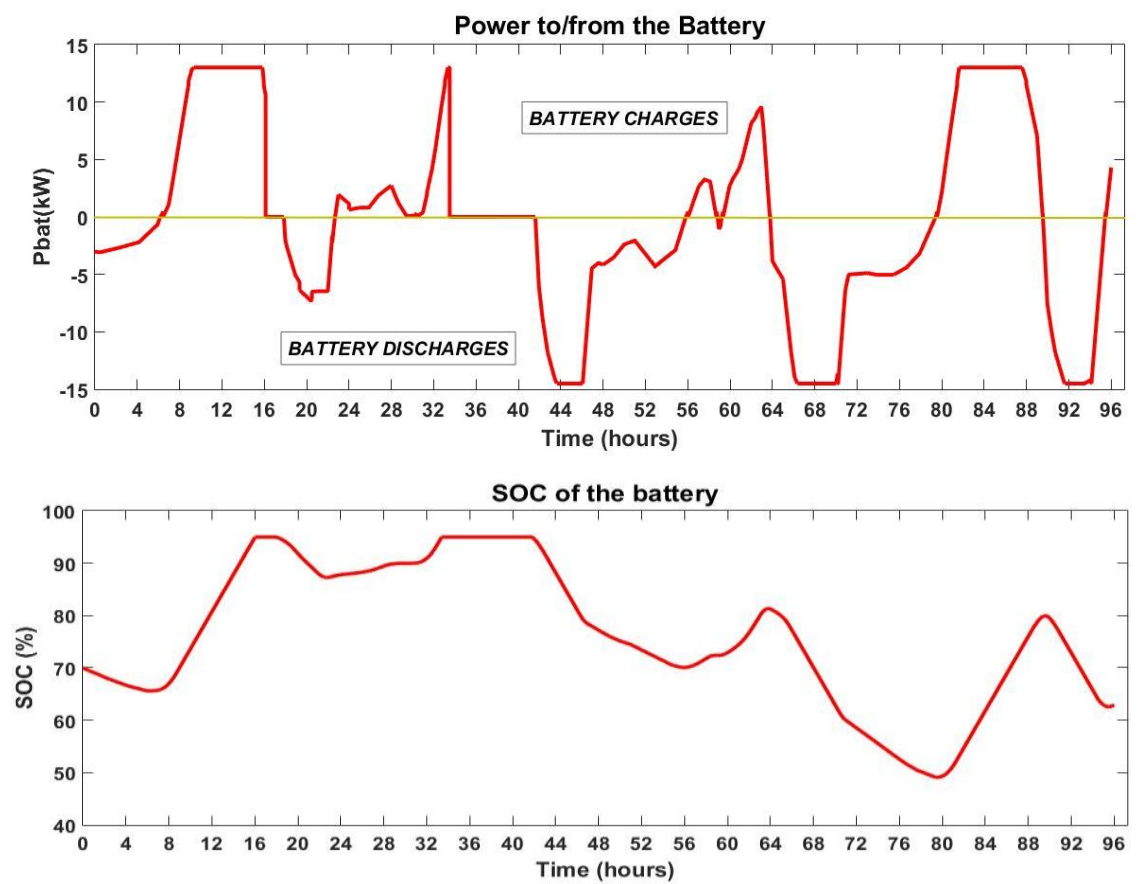

(c)

(d)

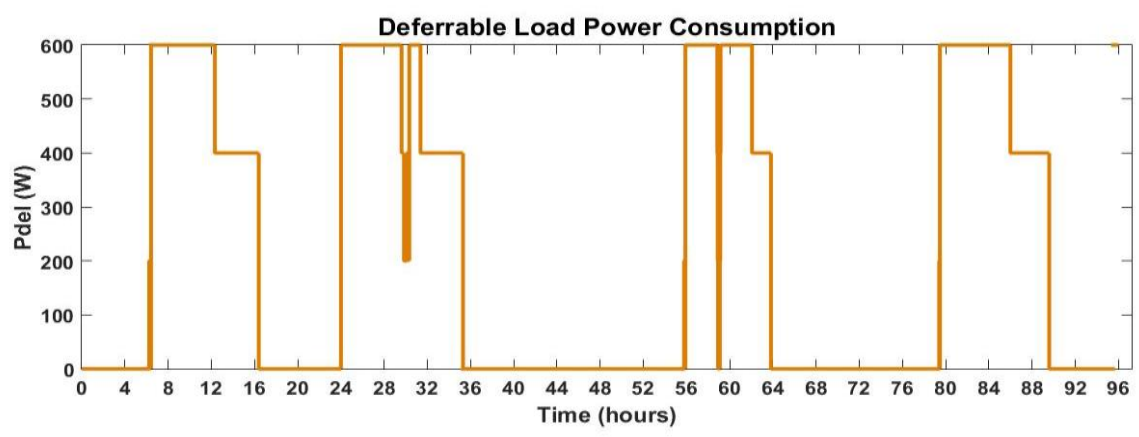

Figure 41. (a) Power plots describing mainly the condition of excess power in the system, (b) that was rejected because of deficit of power in relation to the total power demand, (c) Power absorbed and provided by the battery and (d) the SOC of the battery, (e) Deferrable load (a) power consumption for extended Case (i) 


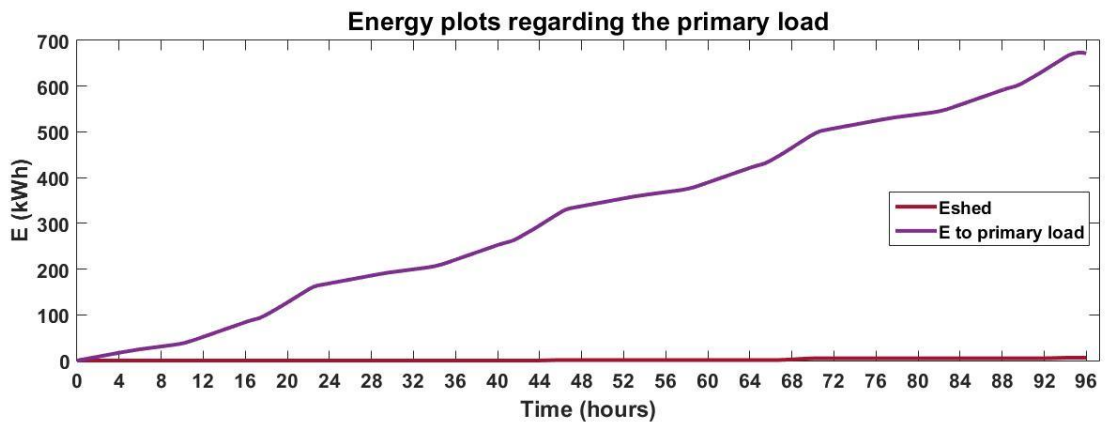

Figure 42. The uncovered energy demand in relation to the original energy demand for extended Case (i)

The batteries performance during these four days of September is described in the graphs of Figure $41(\mathrm{c})$ and (d) with the exchanged power with the system and the SOC. At this simulation, the initial State Of Charge of the batteries was set to $70 \%$ rather than $80 \%$, since it is a more representative state of charge for that time of the year. During the first two days, when there is plenty of produced power, the SOC of the battery remains at higher levels, but at the following days there is a significant part of energy provided by the batteries and this brings a reduction in the SOC of the battery bank.

The deferrable load curve cannot be really followed in Figure 41(a), because of its comparatively low values, but both its power consumption is presented at Figure $41(\mathrm{e})$ and its electrical energy consumption at Figure 43. There, one can notice that the curve of the power provided for the water pumping and treatment need of the community (as this is stated to be the deferrable load) changes from day to day in order to follow the control method defined in Chapter 4. While the daily energy needed to cover this daily demand is specified to be $5.19 \mathrm{kWh}$, the second day it is not covered since there is not enough excess of energy. Here is where aspect (vi) from the brief introductory analysis comes in the discussion. To be on the safe side, during the design of the system, there was predicted to have and provide the system with three days storage of water appropriate for usage, so that no problem would be caused in a case like the third day, when the $E_{\text {del }}$ is less than its defined daily value. In addition to that, it is important to decide if the deferrable load will be considered as a vital but able to be shifted daily service or as an extra improving storage capacity service. The latter consideration applies in this case, taking into account also that part of the power appeared to be dumped can be used to store and treat additional water quantities.

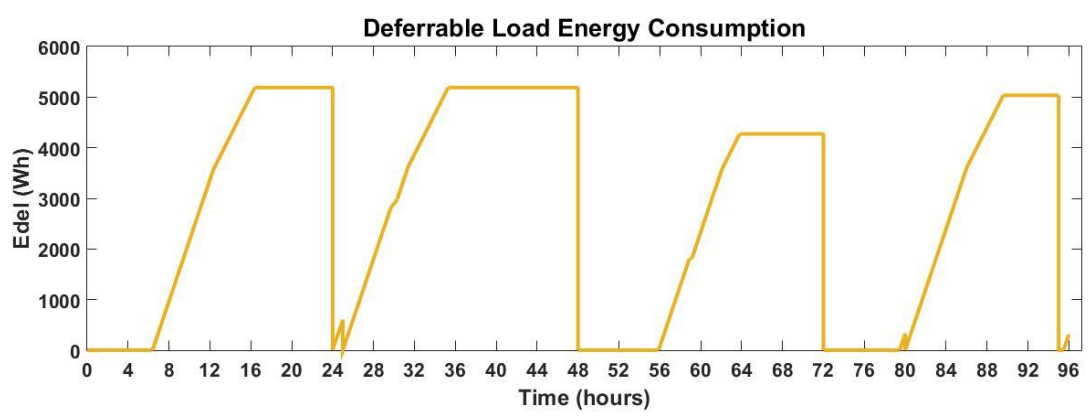

Figure 43. Deferrable load energy consumption for extended Case (i)

However, this model can also simulate what would happen in the first case, when the energy needed to cover the daily demand for water treatment would partially come from the storage and next days the storage should be supplemented. Only the fourth day (73-96 hours) is being simulated for this purpose and the energy shortage of the third day (equal to $E_{\text {daily }}-E_{\text {del3rd }}=4.275$ $\mathrm{kWh}$ ) will be compensated the fourth day to clean and store more water, while the initial SOC of 
the battery pack for this day is around $58 \%$. The power curve of the deferrable load for the day No.4 of the precedent simulation is presented, along with the graph of energy absorbed by the deferrable load in Figure 44.

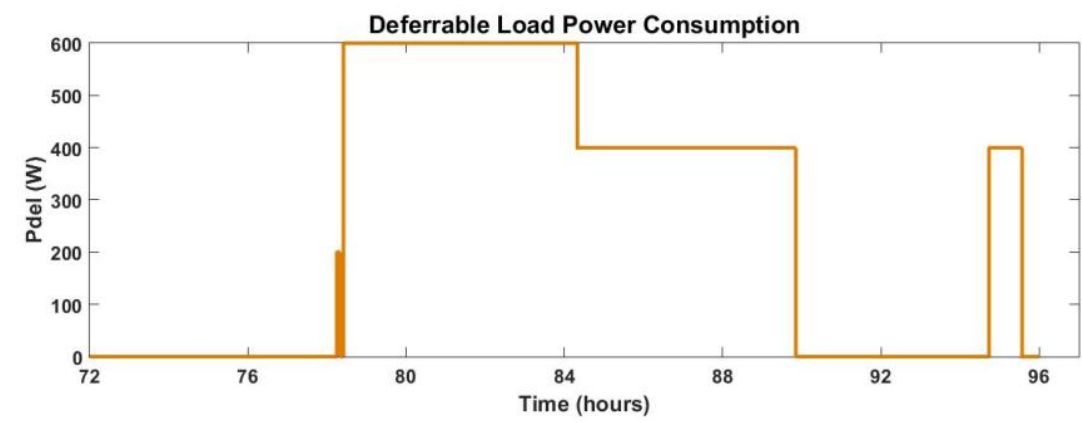

(a)

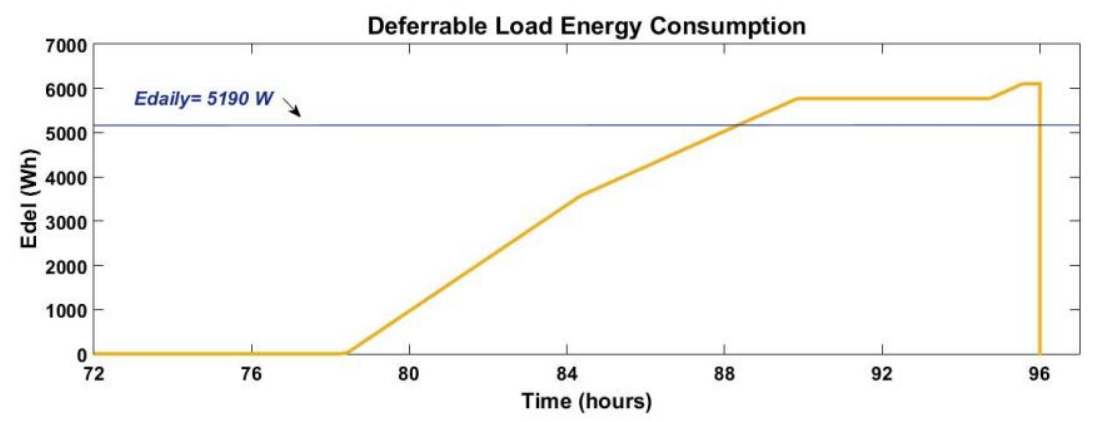

'b)

Figure 44. Deferrable load (a) power and (b) energy during the 4rth day of the simulation with the aim to compensate for the lost water from storage during the $3^{\text {rd }}$ day

Going back to analyzing the results of the 4-September-days simulation, there is the issue of dumped power to be discussed. The plot of the dumped electrical energy in relation to the energy produced by the renewable sources is given in Figure 45, showing that around $30 \%$ of the produced electrical power fails to be exploited.

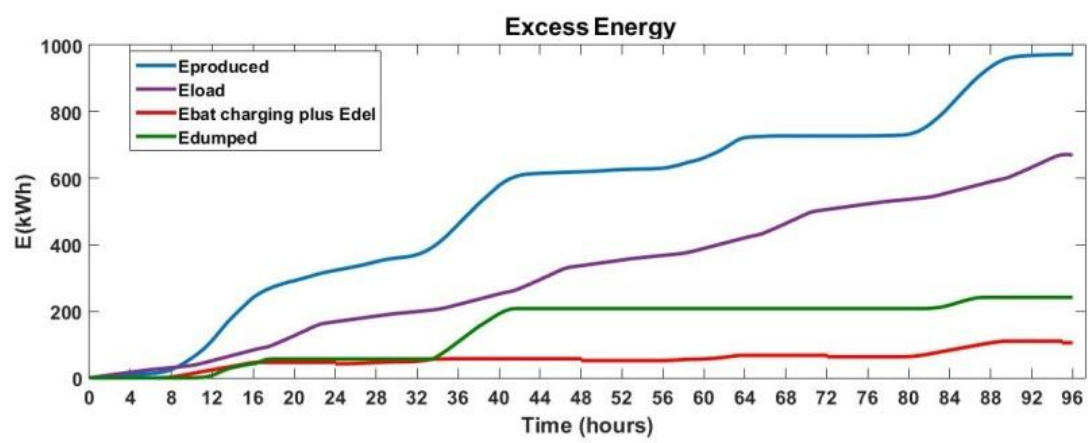

Figure 45. Plots of energy describing the management of the surplus of power in the system for the extended Case (i)

In these areas though, every amount of available energy is highly important. This generates the need of investigating alternative solutions which could increase the usability fraction of the system. One way to reduce the problem, but not completely solve it, could be the small expansion of the battery pack or a different control of the conditions under which it charges and of its maximum permitted current. Another solution that could be more profitable for the village is to include a small industrial application that could be supported some days during months with high average power production, or to allow the purification of higher amounts of water that can be either stored and locally used or being sold in order to generate an additional income for the village and improve the overall performance of the system. For example, in this case, the total 
dumped electrical energy is around $305 \mathrm{kWh}$. If the $100 \mathrm{kWh}$ were used for water purification, they would result in the production of 5 times the water this small village of 100 inhabitants need. Another option is to use the pumped water for irrigation purposes, except for during the rainy season months (April, May, November, December) [71]. Moreover, in many systems the dumped power is used to provide hot water for daily usage. Another option could be the installation of a battery charging station facilitating the villages nearby, which may not have access to electricity network yet.

An example of a small industrial application is to use the extra power to run small flour mill. This was done in Ethiopia for a much bigger community [44], but still, it could be applied here considering a small mill of $3 \mathrm{~kW}$. Under this condition, the 'Excess Power' and 'Energy Excess' graphs are given in Figure 46 and Figure 47. The decrease of the dumped power is shown in Figure 46, while the not used energy reached approximately the $23 \%$ of the total production according to Figure 47. It could be further decreased by a combination of different actions mentioned above. It worth being noted at this point that the dumped energy was equal to $38 \%$ after the two-days simulation and $30 \%$ after the four days simulation.

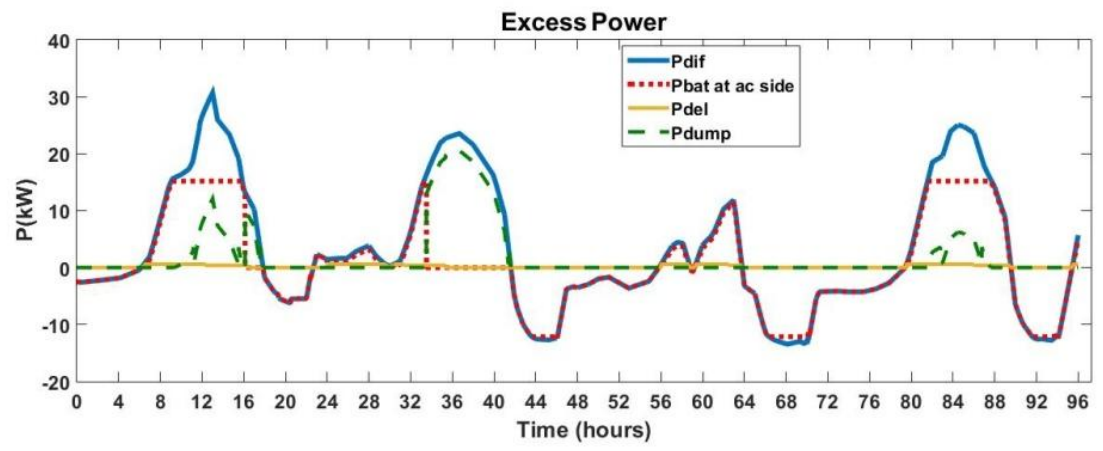

Figure 46. Power plots describing mainly the condition of excess power in the system for extended Case (i) when there is a small flour mill of $3 \mathrm{~kW}$ added to the system

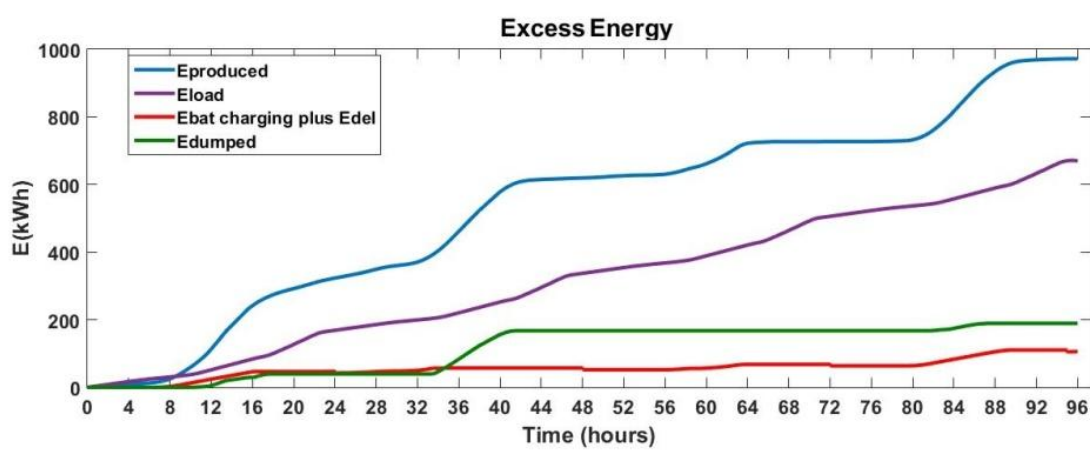

Figure 47. Plots of energy describing the management of the surplus of power in the system for extended Case (i) when there is a small flour mill of $3 \mathrm{~kW}$ added to the system

\subsubsection{Case (ii)}

Extending the simulation time in Case (ii) of July does not show so much variation as in September, since the wind speed remains high all these days, resulting in high overall produced power and high excess amounts of it. The power production and 'Excess Power' related plots are depicted in Figure 48(a) and (b) respectively, and once again the issue of additional needed actions to manage and productively utilize the excess power should be investigated, as it was done before. These days, there is no load shedding appeared, since the batteries always can cover the power demand during night time. Figure 49 shows that around $43 \%$ of the produced energy by the renewable energy sources fails to be utilized. 


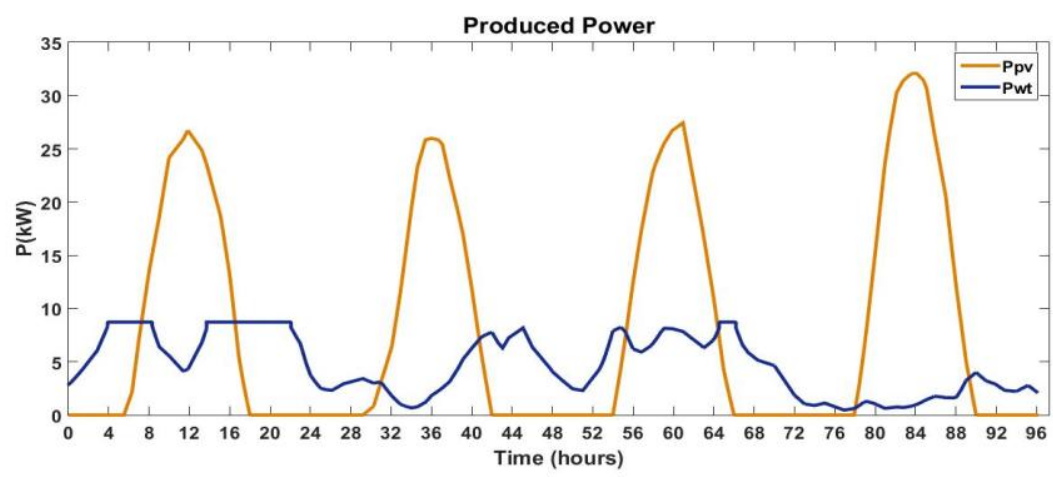

(a)

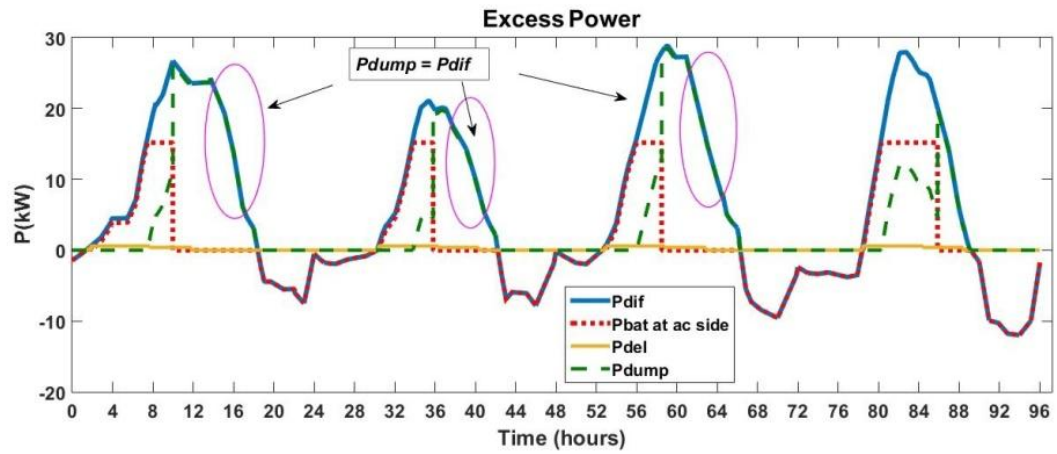

(b)

Figure 48. (a) Power produced by the photovoltaics and the wind turbine and (b) Power plots describing mainly the condition of excess power in the system during the 4 days of the extended Case (ii)

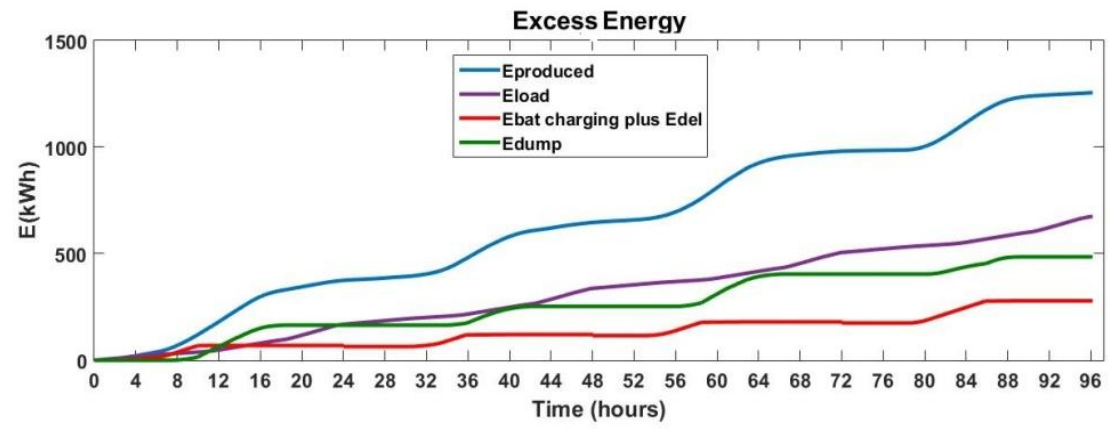

Figure 49. Plots of energy describing the management of the surplus of power in the system for extended Case (ii)

The batteries participate in the management of energy in these days too, but while they provide all the power needed during the evening time, they cannot absorb an important part of the excess energy appearing in the system, as their SOC reaches its maximum limit every day. The initial value of SOC was set to be $80 \%$, based on the high levels of available power during that time. The batteries are never deeply discharged during that time, as their available capacity never falls lower than $71 \%$ of its nominal capacity, while remaining for long periods of time at its maximum capacity. The graph showing the variations of $\mathrm{SOC}$ of the battery during the four days of July is given in Appendix IV.

\subsubsection{Case (iii)}

In this section, the results occurring from a longer simulation of case (iii) (in December) are reviewed. There will be two different simulations for this case: the first one will describe the normal operation of the microgrid under the registered weather conditions and the second one will describe the operation of the microgrid in the case of a hypothetical break down at one of the two inverters connecting the photovoltaic arrays to the ac bus, resulting in reducing at half the power injected by photovoltaics to the system. 
The power production from the photovoltaic array and the wind turbine during the 3 rd till the 5 th of December are depicted in Figure 50(a). In Figure 50(b), all the related with excess power plots are given: the power difference signal $P_{\text {dif, }}$, the power exchanged with the battery as it is measured at the ac bus $P_{\text {bat_at_acside, }}$ the power directed to the deferrable load $P_{\text {del }}$ and the dumped power $P_{\text {dump }}$. Observing Figure $50(b)$, one can understand that there is every day a part of power unused and a small part of load that is not covered by the batteries. The need for water purification and pumping is fully satisfied every day.

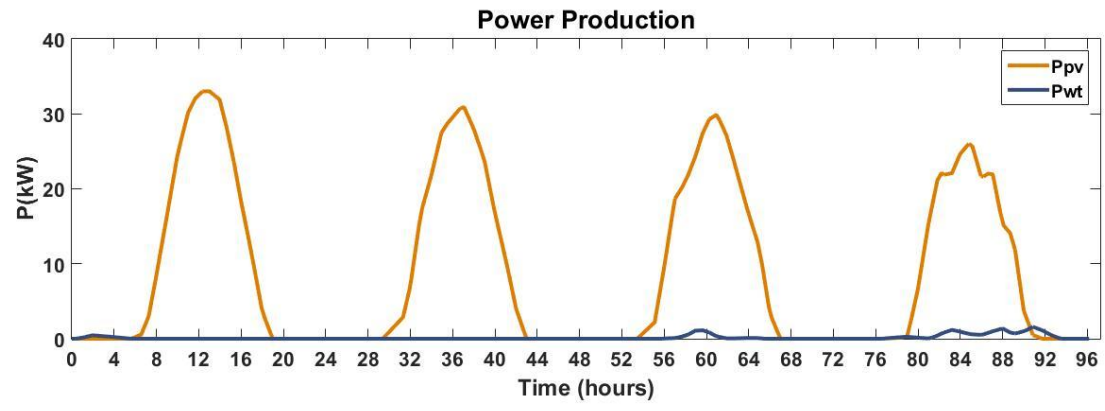

(a)

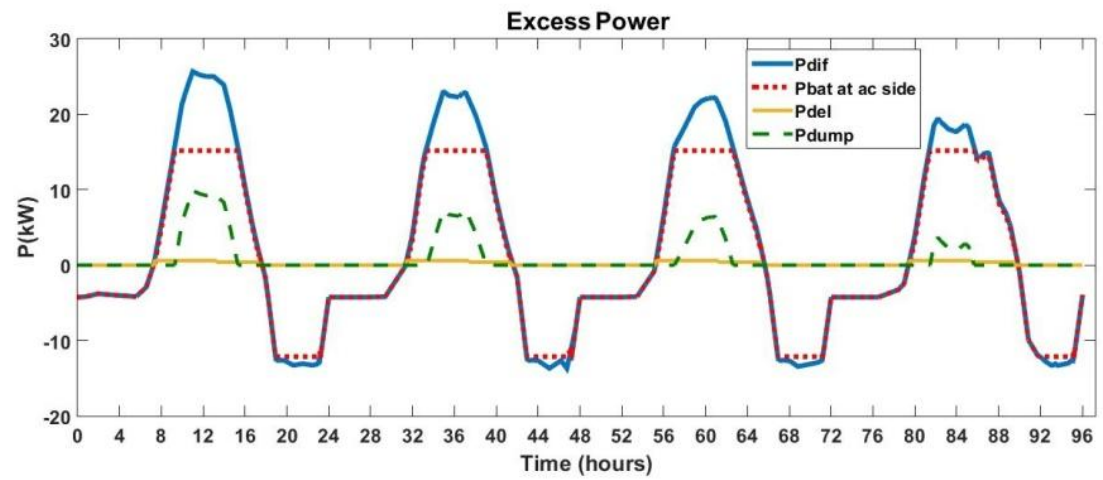

(b)
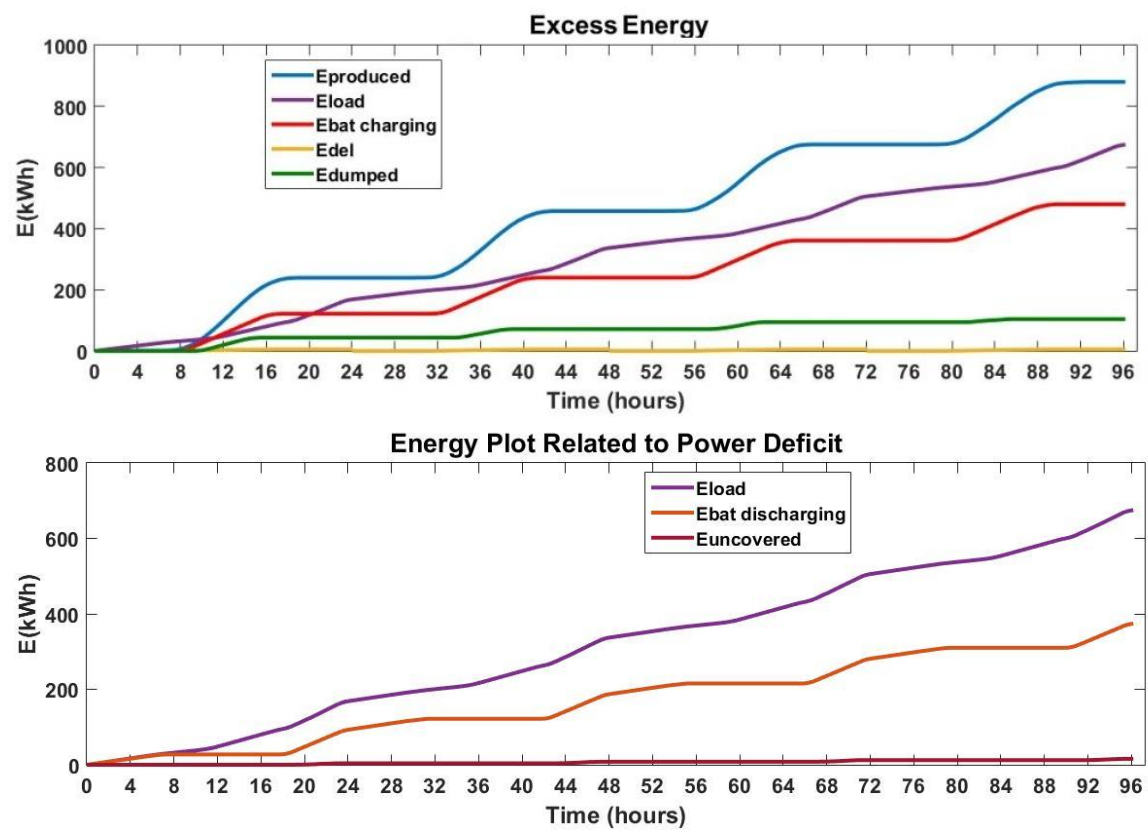

Figure 50. (a) Power produced by the photovoltaics and the wind turbine, (b) Power plots describing mainly the condition of excess power in the system, (c) Plots of energy describing the management of the surplus of power in the system, (d) The uncovered energy demand in relation to the original energy demand and the energy provided by the batteries while discharging during the 4 days for the extended Case (iii)

As far as the batteries are concerned, they remain charged above $60 \%$ of their nominal capacity through the whole time, without reaching their maximum limit of SOC as in other simulations. 
The initial state of charge for December simulation was set to $75 \%$. Moreover, the lowest measured state of charge is getting shorter and shorter day after day. In this case too, despite that the SOC is always inside the acceptable range, the batteries reach their maximum charge and discharge rate and that is why they can neither absorb nor provide any more electrical energy (like in times 8-16 hours or $43-47$ hours). The graph describing their SOC is given in Appendix IV.

The energy plots related with the case of excess power in the system are depicted in Figure 50(c) and show that almost $12 \%$ of the produced electrical energy is not used while around half of it is stored in the batteries to be used during night time. Here also, there is a significant margin for additional actions and applications in order to exploit this surplus of power and make the system more profitable for the inhabitants.

On the other hand, information regarding the handling of power shortage can be given through Figure 50(d). It shows firstly that the energy need remaining unmet is approximately $1.8 \%$ of the total energy demand, which is again inside the acceptable range and secondly, that batteries provide more than half of the electrical energy needed by the consumers. The peak value of load to be taken off is $1.5 \mathrm{~kW}$ during the second day of simulation, as one can see at the plot of load shedding is Appendix IV, if needed.

Continuing to the second possible operation of the microgrid under malfunction of the photovoltaic inverter during the second and third day [25-72 hours], the power production is plotted in Figure 51(a) and the 'Excess Power' curves in Figure 51(b). It is evident how strongly the power production has been decreased, especially these days where there is not enough wind power too. Dumped power occurs mainly during the first day, while the $\mathrm{P}_{\text {dif }}$ signal takes higher negative values and for longer periods of time than before. What is more, one can note that while during the first, second and fourth day the batteries can cover most of the demand, this does not happen during the third day. Then, the power deficit is partly covered by the diesel genset, but it also leads to significant amounts of load rejection. All these appear in Figure 51(c), which includes the measurements related with power deficit:

- the main power deficit of the system $P_{\text {def }}=\left|P_{\text {dif }}\right|$ when $\mathrm{P}_{\text {dif }}<0$

- the power provided by the batteries to the system $P_{\text {bat_discharging }}=\left|P_{\text {bat }}\right|$, when $\mathrm{P}_{\text {bat }}<$ 0

- the total load needed to be taken off $P_{\text {shed }}$ and

- the power coming by the diesel genset Pdg. 


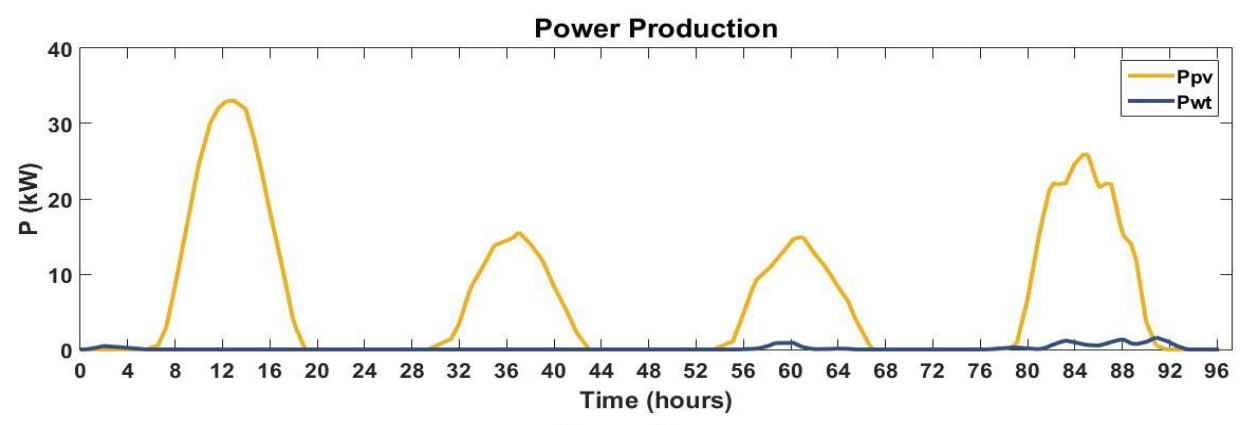

(a)

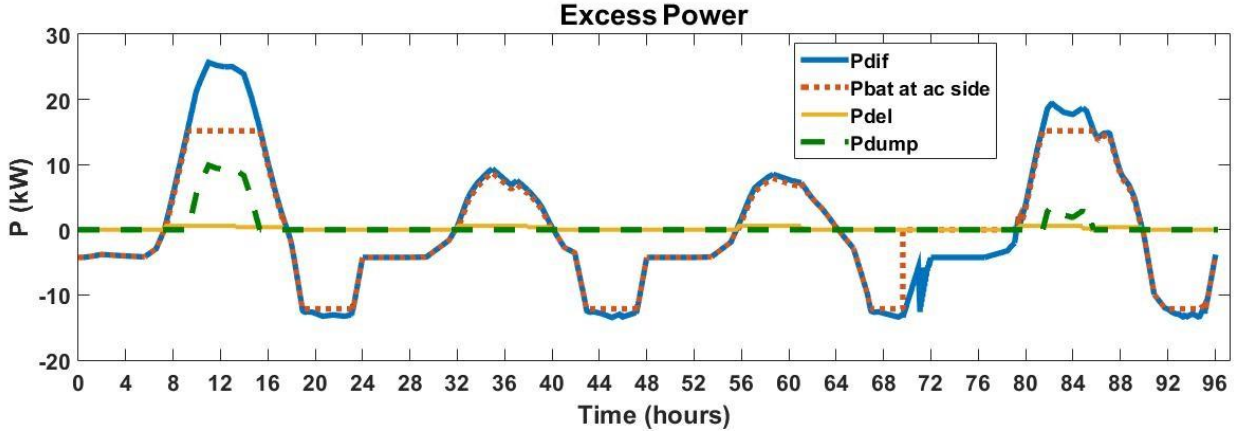

(b)

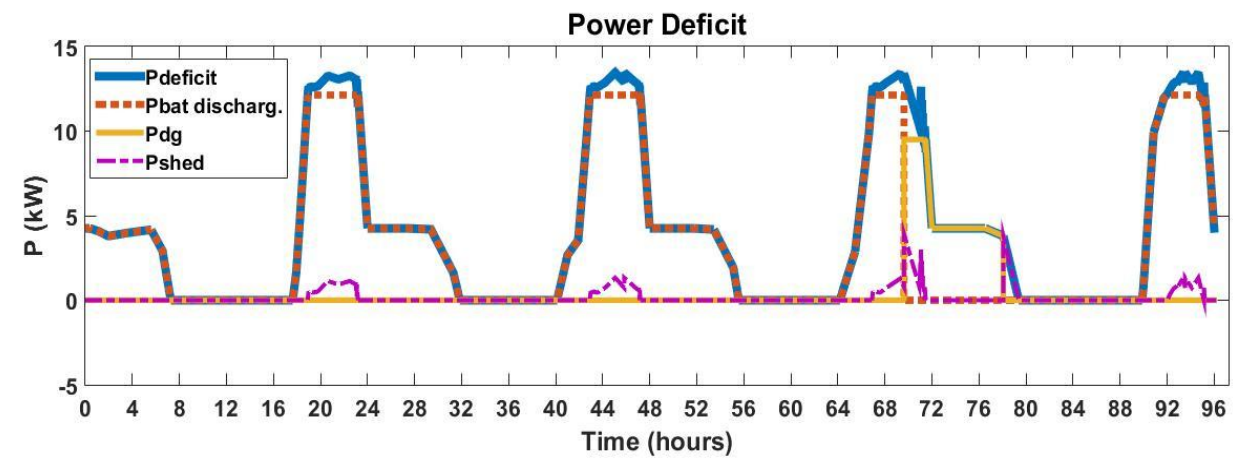

(c)

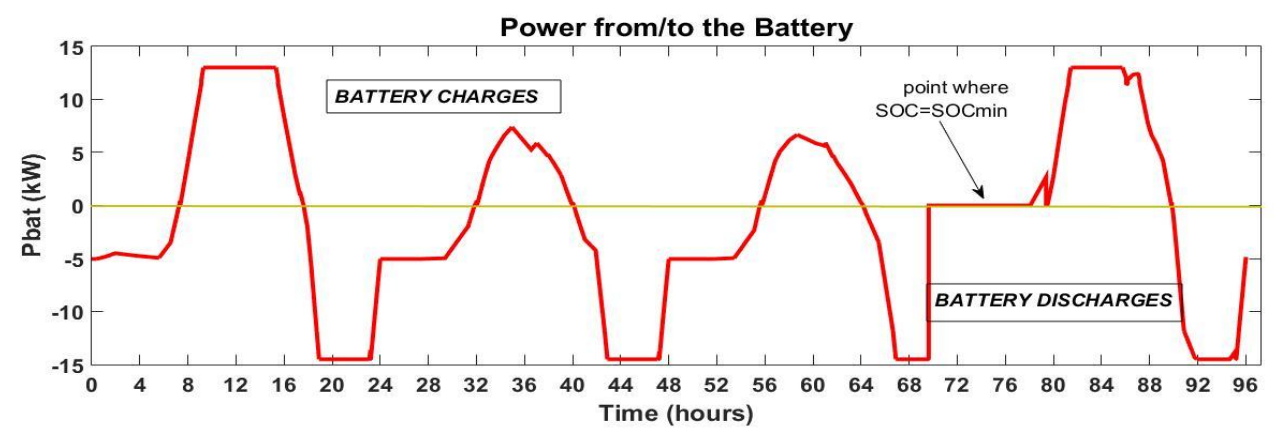

'd)

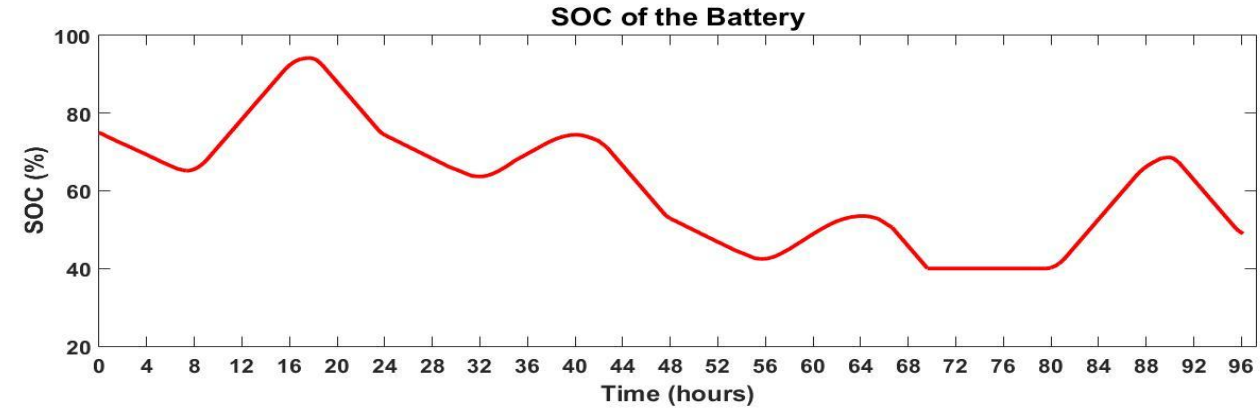

(e)

Figure 51. (a) Power produced by the photovoltaics and the wind turbine, (b) Power plots describing mainly the condition of excess power in the system, (c) Power signals strictly related with power deficit condition of the system, (d) Power absorbed and provided by the battery and (e) the SOC of the battery during the 4 days of December when one of the pv inverters breaks down during the $2^{\text {nd }}$ and $3^{\text {rd }}$ day 


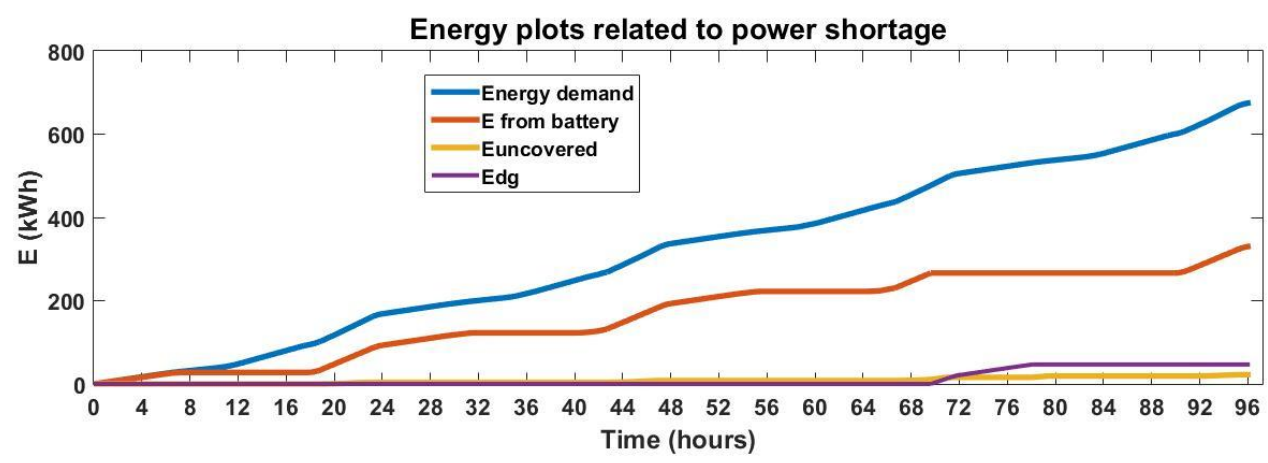

Figure 52. The total energy demand in comparison with the energy provided by the batteries and the diesel generator and the uncovered energy demand during the 4 December days with less pv power than expected

One can observe the decrease of the SOC mainly during the second and third day, when the batteries discharge trying to cover the power demand, at Figure 51(d) and (e). At around the 70th hour the batteries have reached their lowest limit of state of charge, $40 \%$, and they stop providing power to the system. Then, initially, a small part of the load is turned off and the diesel generator is activated when the power needed to be covered by itself reaches the amount of $0.4 * P_{d_{-} \_}=3.8 \mathrm{~kW}$. Figure 52 provides information on the energy provided by the batteries to cover the demand in comparison with the total energy demand, the energy contribution from the diesel genset and the energy that remained uncovered when loads were rejected.

The demand that the system has failed to satisfy is around $3.3 \%$ of the total, which is close to the maximum acceptable shortage, initially set at $3 \%$. If there were two diesel generators of 5 $\mathrm{kW}$ instead of one generator of $9.5 \mathrm{~kW}$, then the power low limit to activate the diesel generator would be around $2 \mathrm{~kW}$ and in this case there would be lower load shedding only during the third day, since the diesel generator would be triggered earlier. But this was also set as a possibility during the techno-economical evaluation (as sensitivity variable in HOMER) and it was not a suggested solution by the software.

It is also interesting to mention how the deferrable load is served during these days with low production rates. Only during the first day, there is enough of energy excess to cover the whole daily amount for water pumping and purification. During the second and third day, the available energy for this use is reduced and insufficient, but increases slowly during the fourth day. These days, the previously clean stored water can be used and then the water storage can be filled up the next days decreasing the amount of dumped power. The related plots are also given in Appendix IV.

\subsection{Outcomes}

This is the final section of the chapter devoted to the description of the simulation results and a final short analysis about the response of the model and the system is done.

Firstly, it seems that the model can adapt to the different conditions, following the designed operational strategy and method of power management. The results occurring are more close to the ones expected when the simulation time gets longer, but for short times (even two days) they deviate from what one would expect based on the results of the techno-economical optimization described in Chapter 3. On a modeling level, it can be further advanced in the field of battery bank control, but it facilitates the integration of complementary actions (as the milling application). Also, on a system design level, it can be further developed and improved in the future, in order to integrate different solutions to take advantage of the surplus of power and 
reconsider the diesel generator rated power, after assessing, of course, what is preferred: low but perhaps not rare load sheddings or more power generated by diesel genset with a bit more complex control. 


\section{Conclusion}

\subsection{Conclusion}

In this project, a hybrid autonomous power system was designed, modeled and simulated. It was designed with the aim to electrify a small remote village in Kenya and cover the basic needs of the inhabitants regarding electrification and clean water in a techno-economical way. It was modeled and simulated in order to attain a better picture of its operation, strengths and weaknesses.

First, a literature review was conducted in order to specify a representative load curve for the village comprising basic loads for the households, streetlights, loads of the primary school and water pumping and purification. Weather data of the region were acquired, including solar irradiance, temperature and wind speed. Considering the photovoltaics, the wind turbine, the diesel generator and the batteries as the basic components of the autonomous system, an extensive research was done aiming to determine their costs. Then, the HOMER software was used to implement the techno-economical optimization of the system resulting in an autonomous microgrid of $40 \mathrm{kWp}$ photovoltaics, $10 \mathrm{~kW}$ wind turbine, $9.5 \mathrm{~kW}$ diesel genset, batteries of total capacity $6.936 \mathrm{kAh}$, the primary load of the village and water pumping and purification as the deferrable load. During this process, it became apparent how important it is and how difficult it can be to find representative and reliable information and data in order to estimate the power demand in an unelectrified till that time region, as well as find reliable data on the costs and the provided equipment.

Subsequently, the autonomous hybrid power system was modeled in order to facilitate the assessment of different power management strategies, and more specifically the load following dispatch strategy. While the microgrid was modeled, it became apparent how the aspect of the elements one want to study affects the way of modeling. This is why logical operators and simple conditions were used in this case, to guide the power management in the system.

The simulations extended in time slots of several days exactly for the same reason; to show the results of the implementation of this operational strategy in the operation of the system and its performance during different periods of the year under different weather conditions. So, the three different cases involved initially 2 days and later 4 days time slots in September, July and December.

During the analysis of the results, various graphs were used to indicate the operation of the different components and an emphasis was given on the management of power while there was excess or deficit in the system. In the first case, either the batteries would be charged, or the deferrable load would be activated or the extra power would be dumped. In the case of deficit of power, either the batteries would be discharged, or the diesel generator would be turned on or some loads would be rejected. The results were not exactly as expected, but they were better when the simulation time got longer. There was the problem of the dumped power during the peak production hours, for which different alternatives have been suggested and could improve the overall efficiency of the microgrid. The possibilities of including a flour mill or pumping more water were investigated as ways of exploiting the excess power in favor of the inhabitants, showing positive results. Generally the model followed the desired strategy and provided a representative idea about the microgrid performance. 


\subsection{Future Work}

The work that has been done in the framework of this thesis can be used as basis for diverse future work.

In terms of modeling, the system controlling the charge rate of the battery can be further developed. Additionally, the way the model is built facilitates the integration of phasors and the implementation of the basic principles of droop control (using the characteristic curves of the inverters). If this is done, the reactive power will also be taken into account and more aspects of control will be examined.

Moreover, regarding the type of control, a centralized approach has been adopted. An implementation of a decentralized control method, though, like multi agents, could be valuable and produce really interesting results developing the microgrid's performance.

Finally, as far as the system and its services to the people are concerned, there are two aspects, which worth deeper consideration. First of all, it is the ability of the inhabitants to pay for the designed microgrid. There was not enough information on this matter and that is why it was not considered. But if it is to be a really representative case study, this is a parameter that cannot be ignored. Secondly, the additional services, which could be provided, on the basis of the existing amount of dumped power, should be further investigated and tested. 


\section{Bibliography}

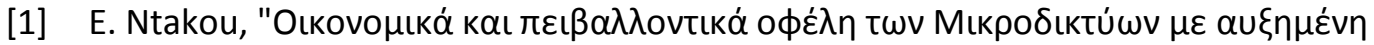

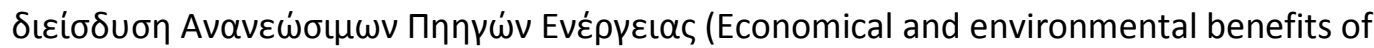
Microgrids with increased penetration of Renewable Energy Resources)," Master thesis, National and Technical University of Athens, Athens, 2011, http://artemisnew.cslab.ece.ntua.gr:8080/jspui/handle/123456789/5575.

[2] K. Tweed, "GreenTech Media," 09 July 2015. [Online]. Available: http://www.greentechmedia.com/articles/read/new-york-looks-to-cement-its-lead-asmicrogrid-capital-of-the-world. [Accessed 24 September 2015].

[3] "Microgrid Institute," 2014. [Online]. Available: http://www.microgridinstitute.org/aboutmicrogrids.html. [Accessed 24 September 2015].

[4] G. Venkataramanan and C. Marnay, "A Larger Role for Microgrids - Are Microgrids a Viable Paradigm for Electricity Supply Expansion?," IEEE power and energy magazine, May / June 2008.

[5] "Wikipedia - Appopriate Technology," [Online]. Available: https://en.wikipedia.org/wiki/Appropriate_technology. [Accessed 24 September 2015].

[6] D. Brandt, "Microgrids for Rural Electrification," in Symposium on Microgrids, Montreal, 2006.

[7] F. Katiraei, R. Iravani, N. Hatziargyriou and A. Dimeas, "Microgrids Management - Controls and Operation Aspects of Microgrids," IEEE power and energy magazine, 2008.

[8] C. Nayar, S. Islam, H. Dehbonei, K.Tan and H.sharma, "Power Electronics Handbook Devices, Circuits and Applications," in Power Electronics for Renewable Energy Sources, USA, Elsevier, 2011, pp. 723-766.

[9] C. D. Barley and C. B. Winn, "Optimal Dispatch Strategy in Remote Hybrid Power Systems," ELSEVIER Solar Energy, vol. 58, pp. 165-179, 1996.

[10] G. Dafermos, "P2P foundation - Kythnos Island Community Microgrid Project," [Online]. Available: http://p2pfoundation.net/Kythnos_Island_Community_Microgrid_Project. [Accessed 25 September 2015].

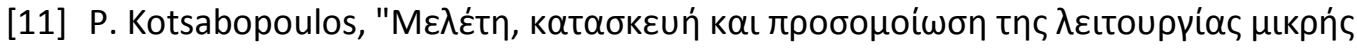

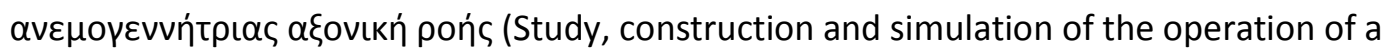
small wind turbine with an axial flow generator)," Master thesis, National Technical University of Athens, Athens, 2015, http://artemisnew.cslab.ece.ntua.gr:8080/jspui/handle/123456789/5156.

[12] "Microgrids - More Microgrids - The project," [Online]. Available: 
http://www.microgrids.eu/default.php. [Accessed 25 September 2015].

[13] "POLYCITY," Stuttgart Region Economic Development Corp., [Online]. Available: http://www.polycity.net/en/cerdanyola-barcelona-project.html. [Accessed 25 September 2015].

[14] A. Al-HAkim, G. M. R. Marie, c. Hioms, P. Kothari, L. Eugene and D. Mewton, "A Study for the Implementation of Microgrids and a Case Study of Bihar", Report, Imperial College London, 2011.

[15] N. G. Johnson, J. W. Glassmire and P. D. Lilienthal, "Comparing Power System Architectures for Domestic Lighting in Isolated Rural Villages with HOMER," in 2012 IEEE Global Humanitarian Technology Conference, Boulder, Colorado, 2012, http://ieeexplore.ieee.org/xpl/login.jsp?tp=\&arnumber=6387079\&url=http\%3A\%2F\%2Fiee explore.ieee.org\%2Fxpls\%2Fabs_all.jsp\%3Farnumber\%3D6387079.

[16] S. Rehman, M. M. Alam, J. Meyer and L. M. Al-Hadhrami, "Study of wind - pv - diesel hybrid power system for a village," ELSEVIER - RENEWABLE ENERGY, vol. 38, no. 1, pp. 258-268, 2012.

[17] S. T. Bahta, "Design and Analyzing of an Off-Grid Hybrid Renewable Energy System to Supply Electricity for Rural Areas," MSc Thesis, KTH, Stockholm, 2013, http://kth.divaportal.org/smash/get/diva2:653049/FULLTEXT01.pdf.

[18] S. Ashok, "Optimised model for community-based hybrid energy system," ELSEVIER Renewable Energy, vol. 32, no. 7, pp. 1155-1164, 2007.

[19] Y. Hongxing, Z. Wei and L. Chengzhi, "Optimal design and techno-economic analysis of a hybrid solar-wind power generation system," ELSEVIER - Applied Energy, vol. 86, no. 2, pp. 163-169, 2009.

[20] H. Asanol and S. Bandol, "Economic Analysis of Microgrids," in Power Converion Conference, Nagoya, 2007, http://ieeexplore.ieee.org/xpl/login.jsp?tp=\&arnumber=4239225\&url=http\%3A\%2F\%2Fiee explore.ieee.org\%2Fxpls\%2Fabs_all.jsp\%3Farnumber\%3D4239225.

[21] D. Bica, C. D. Dumitru, A. Gligor and A. -. V. Duka, "Isolated hybrid solar - wind - hydro renewable energy systems", in Renewable Energy, InTech, 2009, pp 297-315.

[22] P. Basak, A. Saha and S. Chowdhury, "Microgrid: Control technoques and modeling," in 44th Universities Power Engineering Conference, Glasgow, 2009, http://ieeexplore.ieee.org/xpl/login.jsp?tp=\&arnumber=5429547\&url=http\%3A\%2F\%2Fiee explore.ieee.org\%2Fxpls\%2Fabs_all.jsp\%3Farnumber\%3D5429547.

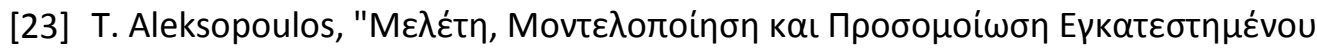
Mıкробıктúou (Study, Modelling and Simulation of an Installed Microgrid),"MSc Thesis, National Technical University of Athens, Athens, 2008, 
http://artemis.cslab.ntua.gr/el_thesis/artemis.ntua.ece/DT2009-0007/DT2009-0007.pdf.

[24] H. Wang and D. Zhang, "Accurate Load Sharing Contro in Autonomous Operation of Microgrid," in 7th International Power Electronics and Motion Control Conference, Harbin, 2012, http://ieeexplore.ieee.org/xpl/login.jsp?tp=\&arnumber=6259347\&url=http\%3A\%2F\%2Fiee explore.ieee.org\%2Fiel5\%2F6243571\%2F6259211\%2F06259347.pdf\%3Farnumber\%3D6259 347.

[25] J. M. Guerrero, M. Chandorkar, T. -. L. Lee and P. C. Loh, "Advanced Control Architectures for Intelligent Microgrids_Part I: Dentralized and Hierarchical Control," IEEE Transactions on Industrial Electronics, vol. 60, 2013.

[26] A. G. Tsikalakis and N. D. Hatziargyriou, "Centralized Control for Optimizing Microgrids Operation," in Power and Energy Society General Meeting, IEEE, San Diego, California, 2011, http://ieeexplore.ieee.org/xpl/login.jsp?tp=\&arnumber=4454000\&url=http\%3A\%2F\%2Fiee explore.ieee.org\%2Fxpls\%2Fabs_all.jsp\%3Farnumber\%3D4454000.

[27] M. Pipattanasomporn, H. Feroze and S. Rahman, "Multi - Agent Systems in a Distributed Smart Grid : Design and Implementation," in Power Systems Conference and Exposition, IEEE/PES, Seattke, WA, 2009, http://ieeexplore.ieee.org/xpl/login.jsp?tp=\&arnumber=4840087\&url=http\%3A\%2F\%2Fiee explore.ieee.org\%2Fxpls\%2Fabs_all.jsp\%3Farnumber\%3D4840087.

[28] C. Li, T. Dragicevic, M. G. Plaza, F. Andrade, J. C.Vasquez and J. M. Guerrero, "Multiagent Based Distributed Control for State-of -Charge of Distributed Energy Storage in DC microgrids," in 40th Annual Conference of the IEEE Industrial Electronics Society , Dallas, TX, 2014, .

[29] H. Han, X. Hou, J. Yang, J. Wu, M. Su and J. M. Guerrero, "Review of Power Sharing Control Strategies for Islanding Operation of AC Microgrids," IEEE Transaction on Smart Grid, 2015, http://ieeexplore.ieee.org/xpl/login.jsp?tp=\&arnumber=7121016\&url=http\%3A\%2F\%2Fiee explore.ieee.org\%2Fiel7\%2F5165411\%2F5446437\%2F07121016.pdf\%3Farnumber\%3D7121 016.

[30] E. Dursun and O. Kilic, "Comparative Evaluation of Different Power Management Strategies of a Stand-Alone PV/Wind/PEMFC Hybrid Power System," ESLEVIER Electrical Power and Energy Systems, vol. 34, pp. 81-89, 2012.

[31] W. Su, "Microgrid Modeling, Planning and Operation," MSc Thesis, Virginia Polytechnic Institute, Blacksburg, Virginia, 2009.

[32] P. Nema, R. Nema and S. Ragnekar, "A current and future state of art development of hybrid energy system using wind and pv-solar : A review," ELSEVIER Renewable and Sustainable ENergy Review, vol. 13, pp. 2096-2103, 2009.

[33] D. S. -. Koussa, M. Haddadi and M. Belhamel, "Economic and Technical Study of a Hybrid System (wind - photovoltaic - diesel) for Rural Electrification in Algeria," ELSEVIER Applied 
Energy, vol. 86, pp. 1024-1030, 2009.

[34] "HOMER ENERGY," [Online]. Available: http://www.homerenergy.com/index.html. [Accessed April 2015].

[35] K. F. Sklivaniotis, "Integrated Techno-Economic Comparative and Socio-Economic Impact Study for Increasing Energy Access in Rural Kenya," Master Thesis, KTH, Stockholm, 2014, http://kth.diva-portal.org/smash/get/diva2:790483/FULLTEXT01.pdf.

[36] S. Phrakonkham, J.-Y. L. Chenadec, D. Diallo, G. Remy and C. MArchand, "Reviews on MlcroGrid Configuration and Dedicated Hybrid System Optimization Tools: Application in Laos," Engineering Journal, vol. 14, no. 3, 2010.

[37] "The World Factbook - Kenya," C.I.A., [Online]. Available: https://www.cia.gov/library/publications/the-world-factbook/geos/ke.html. [Accessed 27 April 2015].

[38] "reegle," [Online]. Available: http://www.reegle.info/policy-and-regulatory-overviews/KE. [Accessed 13th April 2015].

[39] Kenya Renewable Energy Association, "Overview of the Ministry of Energy and Petroleum's Energy Sector Investment Prospectus," Energy Digest, issue 2, pp 6-7, 2014.

[40] "The World Bank - Energy \& Mining," [Online]. Available: http://data.worldbank.org/topic/energy-and-mining. [Accessed 2015].

[41] H.Camblong, J.Sarr, A. Niang, O.Curea, J. Alzola, E. Sylia and M.Santos, "Micro-grids project, Part 1: Analysis of Rural Electrification with High Content of Renewable Energy Sources in Senegal," Renewable Energy (Elsevier), vol. 34, pp. 2141-2150, 2009.

[42] Y. Himri, A. B. Stambouli, B. Draoui and S. Himri, "Techo-economical study of hybrid power system for a remote village in Algeria," ELSEVIER - ENERGY, vol. 33, no. 7, pp. 1128-1136, 2008.

[43] J. Lukuyu, "Wind-diesel Microgrid System for Remote Villages in Kenya," in North American Power Symposium, Champaign, IL, 2012, http://ieeexplore.ieee.org/xpl/login.jsp?tp=\&arnumber=6336319\&url=http\%3A\%2F\%2Fiee explore.ieee.org\%2Fiel5\%2F6329735\%2F6336304\%2F06336319.pdf\%3Farnumber\%3D6336 319.

[44] G. Bekele and G. Tadesse, "Feasibility Study of Small Hydro/PV/Wind Hybrid System for Offgrid Rural Electrification in Ethiopia," ELSEVIER - Applied Energy, vol. 97, pp. 5-15, 2012.

[45] Wikipedia, "Education in Kenya," [Online]. Available: http://en.wikipedia.org/wiki/Education_in_Kenya. [Accessed April 2015].

[46] E. Friends, "CFL VS Incadescent," [Online]. Available: http://www.earthsfriends.com/cfl-vs- 
incandescent/. [Accessed April 2015].

[47] C. Nayar, S. Islam, H. Dehbonei and H. K.Tan, "Power Electronics Handbook - Devices, Circuits and Applications," in Power Electronics for Renewable Energy Sources, USA, Elsevier, 2011, pp. 723-766.

[48] "Standard TMY Data," The University of Wiskonsin - Madison, [Online]. Available: http://sel.me.wisc.edu/trnsys/weather/standard_tmy.htm. [Accessed 2 October 2015].

[49] P. G. I. Weather Analytics, "What are TMY and AMY files?", http://www.weatheranalytics.com/images/media/TMY_and_AMY_Files.pdf.

[50] The University of Wisconsin - Madison, [Online]. Available: http://sel.me.wisc.edu/trnsys/mailinglist/archive2004/msg00636.html. [Accessed 2 October 2015].

[51] "meteonorm.com," Meteotest, [Online]. Available: http://meteonorm.com/. [Accessed 2 October 2015].

[52] J. Alzola, I.Vechiu, H.Camblong, M.Santos, M.Sall and G.Sow, "Microgrids Project, Part 2: Design of an Eletrification Kit with High Content of Renewable Energy Sources in Senegal"," Renewable Energy (Elsevier), vol. 34, pp. 2151-2159, 2009.

[53] T. Suwannakum, "Mini-Grid System for Rural Electrification in the Great Mekong Sub Regional Countries," kassel university press GmbH, Kassel, 2007.

[54] P. Loka, S. Moola, K. Polsani, S. Reddy, S. Fulton and A. Skumanich, "A case study for microgrid PV: lessons learned fom a rural electrification project in India," Progress in Photovoltaics: Research and Applications, vol. 22, no. 7, pp. 733-743, 2014.

[55] "Solar PV Systems," Kenya Renewable Energy Association, [Online]. Available: http://kerea.org/renewable-sources/solar-pv-systems/. [Accessed April 2015].

[56] J. Ondraczek, "Are We There Yet? Improving Solar PV Economics And Power Planning in Developing Countries: The Case of Kenya," Renewable and Sustainable Energy Reviews, vol. 30, pp. $604-615,2014$.

[57] A. Eales, "Locally Manufactured Small Wind Turbines in Ethiopia:Is the Levelised Cost of Energy Competitive with Alternatives for Rural lectrification and if so, where?," academia.edu [Accessed April 2015], 2014.

[58] "the green energy shop," [Online]. Available: http://www.thegreenenergyshop.ie/smawindy-boy-2/. [Accessed April 2015].

[59] GlobalPetrolPrices.com, "Kenyan Diesel Prices, liter," [Online]. Available: http://www.globalpetrolprices.com/Kenya/diesel_prices/. [Accessed April 2015].

[60] A. Khamis, M. Nasir, A. Mohamed and H. Shareef, "Design and Simulation of Small Scale 
Microgrid Testbed," in Third International Conference on Computational Intelligence, Modelling and Simulation, 2011, http://ieeexplore.ieee.org/xpl/login.jsp?tp=\&arnumber=6076372\&url=http\%3A\%2F\%2Fiee explore.ieee.org\%2Fxpls\%2Fabs_all.jsp\%3Farnumber\%3D6076372.

[61] J. Mirez, H. Chamorro, C. Ordonez and R.Moreno, "Energy Management of Distributed Resources in Microgrids," in Circuits and Systems, 2014 IEEE $5^{\text {th }}$ Colombian Workshop, Bogota, 2014, http://ieeexplore.ieee.org/xpl/articleDetails.jsp?reload=true\&arnumber=6994607 .

[62] H. Mita, "Simplified Model of a Small Scaled Microgrid," Mathworks, http://www.mathworks.com/examples/simpower/4226-simplified-model-of-a-smallscaled-micro-grid .

[63] J. R. Hernaz, J. Campayo, J.Larranaga, E. Zulueta, O. Barambones, J. motrico, U. F. Gamiz and I. Zamora, "Two Photovoltaic Cell Simulation Models in Matlab/Simulink," International Journal on 'echnical and Physical Problems of Engineering', vol. 10, no. 4, pp. 45-51, 2012.

[64] C. Solar, "Quartech CS6P-255 / 260P," Canadian Solar, [Online]. Available: http://www.canadiansolar.com/down/en/Datasheet_Quartech_CS6P-P_en.pdf. [Accessed May 2015].

[65] S. S. T. AG, "SMA [Products- Installation Manual]," [Online]. Available: http://files.sma.de/dl/8552/STP10-17TL-IA-en-32.pdf. [Accessed June 2015].

[66] Senwei, "Senwei - Products - SW-10kW," [Online]. Available: http://www.windpowercn.com/products/18.html. [Accessed August 2015].

[67] M. Deshmkh and S. Deshmukh, "Modeling of Hybrid Renewable Energy SYstems," Renewable and Sustainable Energy Reviews - Science Direct - ELSEVIER, vol. 12, no. 1, pp. 235-249, 2008.

[68] X. Bracke, "Maximum Power Point Tracking of Small Wind Turbines with a Full Active Rectifier," Universiteit Gent, 2014.

[69] "Rolls Battery Engineering - Batteries," [Online]. Available: http://rollsbattery.com/catalog/. [Accessed May 2015].

[70] T. Lambert, "How HOMER Calculates the Radiation Incident on the PV Array," HOMER help, 2007.

[71] "EXPERT AFRICA (Kenya Information)," [Online]. Available: https://www.expertafrica.com/kenya/info/kenya-weather-and-climate. [Accessed 20 September 2015].

[72] M. Ranabolbo, B. D. Lega, D. V. Ferrenbach, L. Ferrer-Marti, R. P. Moreno and A. G. -. Villoria, "Renewable Energy Projects to Electrify Rural Communities at Cape Verde," 
ELSEVIER - Applied Energy, vol. 118, pp. 280-291, 2014.

[73] N. G. Hohnson, J. W. Glassmire and P. D. Lilienthal, "Comparing Power System Architectures for Domestic Lighting in Isolated Rural Villages with HOMER," in 2012 IEEE Global Humanitarian Technology Conference, Boulder, Colorado, 2012, http://ieeexplore.ieee.org/xpl/login.jsp?tp=\&arnumber=6387079\&url=http\%3A\%2F\%2Fiee explore.iee.org\%2Fxpls\%2Fabs_all.jsp\%3Farnumber\%3D6387079.

[74] K. Ajao, O.A.Oladosu and O. Popoola, "Using HOMER Power Optimization Software for Cost Benefit Analysis of Hybrid-Solar Powe Generation Relative to Utility Cost in Nigeria," www.arpapress.com, 2011.

[75] V. A. Ani and B. Abubakar, "Feasibility Analysis and Simulation of Integrated Renewable Energy System for Power Generation: A Hypothetical Study of Rural Health Clinic," Journal of Energy from Hindawi Publishing Corporation, vol. 2015, 2014. 


\section{List of Figures}

Figure 1. An indicative figure of the studied power system with the $p v$, the wind turbine, the

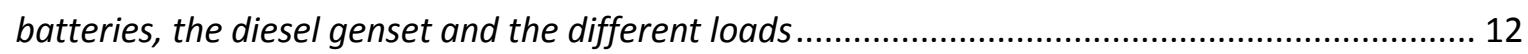

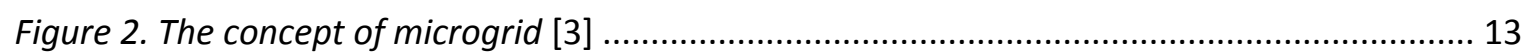

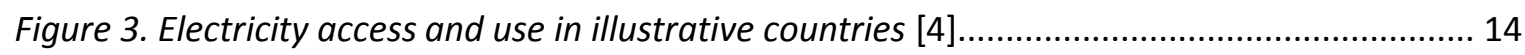

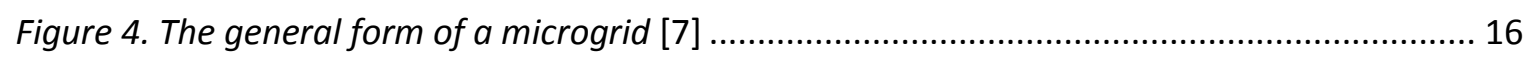

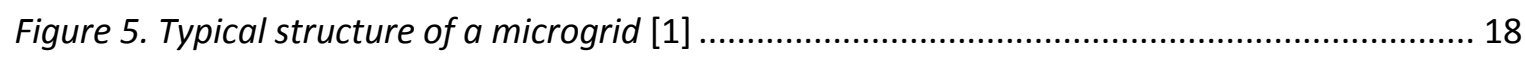

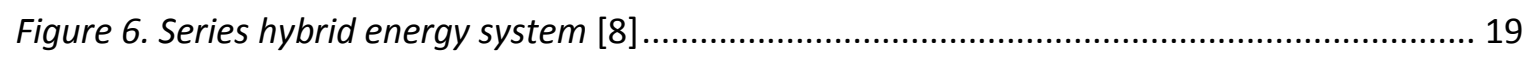

Figure 7. A PV-diesel hybrid energy system in switched configuration [8] ................................... 19

Figure 8. Parallel configuration of (a) a DC and (b) an AC coupled microgrid [8] ........................ 19

Figure 9. The microgrid installed at location Gaidouromantra in Kythnos [11] ............................ 20

Figure 10. (a) The Bulyansungwe microgrid with its future expansion and (b) the pumping system

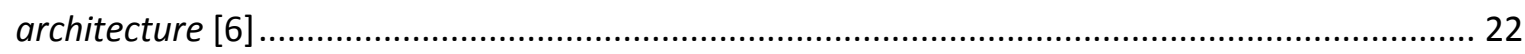

Figure 11. The load curve during a weekday with open school................................................... 27

Figure 12. Average monthly radiation data over a year for a village near Garissa ......................... 28

Figure 13. Average wind speed data over a year for a village near Garissa .................................. 28

Figure 14. The scheme of the hybrid power system as it was made for HOMER simulation ......... 28

Figure 15. The net present cost of all the power system components ........................................ 31

Figure 16. Nominal Cash Flow in relation with the time (years) of operation................................ 31

Figure 17. The monthly average electric production ................................................................ 31

Figure 18. Comparison of the electrification cost with the autonomous power system in relation

to the grid extension cost. The breakeven grid extension distance is at $19.3 \mathrm{~km} \mathrm{............................} 32$

Figure 19. Frequency histogram of the State Of Charge of the battery bank ............................... 32

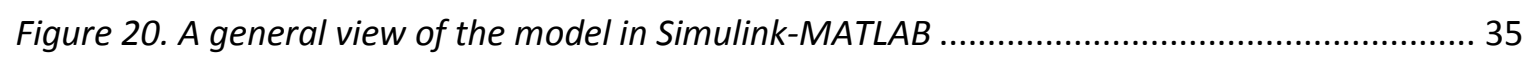

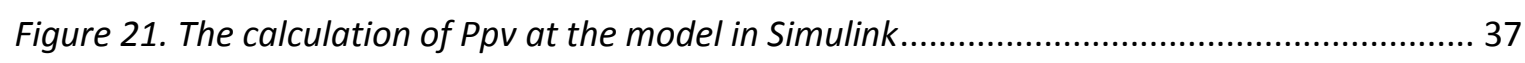

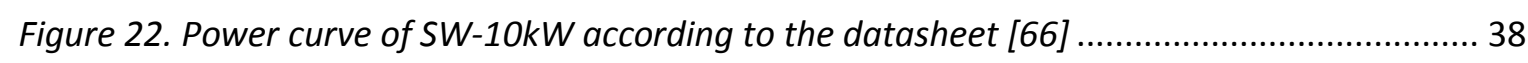

Figure 23. Wind Turbine Power Output Curve according to eq. (4) ................................................ 39

Figure 24. The calculation of Pwt at the model in Simulink ........................................................ 40

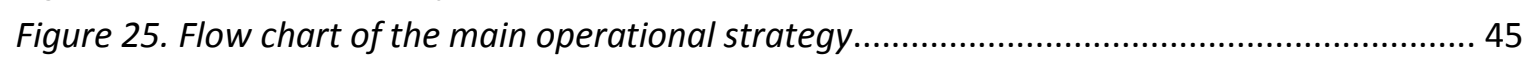

Figure 26. The average monthly values of wind speed at the village in Kenya ............................... 46

Figure 27. The average values of daily irradiation for every month in the village in Kenya .......... 46

Figure 28. The (a) solar irradiance, (b) wind speed and (c) ambient temperature on the $15^{\text {th }}-16^{\text {th }}$ of

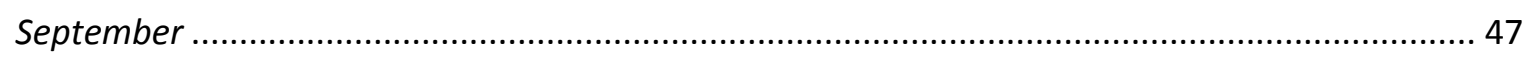

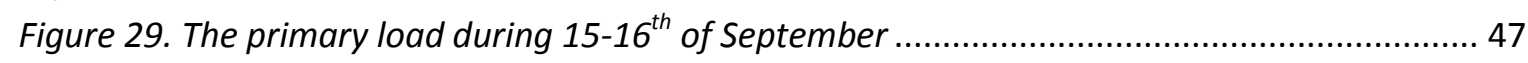

Figure 30. The (a) solar irradiance, (b) wind speed and (c) ambient temperature on the $20^{\text {th }}-21^{\text {st }}$ of

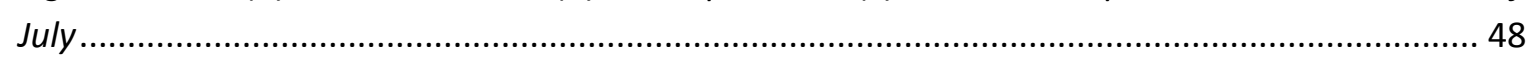

Figure 31. The (a) solar irradiance, (b) wind speed and (c) ambient temperature on the $3^{\text {rd }}-4^{\text {th }}$ of

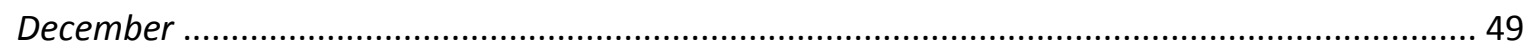

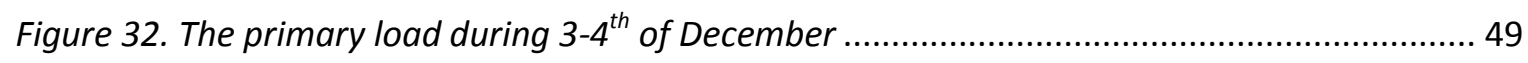

Figure 33. (a) Power produced by the photovoltaics and the wind turbine, (b) Power demand and

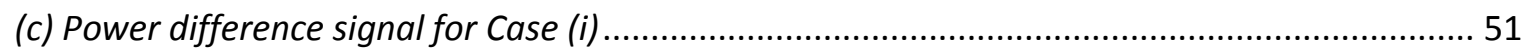

Figure 34 (a) Power plots describing mainly the condition of power excess in the system,

Deferrable load (b) detailed power consumption and (c) energy consumption, (d) Power absorbed and provided by the battery and (e) the SOC of the battery, (f) Power output from diesel genset and (g) Load that was rejected because of deficit of power for Case (i). 
Figure 35. Plots of energy describing the management of the surplus of power in the system for

Case (i).....

Figure 36. Comparison of the battery bank operation in terms of SOC for different allowed charge rates for Case (i)

Figure 37. (a)Power produced by the photovoltaics and the wind turbine, (b) Power demand, (c) Power plots describing mainly the condition of power excess in the system, (d) Plots of energy describing the management of the surplus of power in the system for Case (ii) 56 Figure 38. (a)Power produced by the photovoltaics and the wind turbine, (b) Power demand, (c) Power plots describing mainly the condition of power excess in the system, (e) Load failed to be satisfied in comparison with the total primary load for Case (iii)

Figure 39. Plots of energy describing the management of the surplus of power in the system for

Case (iii)

Figure 40. (a) Power produced by the photovoltaics and the wind turbine and (b) Power difference signal during the 4 days for the extended Case (i)

Figure 41. (a) Power plots describing mainly the condition of excess power in the system, (b) that was rejected because of deficit of power in relation to the total power demand, (c) Power absorbed and provided by the battery and (d) the SOC of the battery, (e) Deferrable load (a) power consumption for extended Case (i).....

Figure 42. The uncovered energy demand in relation to the original energy demand for extended

Case (i)

Figure 43. Deferrable load energy consumption for extended Case (i).....

Figure 44. Deferrable load (a) power and (b) energy during the 4rth day of the simulation with the aim to compensate for the lost water from storage during the $3^{\text {rd }}$ day.

Figure 45. Plots of energy describing the management of the surplus of power in the system for the extended Case (i).....

Figure 46. Power plots describing mainly the condition of excess power in the system for extended Case (i) when there is a small flour mill of $3 \mathrm{~kW}$ added to the system.....

Figure 47. Plots of energy describing the management of the surplus of power in the system for extended Case (i) when there is a small flour mill of $3 \mathrm{~kW}$ added to the system.

Figure 48. (a) Power produced by the photovoltaics and the wind turbine and (b) Power plots describing mainly the condition of excess power in the system during the 4 days of the extended Case (ii)

Figure 49. Plots of energy describing the management of the surplus of power in the system for extended Case (ii)

Figure 50. (a) Power produced by the photovoltaics and the wind turbine, (b) Power plots describing mainly the condition of excess power in the system, (c) Plots of energy describing the management of the surplus of power in the system, (d) The uncovered energy demand in relation to the original energy demand and the energy provided by the batteries while discharging during the 4 days for the extended Case (iii) 66

Figure 51. (a) Power produced by the photovoltaics and the wind turbine, (b) Power plots describing mainly the condition of excess power in the system, (c) Power signals strictly related with power deficit condition of the system, (d) Power absorbed and provided by the battery and (e) the SOC of the battery during the 4 days of December when one of the pv inverters breaks down during the $2^{\text {nd }}$ and $3^{\text {rd }}$ day..... 
Figure 52. The total energy demand in comparison with the energy provided by the batteries and the diesel generator and the uncovered energy demand during the 4 December days with less $p v$ power than expected

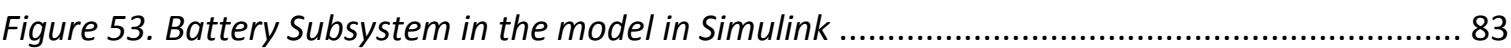

Figure 54. Battery's Parameters Subsystem in the model in SImulink .

Figure 55. The Dump Load subsystem of the model in Simulink where the dumped power and unused energy are calculated.

Figure 56. (a) The Battery Charging Conditions and (b) the Battery Discharging Conditions subsystems of the model generating that activating signals BAT_CH and BAT_DISCH respectively

Figure 57. The Diesel generator and Load Shedding Subsystem of the model in Simlink where the power output of the diesel genset as well as the load rejection and the uncovered energy demand

Figure 58. The Deferrable Load subsystem model in Simulink with the control part with logical operators and the integrators for calculating the energy consumption (The input with magenta color is the $P_{\text {dif }}$ signal, the green one is the SOC of the batteries, the light blue is the $E_{d e l}$ the orange blocks are all the related block with the signal DL_ON, the yellow blocks are for water treatment and the grey for water pumping

Figure 59. The Control of Diesel Genset Operation Mode Subsystem where if the load shedding should happen is decided as well as if the generator should be switched on. (The green signal $p_{\text {check }}$ is an auxiliary signal, through which one can follow if the model works appropriately in the case of power deficit)

Figure 60. (a) Power absorbed and provided by the battery and (b) the SOC of the battery for Case (ii).

Figure 61. (a) Power absorbed and provided by the battery and (b) the SOC of the battery for Case (iii).

Figure 62. Comparison of the battery bank operation in terms of (a) SOC and (b) power exchange and (c) Comparison of the occurring $P_{\text {dump }}$ for different allowed maximum charge rates for Case (iii)

Figure 63. The SOC of the battery for the extended Case (ii) 94

Figure 64. (a)The SOC of the batteries and (b) The load that was rejected because of deficit of power in relation to the total power demand for extended Case (iii)

Figure 65. Deferrable load (a) power consumption and (b) energy consumption during the 4 December days with less pv power than expected. 


\section{Appendix I}

In this Appendix, the reader can see the most important figures of the microgrid model as it is created in Simulink MATLAB.

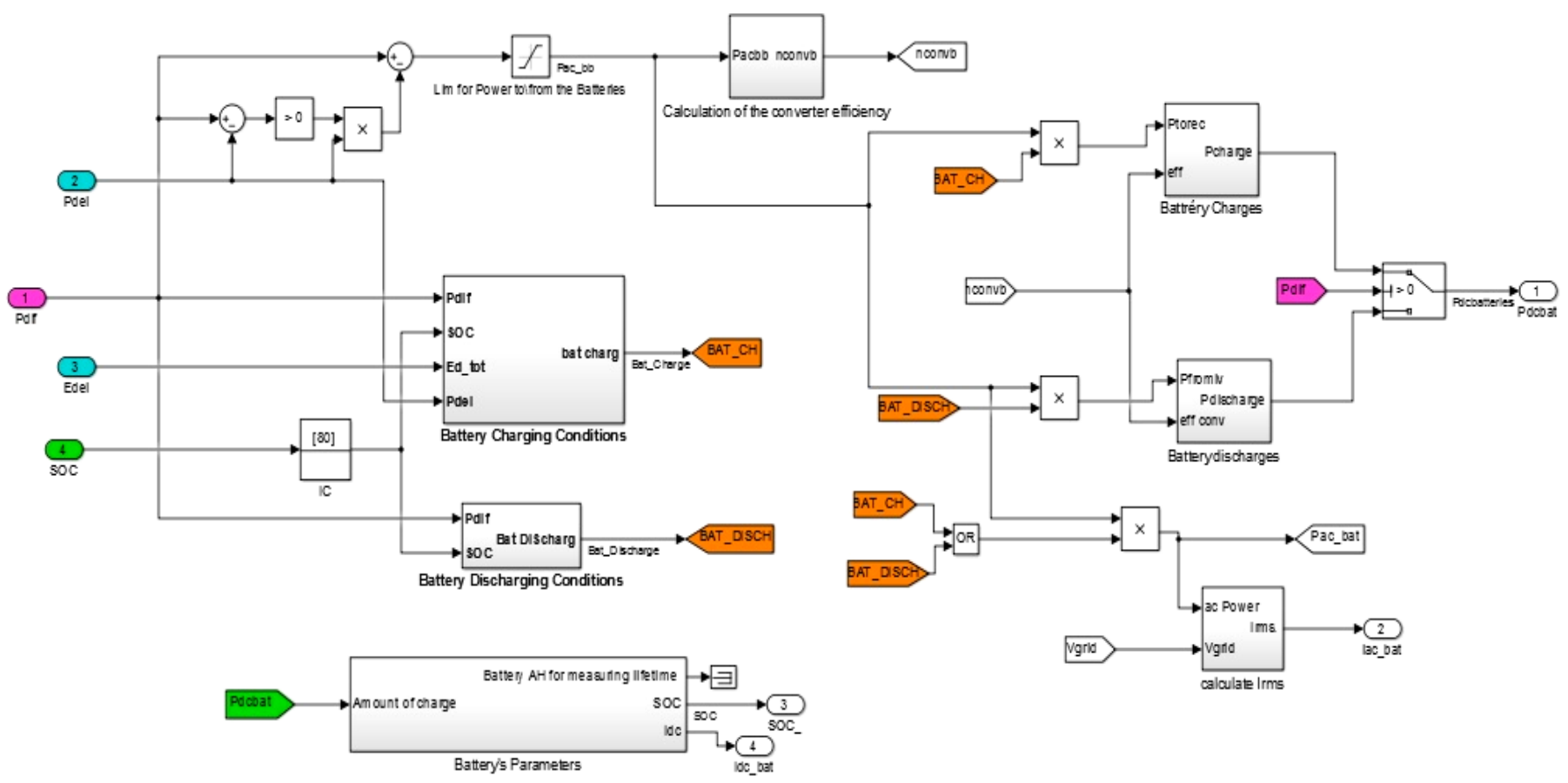

Figure 53. Battery Subsystem in the model in Simulink

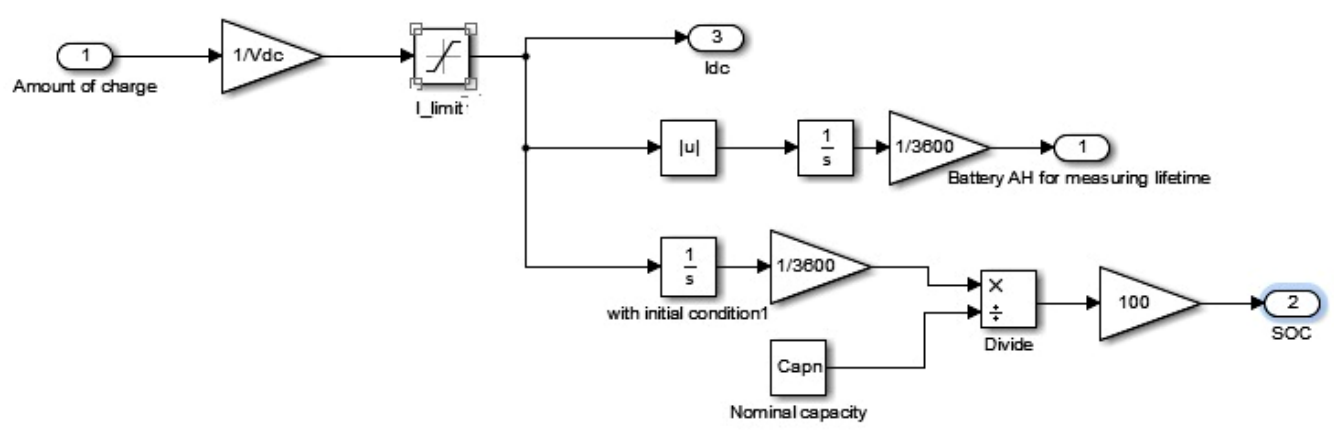

Figure 54. Battery's Parameters Subsystem in the model in SImulink

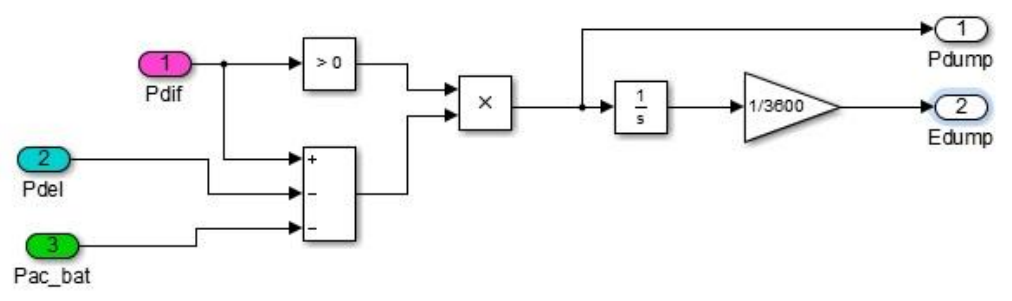

Figure 55. The Dump Load subsystem of the model in Simulink where the dumped power and unused energy are calculated 


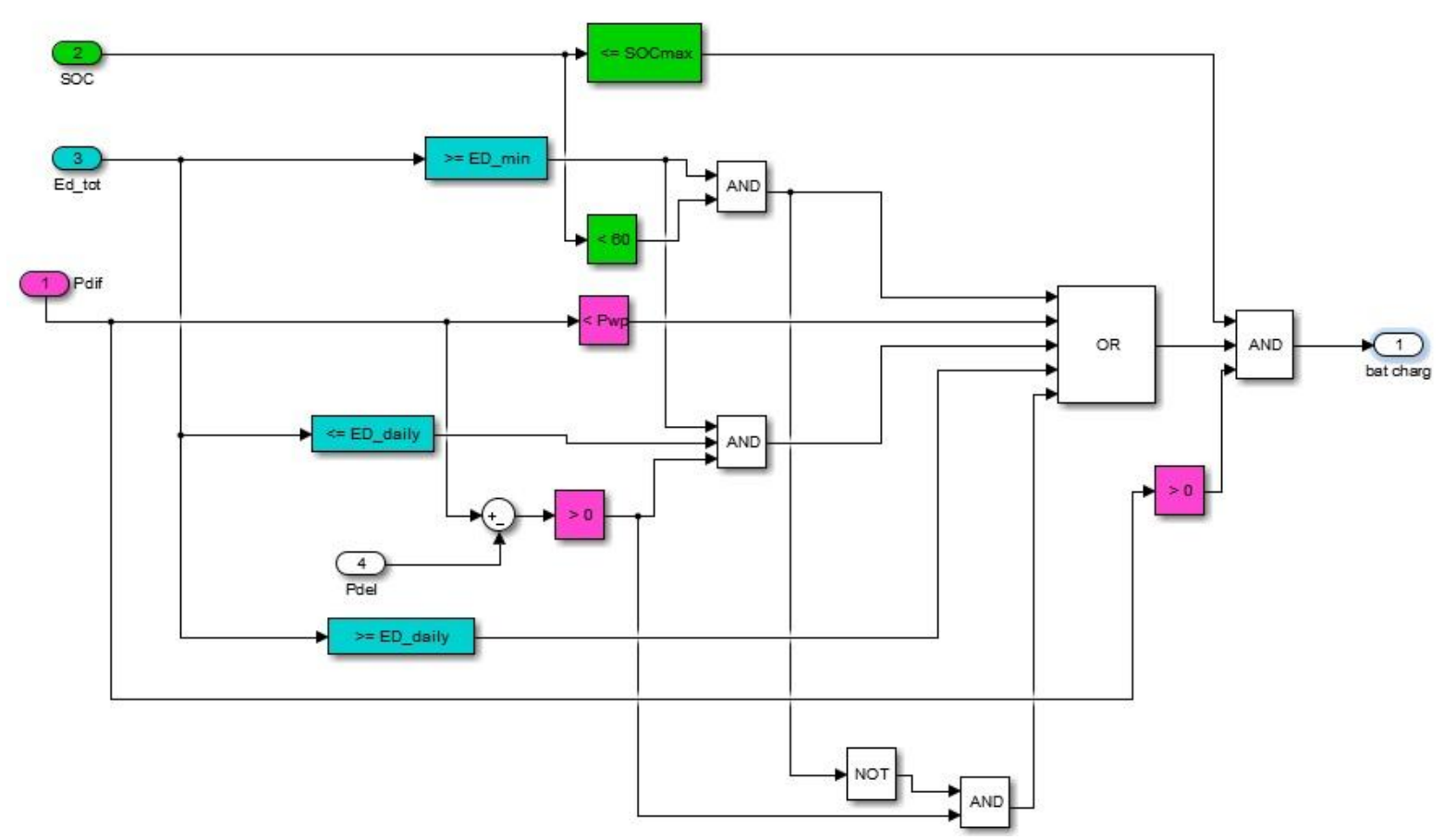

(a)

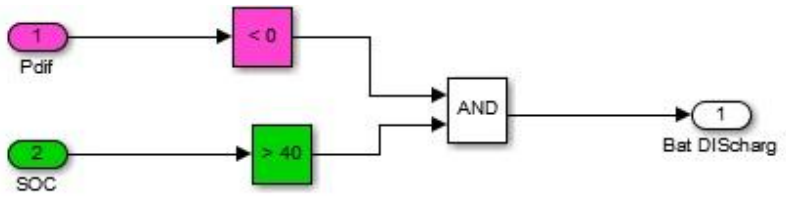

(b)

Figure 56. (a) The Battery Charging Conditions and (b) the Battery Discharging Conditions subsystems of the model generating that activating signals BAT_CH and BAT_DISCH respectively

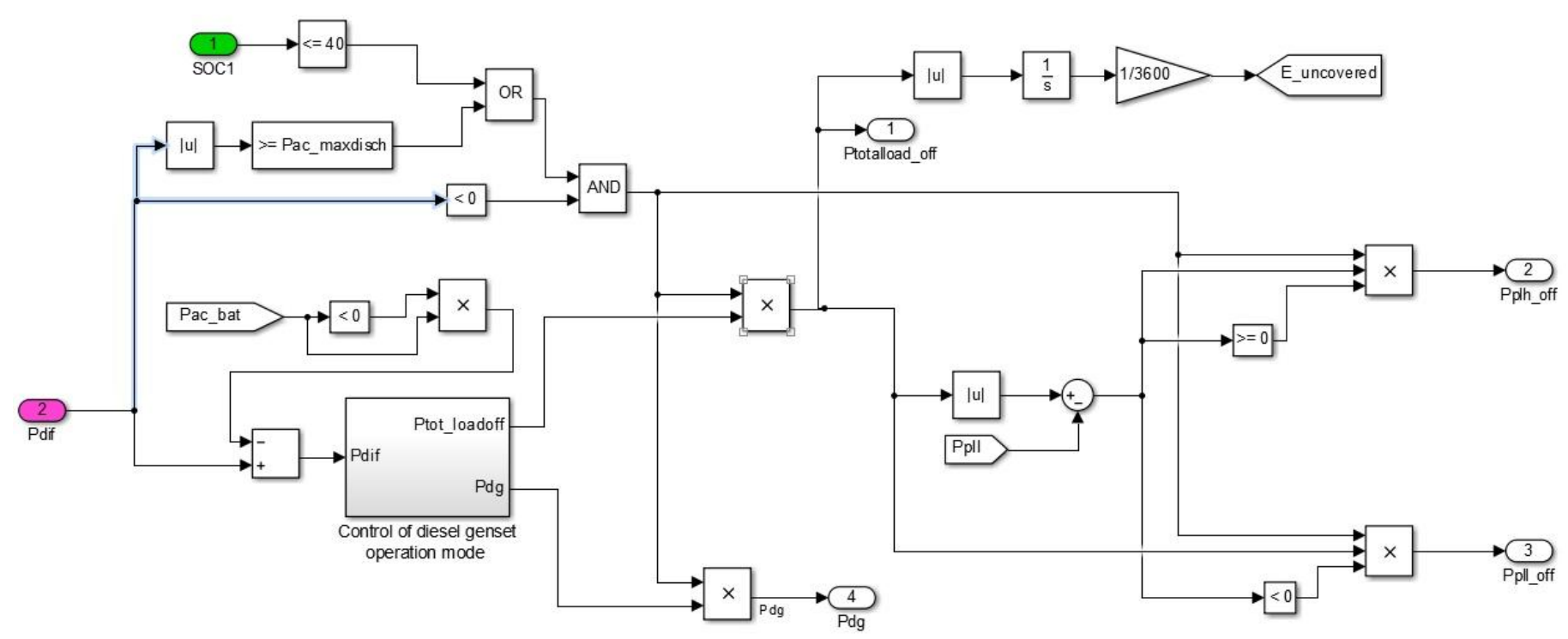

Figure 57. The Diesel generator and Load Shedding Subsystem of the model in Simlink where the power output of the diesel genset as well as the load rejection and the uncovered energy demand 


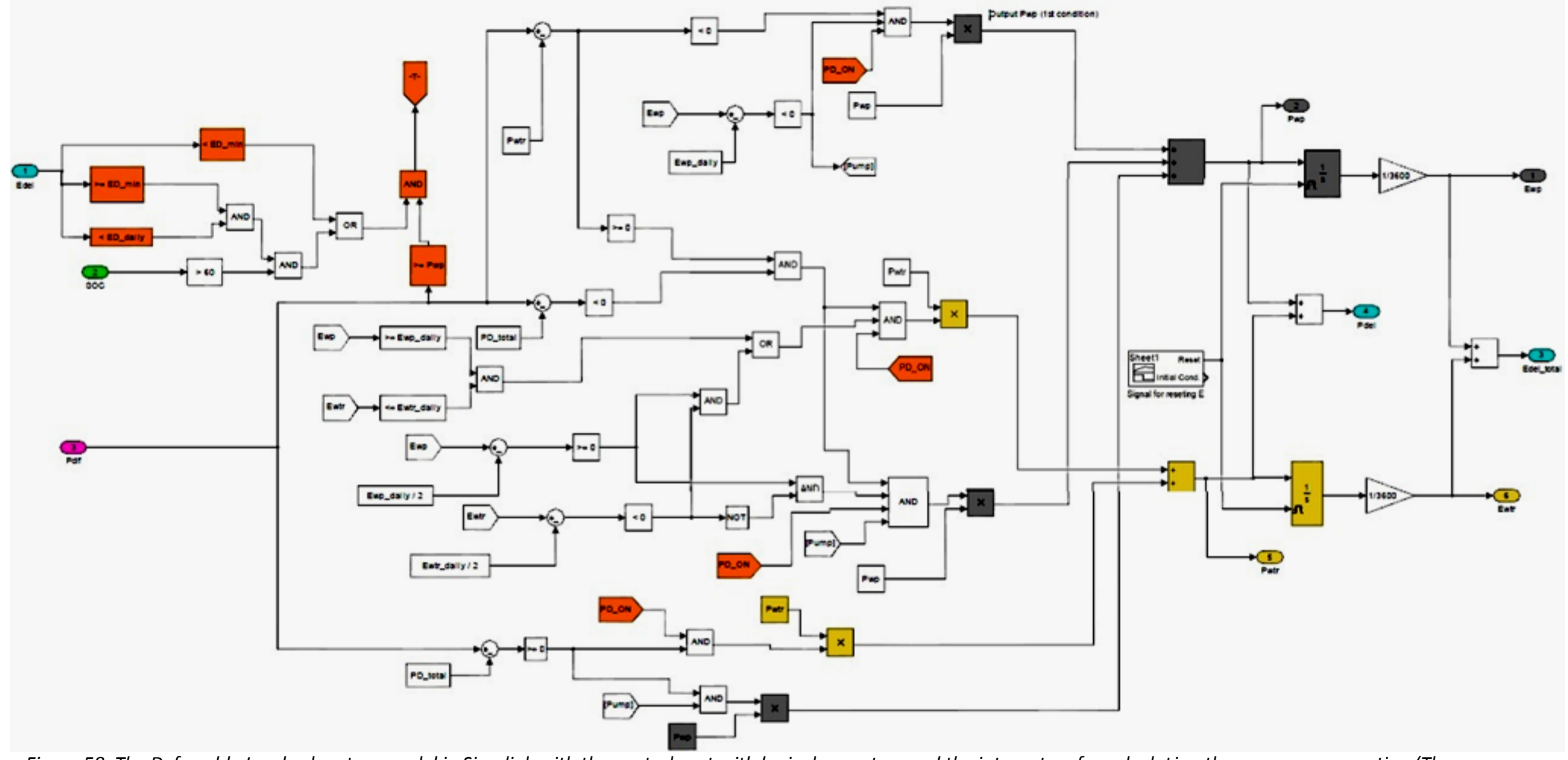

Figure 58. The Deferrable Load subsystem model in Simulink with the control part with logical operators and the integrators for calculating the energy consumption (The input with magenta color is the $P_{\text {dif }}$ signal, the green one is the SOC of the batteries, the light blue is the $E_{\text {del, }}$ the orange blocks are all the related block with the signal

$D L \_O N$, the yellow blocks are for water treatment and the grey for water pumping 


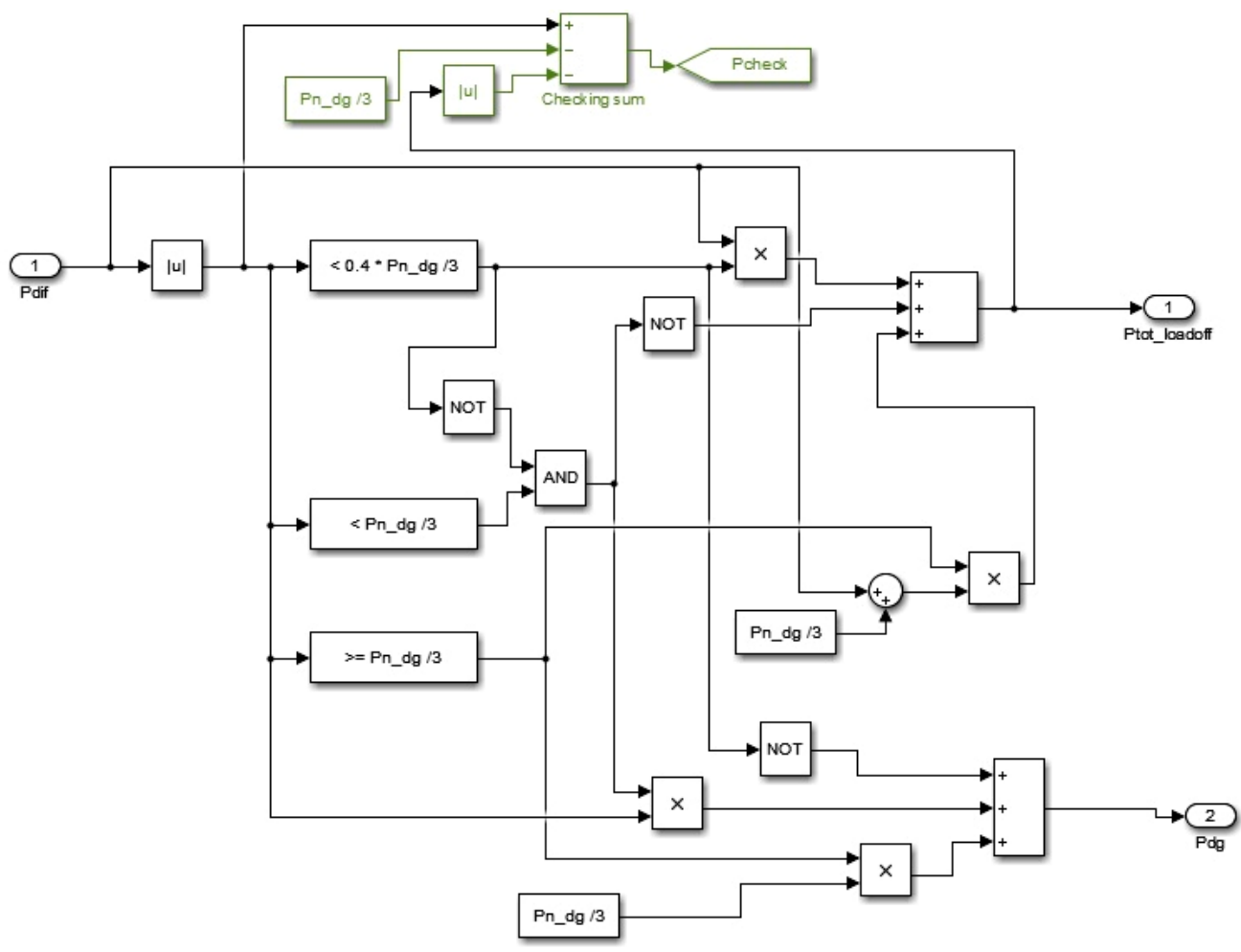

Figure 59. The Control of Diesel Genset Operation Mode Subsystem where if the load shedding should happen is decided as well as if the generator should be switched on. (The green signal $p_{\text {check }}$ is an auxiliary signal, through which one can follow if the model works appropriately in the case of power deficit) 


\section{Appendix II}

The operational control description:

Actions when $\mathbf{P}_{\text {dif }}>\mathbf{0}$ :

- If $E_{d}<E_{D_{-} \min } \quad \& \quad P_{\text {dif }} \geq P_{\text {wp }}$, then the extra power will be directed to the deferrable load

$\rightarrow$ PD_ON=1 \& BAT_CH=0 $\left[E_{D_{-} \min }=30201 \mathrm{Wh}\right.$ is the electrical energy consumed for 4 hours of water pumping and 6 hours of water treatment]

- If $\quad E_{d}<E_{D_{-} \text {min }} \quad \& \quad P_{\text {dif }}>P_{\text {del }} \quad \& \quad S O C<$ SOC $_{\text {max }}$,

then the extra occurring power $\mathbf{P}_{\text {dif }}-\mathbf{P}_{\text {deftotal }}$ will be directed to the batteries

$\rightarrow$ BAT_CH=1 \& $\quad P_{\text {ac_bat }}=P_{\text {dif }}-P_{\text {del }} \leq P_{\text {max } \_ \text {ch }} \quad \& \quad P D \_O N=0$

- If $E_{D_{-} \text {min }}<E_{d}<E_{\text {del_daily }} \quad \& \quad S O C<60 \% \quad \& \quad P_{\text {dif }} \leq P_{\text {max_ch }}$, then the extra power $\mathbf{P}_{\text {dif }}$ will be fed to the batteries to charge them and reduce the time they stay under deep discharge to increase their lifetime.

$\rightarrow$ BAT_CH=1 \& $\quad P_{\text {ac_bat }}=P_{\text {dif }} \quad \& \quad$ PD_ON=0

- If $E_{D_{-} \text {min }}<E_{d}<E_{\text {del_daily }} \quad \& \quad S O C<60 \% \quad \& \quad P_{\text {dif }}>P_{\text {max_ch, }}$, then the batteries will be charged with their maximum power and the rest will be used by the deferrable load

$\rightarrow$ BAT_CH=1 \& $\quad P_{\text {ac_bat }}=P_{\text {max_ch }} \& \quad$ PD_ON=1.

- If $\mathrm{E}_{\mathrm{D}_{-} \min }<\mathrm{E}_{\mathrm{d}}<\mathrm{E}_{\text {del_daily }} \quad \& \quad \mathrm{SOC}>60 \% \quad \& \quad \mathbf{P}_{\mathrm{wp}} \leq \mathbf{P}_{\text {dif }} \leq \mathbf{P}_{\mathrm{wp}}+\mathbf{P}_{\mathrm{wtr}}$ then all the extra power will be directed to the deferrable load

$\rightarrow$ PD_ON $=1 \quad \& \quad$ BAT_CH $=0$

- If $\quad E_{D_{-} \min }<E_{d}<E_{\text {del_daily }} \quad \& \quad$ SOC $>60 \% \quad \& \quad P_{\text {dif }}>P_{w p}+P_{w t r}$ then the deferrable load will use the needed power and the rest will be absorbed by the batteries

$\rightarrow$ PD_ON=1 \& BAT_CH=1 \& $\quad \mathbf{P}_{\text {ac_bat }}=\mathbf{P}_{\text {dif }}-\mathbf{P}_{\text {del }} \leq \mathbf{P}_{\text {max } \_ \text {ch }}$

- If $\mathrm{E}_{\mathrm{d}}=\mathrm{E}_{\text {del_daily }} \quad \& \quad \mathrm{SOC}<\mathrm{SOC}_{\max } \& \quad \mathbf{P}_{\text {dif }} \leq \mathbf{P}_{\text {max_ch, }}$ then the extra power will be transferred to the batteries to charge them
$\rightarrow$ BAT_CH=1
\& $\quad \mathbf{P}_{\text {ac } \_ \text {bat }}=\mathbf{P}_{\text {dif }}$
\& PD_ON=0

- If $E_{d}=E_{\text {del_daily }} \& \quad S O C<S O C_{\max } \& \quad P_{\text {dif }}>P_{\text {max_ch }}$, then the batteries will use only the amount of their maximum allowed power to get charged

$\rightarrow$ BAT_CH $=1 \quad \& \quad P_{\text {ac_bat }}=P_{\text {max_ch }} \& \quad$ PD_ON $=0$

- If $\mathrm{E}_{\mathrm{d}}=\mathrm{E}_{\text {del_daily }} \& \quad \mathrm{SOC}=\mathrm{SOC}_{\max }$,

then the batteries stop charging and the deferrable load too, 
$\rightarrow$ BAT_CH $=0 \quad \& \quad$ PD_ON=0

- If $\mathbf{P}_{\text {dif }}>\mathbf{P}_{\text {ac_bat }}+\mathbf{P}_{\text {del, }}$

then the extra amount of power can not be utilized and will be dumped

$\rightarrow \mathbf{P}_{\text {dump }}=\mathbf{P}_{\text {dif }}-\mathbf{P}_{\text {ac_bat }}-\mathbf{P}_{\text {del }}$

Actions when $\mathbf{P}_{\text {diff }}<\mathbf{0}$ :

- If $\quad \mathrm{SOC}>\mathrm{SOC}_{\min } \& \quad \mathbf{P}_{\text {dif }}<\mathbf{P}_{\text {max }}$ disch,

then all the needed power is provided by the batteries

$\rightarrow$ BAT_DISCH $=1 \quad \& \quad \mathbf{P}_{\text {ac } \_ \text {bat }}=\mathbf{P}_{\text {dif }}$

- If $\quad \mathrm{SOC}>\mathrm{SOC}_{\min } \& \quad \mathrm{P}_{\text {dif }}>P_{\text {max } \_ \text {disch }} \& \quad P_{\text {dg_n }} \geq P_{\text {dif }}-P_{\text {max_disch }} \geq 0.4 * P_{\text {dg_n }}$, then the batteries are discharged at their maximum rate and the diesel generator covers the rest of the demand

$\rightarrow$ BAT_DISCH=1 \& $\quad \mathbf{P}_{\text {ac_bat }}=\mathbf{P}_{\text {max_disch }} \quad \boldsymbol{\&} \quad \mathbf{P}_{\mathrm{dg}}=\mathbf{P}_{\text {dif }}-\mathbf{P}_{\text {ac_bat }}$

[ $\boldsymbol{P}_{d g_{n} n}$ is the nominal power output of the diesel generator]

- If $\quad \mathrm{SOC}>\mathrm{SOC}_{\min } \& \quad \mathbf{P}_{\text {dif }}>\mathbf{P}_{\text {max_disch }} \& \quad \mathbf{P}_{\text {dif }}-\mathbf{P}_{\text {max_disch }}<0 . \mathbf{0}^{*} \mathbf{P}_{\text {dg_n }}$, then the batteries are discharged at their maximum rate and the rest of the load can not be served leading to load shedding $\mathbf{P}_{\text {totalload_off }}$ equal to this amount of power

$\rightarrow$ BAT_DISCH=1 \& $\quad P_{\text {ac_bat }}=P_{\text {max_disch }} \quad \& \quad P_{\text {totalload_off }}=P_{\text {dif }}-P_{\text {ac_bat }}$

- If $\quad \mathbf{S O C}>\mathbf{S O C}_{\min } \& \quad \mathbf{P}_{\text {dif }}>\mathbf{P}_{\text {max_disch }} \& \quad \mathbf{P}_{\text {dif }}-\mathbf{P}_{\text {max_disch }}>\mathbf{P}_{\text {dg_nn }}$ then the batteries are discharged at their maximum rate, the diesel generator produce its rated output and the rest of the load can not be served leading to load shedding

$\rightarrow$ BAT_DISCH=1 \& $\quad P_{\text {ac_bat }}=P_{\text {max_disch }} \quad \& \quad P_{d g}=P_{d g \_n} \quad \&$ $P_{\text {totalload_off }}=P_{\text {dif }}-P_{\text {ac_bat }}$

- If $S O C=S O C_{\min } \& \quad P_{\text {dg_n }} \geq P_{\text {dif }} \geq 0.4 * P_{\text {dg_n } n,}$ then the batteries are fully discharged and not able to provide any more energy, and the diesel generator operate to cover the deficit of power in the system

$\rightarrow$ BAT_DISCH $=0 \quad \& \quad \mathbf{P}_{\mathrm{dg}}=\mathbf{P}_{\text {dif }}$

- If $\quad \mathrm{SOC}=\mathrm{SOC}_{\min } \& \quad \mathrm{P}_{\mathrm{dif}}<0 . \mathbf{4}^{*} \mathrm{P}_{\mathrm{dg} \_n}$,

then the batteries are fully discharged and the diesel generator is not activated because of the too low load. The result will be the load shedding

$\rightarrow$ BAT_DISCH $=0 \quad \& \quad \mathbf{P}_{\text {totalload_off }}=\mathbf{P}_{\text {dif }}$

- If $\quad S O C=S_{\text {min }} \& \quad P_{\text {dif }}>P_{\text {dg_n }}$,

then the batteries are fully discharged, the diesel generator produce its rated output and the rest of the load can not be served leading to load shedding
$\rightarrow$ BAT_DISCH $=0$
\&
$\mathbf{P}_{\mathrm{dg}}=\mathbf{P}_{\mathrm{dg} \_} \mathbf{n}$
\& $\quad \mathbf{P}_{\text {totalload_off }}=\mathbf{P}_{\text {dif }}$

Additional needed parameters for the control logic for the deferrable load operation: 
- $P_{D_{-} \text {total }}:$ the maximum power need of the deferrable load when both water pumping and treatment are carried out at the same time, $\mathrm{P}_{\mathrm{D}_{-} \text {total }}=\mathrm{P}_{\mathrm{wp}}+\mathrm{P}_{\mathrm{wtr}}$

- $E_{\text {wp_daily }}$ : the needed daily energy consumption for water pumping, $E_{\text {wp_daily }}=1200 \mathrm{Wh}$

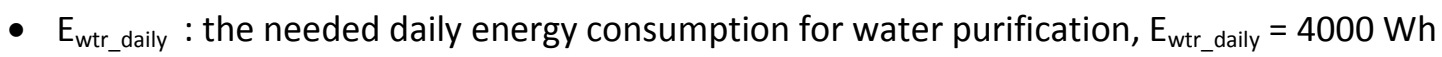

- $E_{w p} \quad$ : the energy consumed on water pumping from the start of the day

- $E_{w t r} \quad$ : the energy consumed on water purification from the start of the day

$E_{\text {del }}, E_{w p}, E_{w t r}$ are calculated by integrating the respective power factors and they are reset every 24 hours.

The 'activation' of the deferrable load means that:

$E_{\text {del }}<E_{\text {del_daily }}$ and $P_{\text {dif }} \geq P_{w p}$

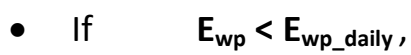

then the bollean signal Pump becomes equal to 1 .

$\rightarrow$ Pump $=1$

- If $\mathbf{P}_{\text {dif }}<\mathbf{P}_{\text {wtr }} \quad \boldsymbol{\&} \quad \mathbf{P u m p}=1$, then the extra power will be used for water pumping

$\rightarrow \mathbf{P}_{\text {del }}=\mathbf{P}_{\mathrm{wp}}$

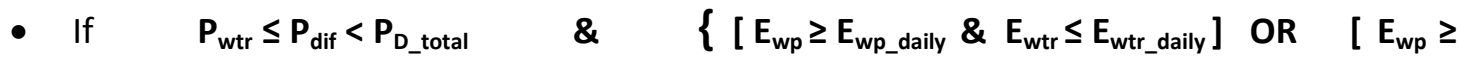

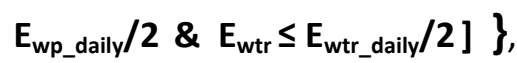

then the extra power will be used for water purification

$\rightarrow \mathbf{P}_{\text {del }}=\mathbf{P}_{\mathrm{wtr}}$

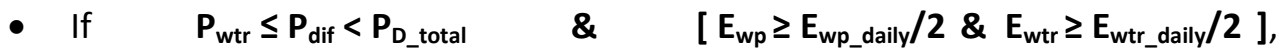

then the extra power will be used for water pumping

$\rightarrow \mathbf{P}_{\text {del }}=\mathbf{P}_{\mathrm{wp}}$

- If $\quad P_{\text {dif }} \geq P_{D_{-} \text {total }} \quad \& \quad P u m p=1$, then the extra power will be used both for water pumping and treatment

$\rightarrow \mathbf{P}_{\text {del }}=\mathbf{P}_{\mathrm{D}_{-} \text {total }}$

- If $P_{\text {dif }} \geq P_{D_{\text {_total }}} \& \quad P u m p=0$,

then the extra power will be used for water purification

$\rightarrow \quad \mathbf{P}_{\text {del }}=\mathbf{P}_{\mathrm{wtr}}$

Control of load shedding:

- If $\mathbf{P}_{\text {totalload_off }}>\mathbf{P}_{\text {pll }}$,

then the low priority load rejection will not be enough to reestablish the balance at the system and a part of the high priority load will be taken off

$\rightarrow \quad P_{\text {totaload_off }}=P_{\text {plh_off }}+P_{\text {pll_off }}, \quad P_{\text {pll_off }}=P_{\text {pll }}, \quad P_{\text {pli_off }}=P_{\text {totaload_off }}-P_{\text {pll }}$ 
- If $\mathbf{P}_{\text {totalload_off }} \leq \mathbf{P}_{\mathrm{pll}}$,

then shutting down part of the low priority load will be enough with $\boldsymbol{P}_{\text {plloff }}=$ $P_{\text {tot }_{\text {loadoff }}}$

$\rightarrow \quad P_{\text {totaload_off }}=P_{\text {plh_off }}, \quad P_{\text {pll_off }}=P_{\text {totaload_off }}-P_{\text {pll }}, P_{\text {plh_off }}=0$ 


\section{Appendix III}

The main parameters and their values used for the simulation of all the three cases, are all gathered here and presented as they are in matlab workspace:

$A=38.65\left[\mathrm{~m}^{2}\right]$

Capn $=6936[\mathrm{Ah}]$

$E D \_d a i l y=5200[\mathrm{Wh}]$

ED_min $=3201[\mathrm{Wh}]$

Ewp_daily $=1200[\mathrm{Wh}]$

Ewtr_daily $=4000[\mathrm{Wh}]$

$\mathrm{g}=9.8\left[\mathrm{~m} / \mathrm{sec}^{2}\right]$

$\mathrm{G}_{\mathrm{STC}}=1000\left[\mathrm{~W} / \mathrm{m}^{2}\right]$

$k_{p}=0.43$ (in the model it is divided by 100)

lamda $=\lambda=6.594$

$\mathrm{n} \_\mathrm{pv}=\eta_{p v}=0.1585$

n_roundtrip $=\eta_{\text {round_trip }}=0.8$

nch_b $=\eta_{c h \_b}=0.8944$

nconvb_rat $=0.9580$

ndsc_b $=\eta_{\text {disch_b }}=0.8944$

$\mathrm{Np}=156$

$\mathrm{nwg}=\eta_{w g}=0.9$

nwt_rated $=180[\mathrm{rpm}]$

po $=101325[\mathrm{~Pa}]$

Pac_maxchar $=15180[\mathrm{~W}]$

Pac_max_disch $=12135[\mathrm{~W}]$

PD_total $=600[\mathrm{~W}]$

Pn_dg $=9500[\mathrm{~W}]$

Prat_convb $=4600[\mathrm{~W}]$

Pstc $=255[\mathrm{~W}]$ 
$\mathrm{Pwp}=200[\mathrm{~W}]$

Pwt-rated $=10000[\mathrm{~W}]$

Pwtr $=400[\mathrm{~W}]$

$\mathrm{R}=287\left[\mathrm{~J} /\left(\mathrm{kg}^{*} \mathrm{~K}\right)\right]$

$\operatorname{Rad}=3.5[\mathrm{~m}]$

SOCmax $=95$

TSTC $=25\left[{ }^{\circ} \mathrm{C}\right]$

$\mathrm{Vdc}=48[\mathrm{~V}]$

veta $=6=0$

Vw_cutin $=3[\mathrm{~m} / \mathrm{sec}]$

Vw_rated $=10[\mathrm{~m} / \mathrm{sec}]$

$Z=155[\mathrm{~m}]$ 


\section{Appendix IV}

In this appendix, the additional graphs related to the simulation results of the different cases are presented.

\section{Simulation Case (ii) - July -2 days}

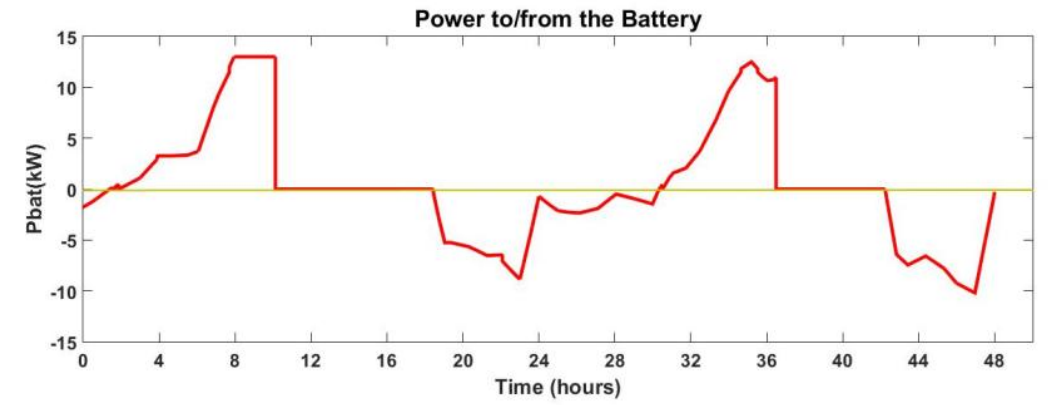

(a)

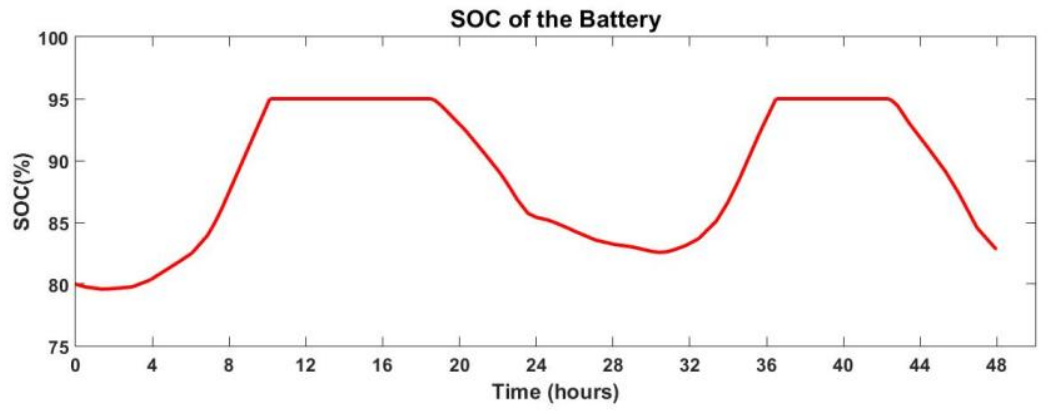

(b)

Figure 60. (a) Power absorbed and provided by the battery and (b) the SOC of the battery for Case (ii)

\section{Simulation Case (iii) - December -2 days}

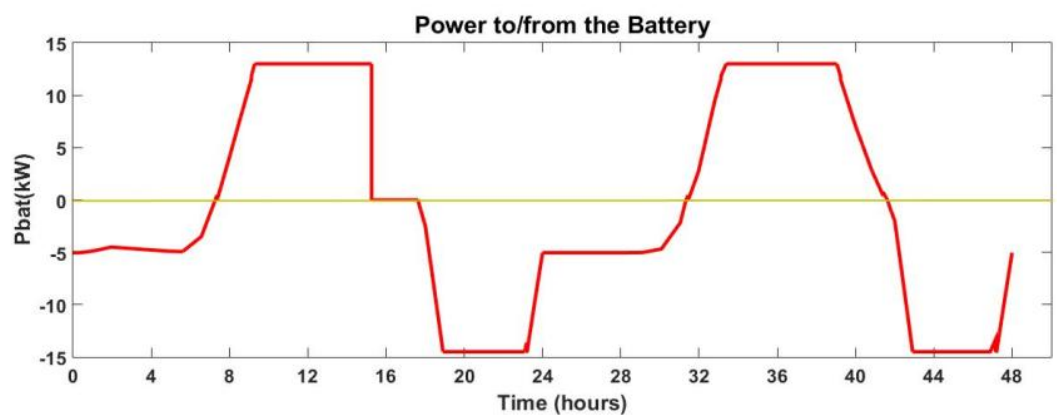

(a)

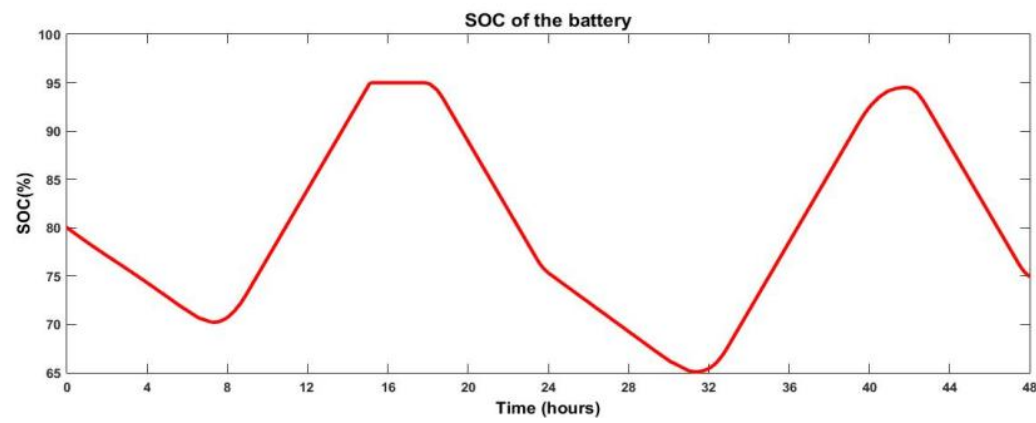

(b)

Figure 61. (a) Power absorbed and provided by the battery and (b) the SOC of the battery for Case (iii) 


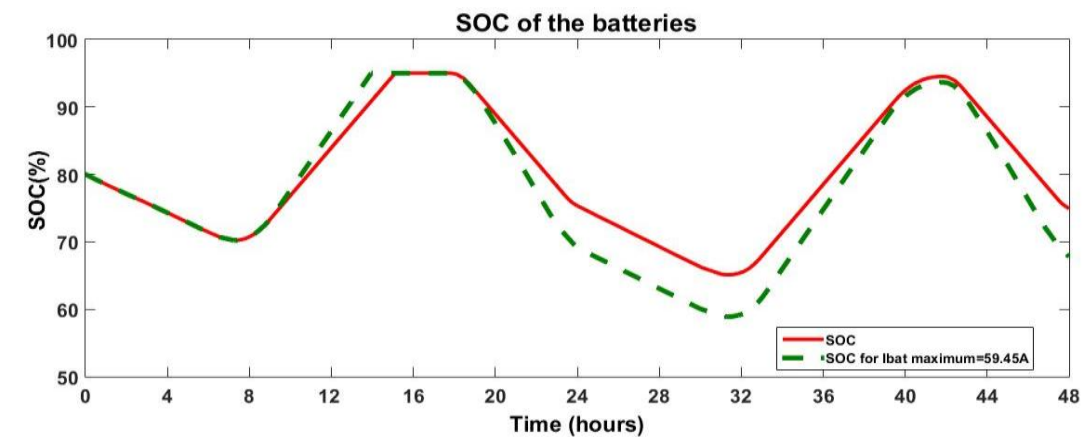

(a)

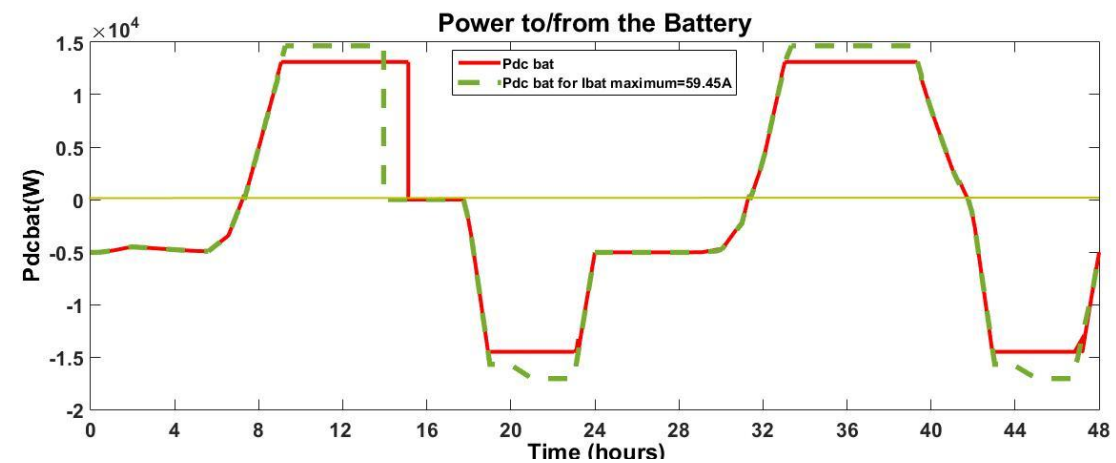

(b)

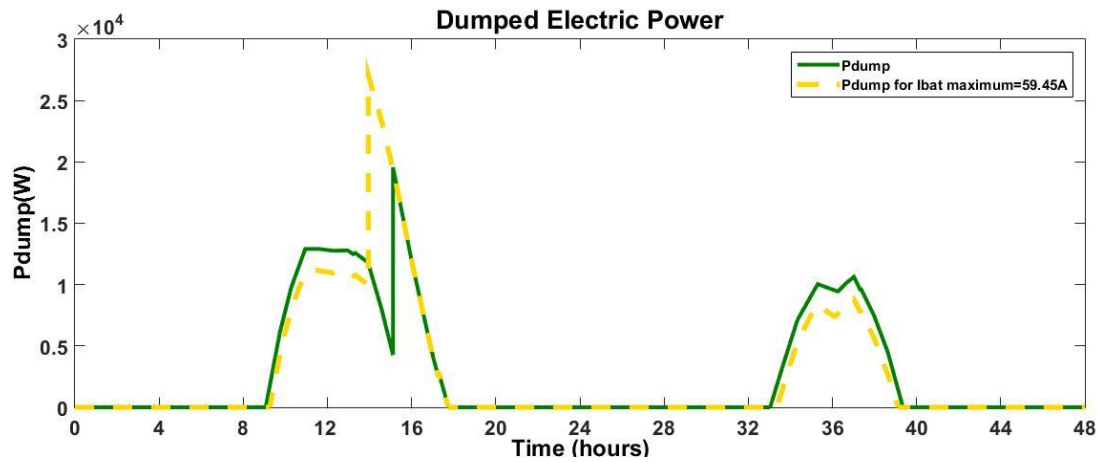

(c)

Figure 62. Comparison of the battery bank operation in terms of (a) SOC and (b) power exchange and (c) Comparison of the occurring $P_{\text {dump }}$ for different allowed maximum charge rates for Case (iii)

\section{Extended Simulation Case (ii) - July - 4 days}

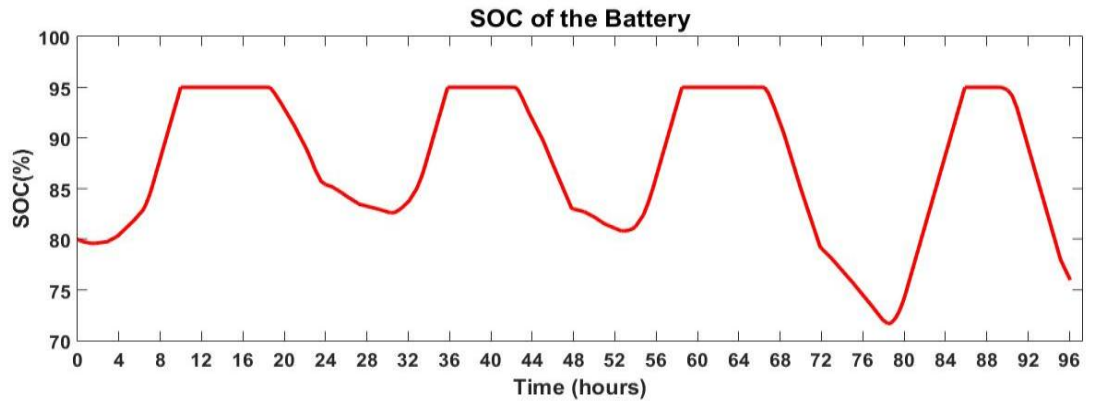

Figure 63. The SOC of the battery for the extended Case (ii) 


\section{Extended Simulation Case (iii) - December - 4 days}

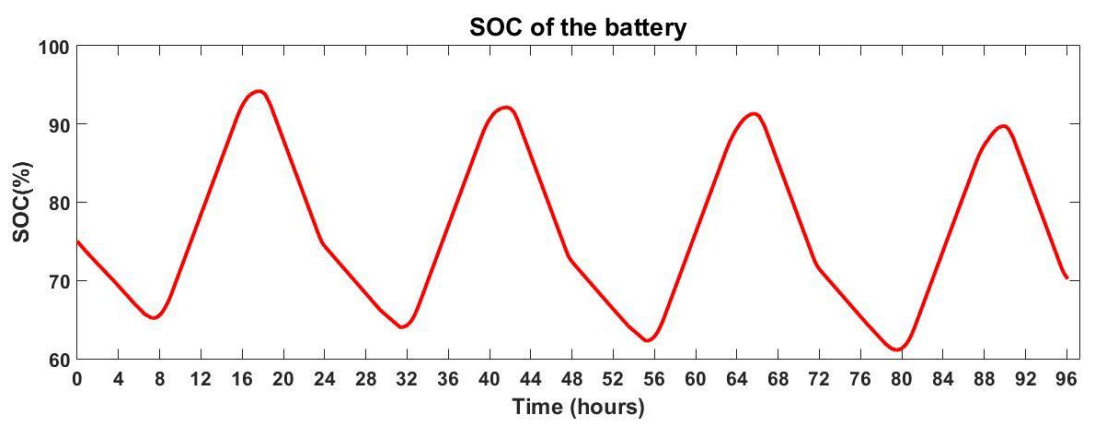

(a)

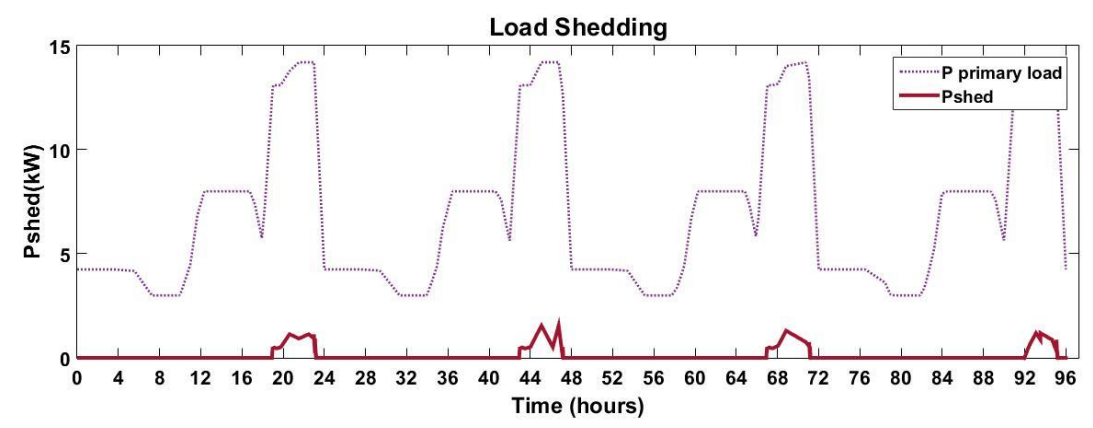

(b)

Figure 64. (a)The SOC of the batteries and (b) The load that was rejected because of deficit of power in relation to the total power demand for extended Case (iii)

Extended Simulation Case (iii) - December - 4 days - with lower pv production on 2$3^{\text {rd }}$ day
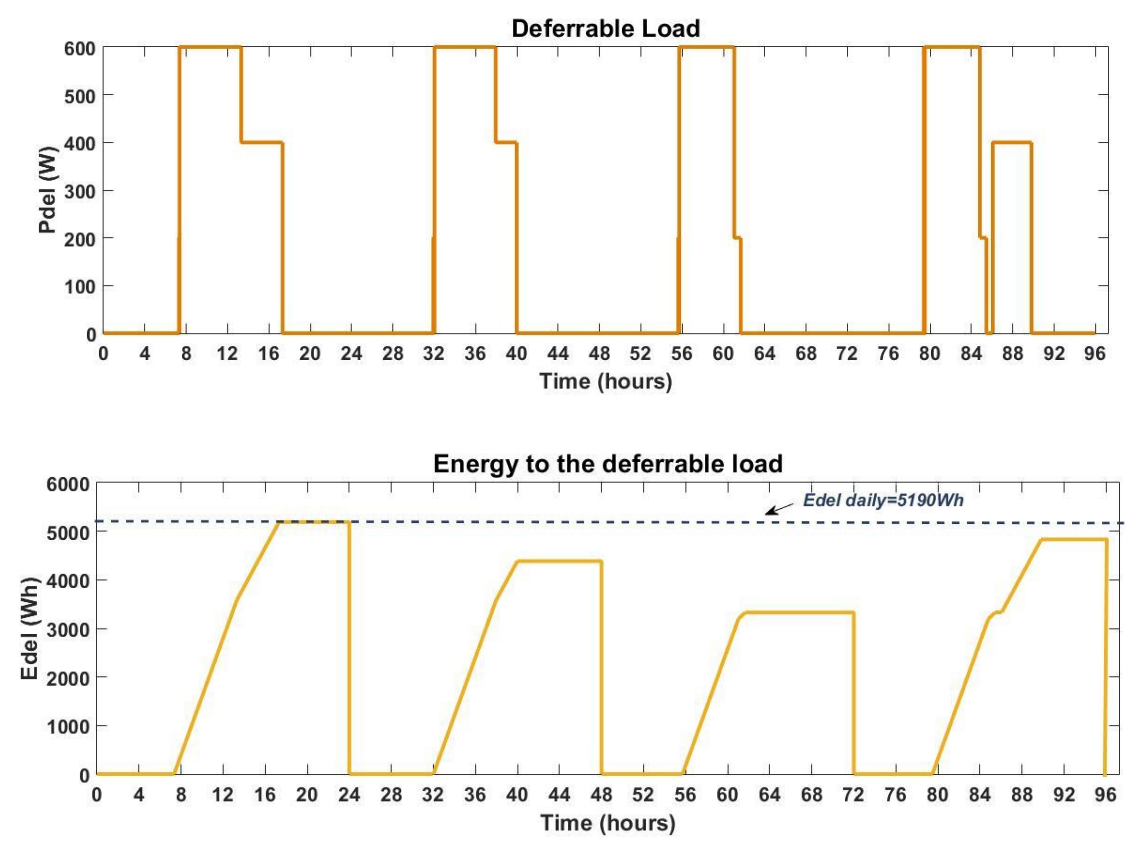

(b)

Figure 65. Deferrable load (a) power consumption and (b) energy consumption during the 4 December days with less $p v$ power than expected 